\title{
Trifluoroacetic anhydride-sodium iodide reagent. Nature and applications
}

\author{
Zbigniew H. Kudzin, ${ }^{a *}$ Marcin H. Kudzin, ${ }^{b}$ Józef Drabowicz, ${ }^{c, d}$ and Andrzej Kotyński \\ ${ }^{a}$ Institute of Chemistry, University of Łódź, Narutowicza Str. 68, 92-136 Łódź, Poland \\ ${ }^{b}$ Textile Research Institute, Brzezińska Str. 5/15, 92-103 Łódź, Poland \\ ${ }^{c}$ Centre of Molecular and Macromolecular Studies, Polish Academy of Sciences, Sienkiewicza \\ Str. 112, 90-363 Łódź, Poland \\ ${ }^{d}$ Institute of Chemistry, University of Częstochowa, Washington Str. 4/8, 42-200 Częstochowa, \\ Poland \\ ${ }^{e}$ Institute of Chemistry, Faculty of Pharmacy, Medical University of Łódź, Muszyńskiego Str. 1, \\ 90-151, Lódź, Poland \\ E-mail: zhk@chemul.uni.lodz.pl
}

\section{Dedicated to Professor J. Epsztajn on the occasion of his $75^{\text {th }}$ birthday}

\begin{abstract}
Trifluoroacetic anhydride - sodium iodide mixture (TFAA-NaI; TFAA-I) reacts with several compounds bearing semipolar $X-O$ bond, usually in the mode of deoxygenation, with liberation of iodine. The results of systematic investigations of the TFAA-I-reaction with various types of $S$-oxo and $N$-oxo compounds were discussed. The majority of these reactions are characterized by quantitative course, with respect to both $X-O$ substrate transformation as well as to the amounts of liberated iodine. On this basis, a variety of sulphoxides and sulphimides were successfully reduced to sulphides and/or arene- $N$-oxides to amines, using TFAA-I at ambient temperature. Arene- and alkyl-sulphonic acids were reduced to the corresponding thiol derivatives in moderate yields. Stoichiometric course of the TFAA-I reaction with several $S$-oxo and $N$-oxo compounds gave origin to their analytical determinations. Thus, due to stoichiometric amounts of iodine formed from sulphoxides, sulphimides, arene- $N$-oxides, nitrones and nitroxide radicals, and nitroso compounds - the TFAA-I reagent can be applied to their analytical determination (titrimetric on $\mu \mathrm{mol}$ and spectrometric on nmol scale) and/or TLC detection.
\end{abstract}

Keywords: Trifluoroacetic anhydride-sodium iodide system, TFAA-I reagent, activated DMSO, redox reactions, deoxygenation, sulphoxides, sulphimides, amine $N$-oxides, nitrones, nitroxide radicals, $N$-nitrosoamines, determination, TLC detection 


\section{Contents}

1. Introduction

2. Reaction of TFAA-I with $S$-oxo compounds

2.1. Synthetic application of TFAA-I for reduction of $S$-oxo compounds

2.1.1. Reduction of sulphoxides

2.1.2. Reduction of sulphimides

2.1.3. Reduction of sulphonic acids and derivatives

2.2. Analytical application of TFAA-I for determination and detection of $S$-oxo compounds

2.2.1. Determination of sulphoxides

2.2.1.1. Determination of sulphoxides by means of TFAA-I

2.2.2. Detection of $S$-oxo compounds

2.2.2.1. Detection of $S$-oxo compounds by means of TFAA-I

3. Reaction of TFAA-I with $N$-oxo Compounds

3.1. Synthetic application of TFAA-I for deoxygenation of $N$-oxo compounds

3.1.1. Deoxygenation of amine $N$-oxides and nitrones

3.1.1.1. Deoxygenation of quinoxaline $N, N^{\prime}$-dioxides using TFAA-I

3.2. Analytical application of TFAA-I for determination and detection of $N$-oxo compounds

3.2.1. Determination of $N$-oxo compounds

3.2.1.1. Determination of amine $N$-oxides, nitroxide radicals and nitroso compounds

3.2.1.2. Determination of $N$-oxo compounds by means of TFAA-I

3.2.2. Detection of $N$-oxo compounds

3.2.2.1. Detection of $N$-oxo compounds by means of TFAA-I

3.2.2.1.1. Detection of nitrones, nitroxide radicals and $N$-nitrosoamines in mixtures

4. Conclusions

5. References

\section{Introduction}

In 1963 Moffatt and Pfitzner reported on the oxidation activity exhibited by the mixture of DMSO and DCC (the so called activated DMSO) towards alcohols ${ }^{1}$. It was very soon realized that other electrophiles, besides carbondiamides, can activate DMSO and allow oxidation of alcohols. Thus, in 1965, acetic anhydride was suggested by Allbright ${ }^{2}$, in 1967 trifluoroacetic anhydride $^{3}$, and oxalyl chloride ${ }^{4}$ by Swern group (Scheme 1). Very recently Tojo and Fenandez ${ }^{5}$ published the review describing the numbers of aspects connected with the formation and application of various types of the activated DMSO. 


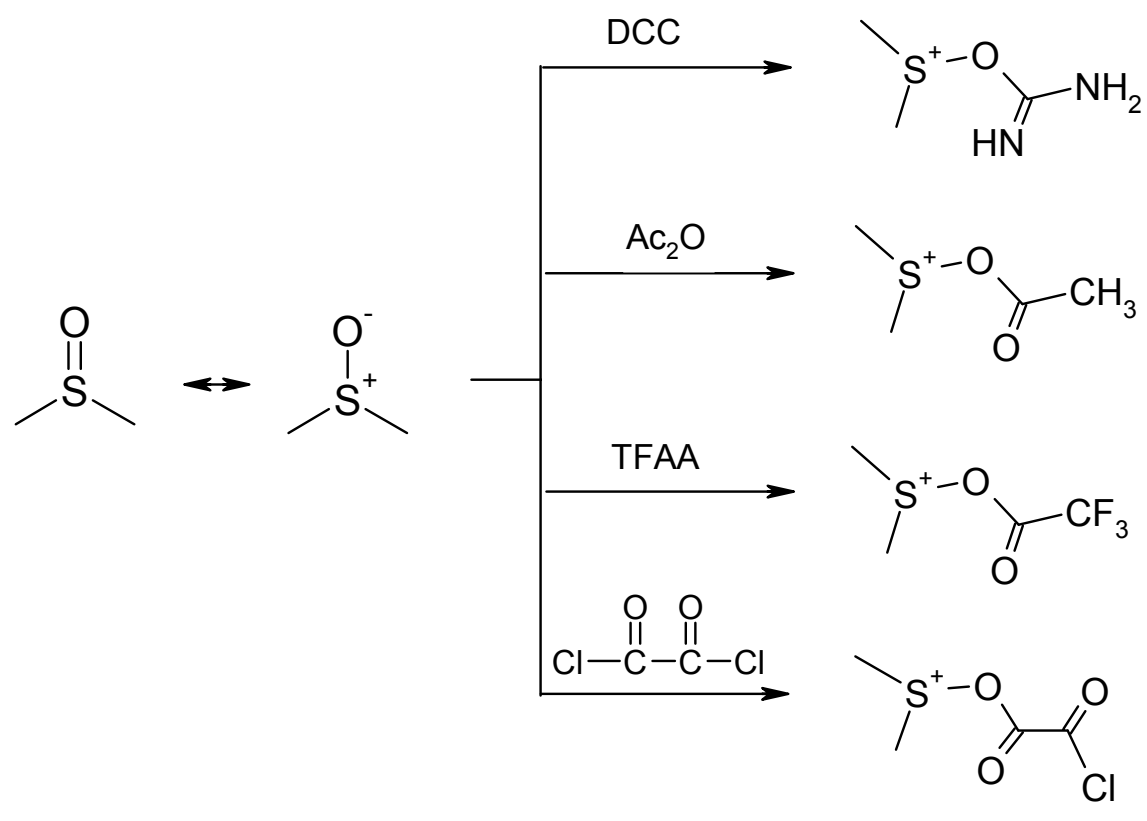

\section{Scheme 1}

In 1973, Numata and Oae described the reaction of sulphoxides (and/or sulphimides) with acetyl chloride, which did not stop at the stage of an acyloxysulphonium salt (also DMSO) but reacted further with formation of sulphide and release of chlorine (Scheme 2$)^{6}$.

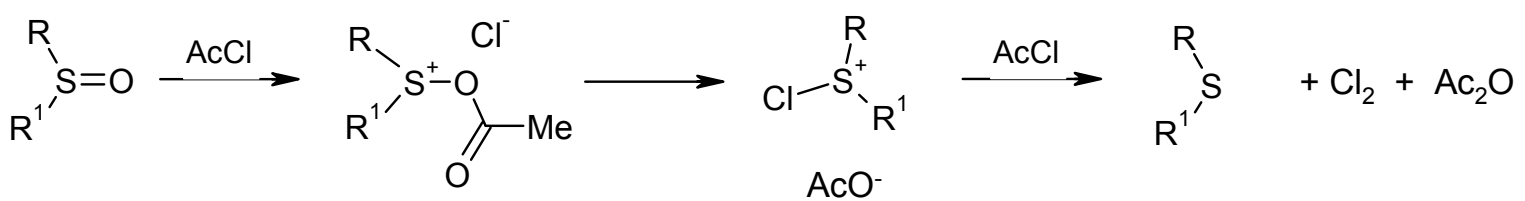

\section{Scheme 2}

One of us, was the first who recognized redox potential of the activated TFA-DMSO (1A) as sufficient for oxidation of iodide anion (Scheme 3), in another words the possibility of deoxygenation of DMSO, and other sulphoxides ${ }^{7}$ and sulphimides ${ }^{8}$, after their prior treatment with TFAA and subsequent reduction of the formed $O$-trifluoroacetylsulphonium salt $\mathbf{1 A}$, by iodide anion. 


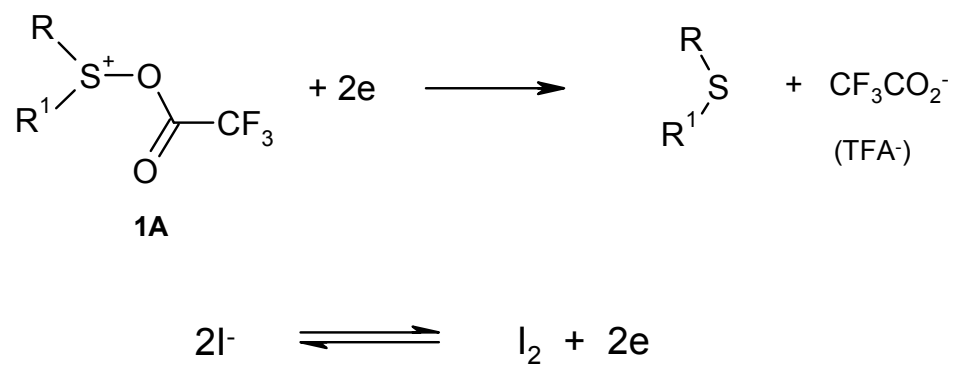

\section{Scheme 3}

The trifluoroacetic anhydride - sodium iodide (TFAA-I) reagent, due to solubility of sodium iodide - the most common iodide donor, was the most frequently applied in anhydrous acetone solutions. In such conditions, TFAA-I reacted in two-stage mode with containing semipolar $X$ - $O$ bond compounds I (Scheme 4), via the $O$-acylation of $X$-O bond by means of TFAA (step $A$ ) with formation of the $O$-acyloxy salts IA. In the subsequent stage (step $\boldsymbol{B}$ ), the salts IA reacted with iodide anion to form intermediary forms $\mathbf{I B} / \mathbf{I C}$, which in reaction with second iodide anion afforded the final products ID with simultaneous release of iodine.

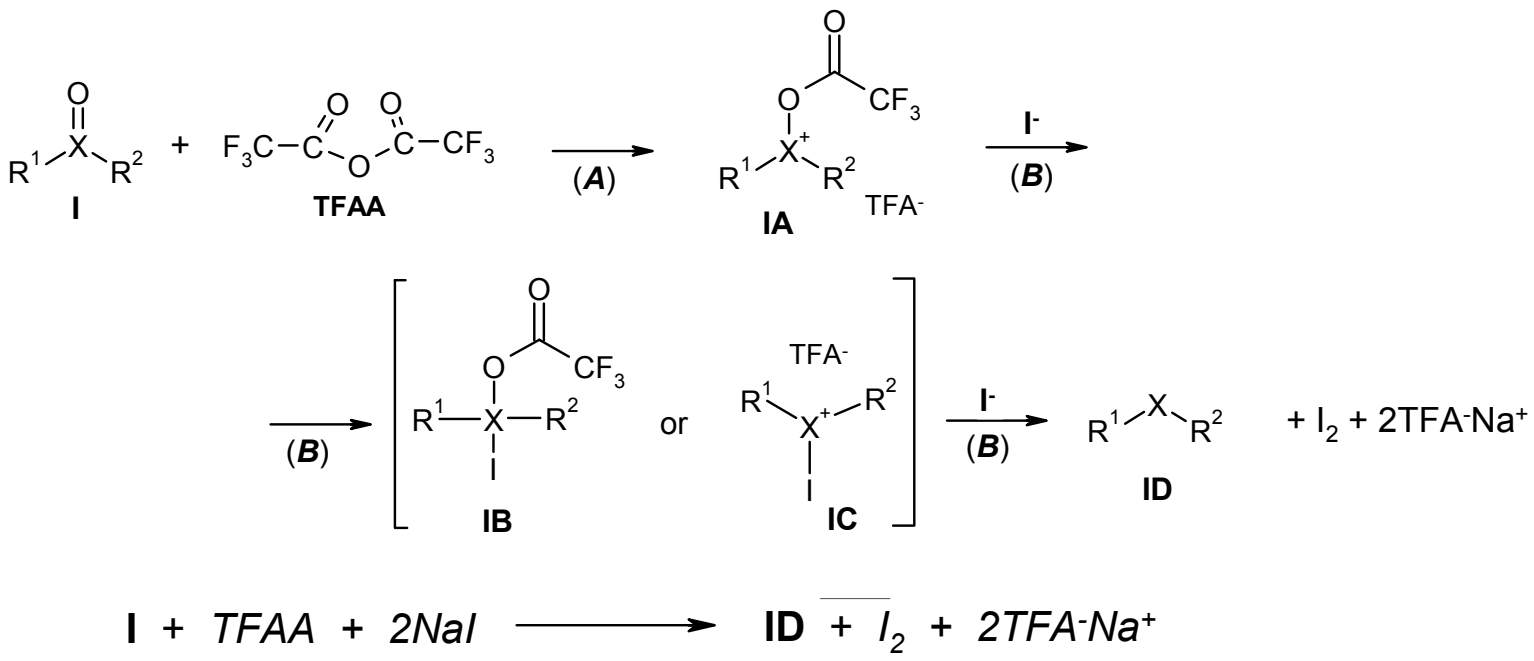

\section{Scheme 4}

The preparative applications of reactions of TFAA-I with semipolar $X$ - $O$ bond containing compounds, are summarized in Scheme 5. Thus, it was used in preparative deoxygenation of sulphoxides $^{7}$ and sulphimides ${ }^{8}$, quinoxaline $N$-oxides ${ }^{9}$, and sulphonic acids and their derivatives ${ }^{10}$.

The "analytically useful" character of the reactions of TFAA-I with several containing $X-O$ semipolar bond compounds, namely stoichiometric iodine evolution, short reaction time and very mild conditions, allows the application of this reagent for their quantitative determination and 
detection. The scope of analytical applications of TFAA-I are schematically presented in Scheme 6.

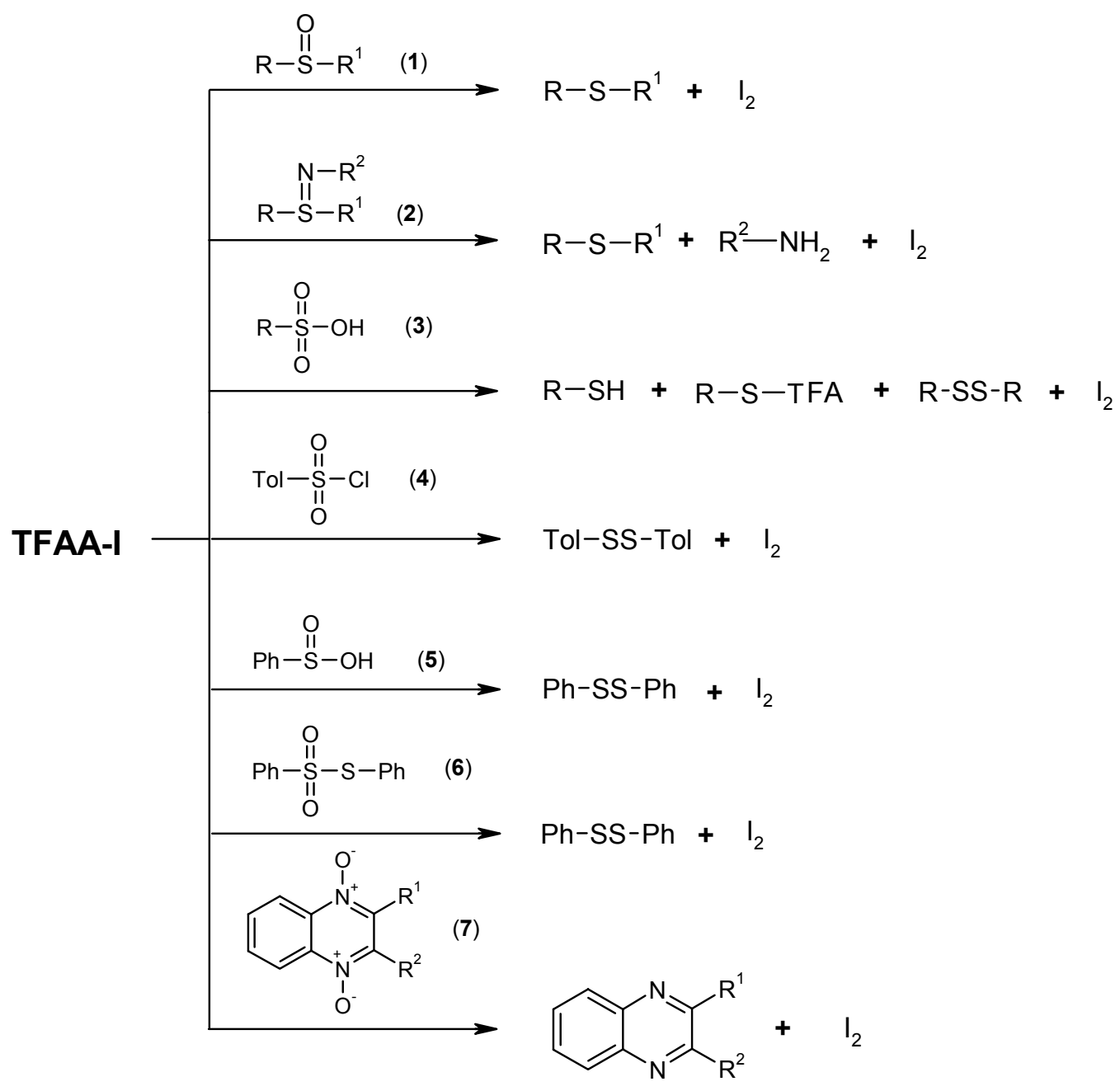

\section{Scheme 5}

Thus, sulphoxides $\mathbf{1}^{11-15}$, sulphimides $2^{15}$ and several types of $N$-oxo compounds ${ }^{16-26}$, including amine $N$-oxides $7^{16-18}$, nitrones $\mathbf{8}^{18-20}$, nitroxide radicals $\mathbf{9}, N$-alkylhydroxylamines $\mathbf{1 0}^{18,20,22,23}, C$-nitroso 11 and $N$-nitroso 12-14 compounds, as well as azoxy compounds $\mathbf{1 5}^{21,22,25,26}$, were determined by iodometric titration (or spectrophotometric determination of iodine) or detected on TLC plates.

Since these reactions (Scheme 5 and 6), which occurred with different stoichiometry of the iodine release, are strongly dependent on the structure of $X$-oxo substrates, we introduced, for their characterization, an iodine equivalent factor $\mathrm{N}_{\mathrm{I} / \mathrm{O}}$ (eq. 1), which equals the number of moles of iodine released during treatment of one mole of $X$-oxo compound with the TFAA-I reagent. 


$$
N_{I / O}=\frac{n l_{2}}{m X-O}
$$

Where:

$N_{I / O}$ - an iodine equivalent;

$n I_{2}$ - number of moles (mmoles, $\mu$ moles, nmoles) released in reaction of $m$ moles of $X$-oxo substrate with TFAA-I;

$m X$-O - number of moles (mmoles, $\mu$ moles, nmoles) of a $X$-oxo substrate.

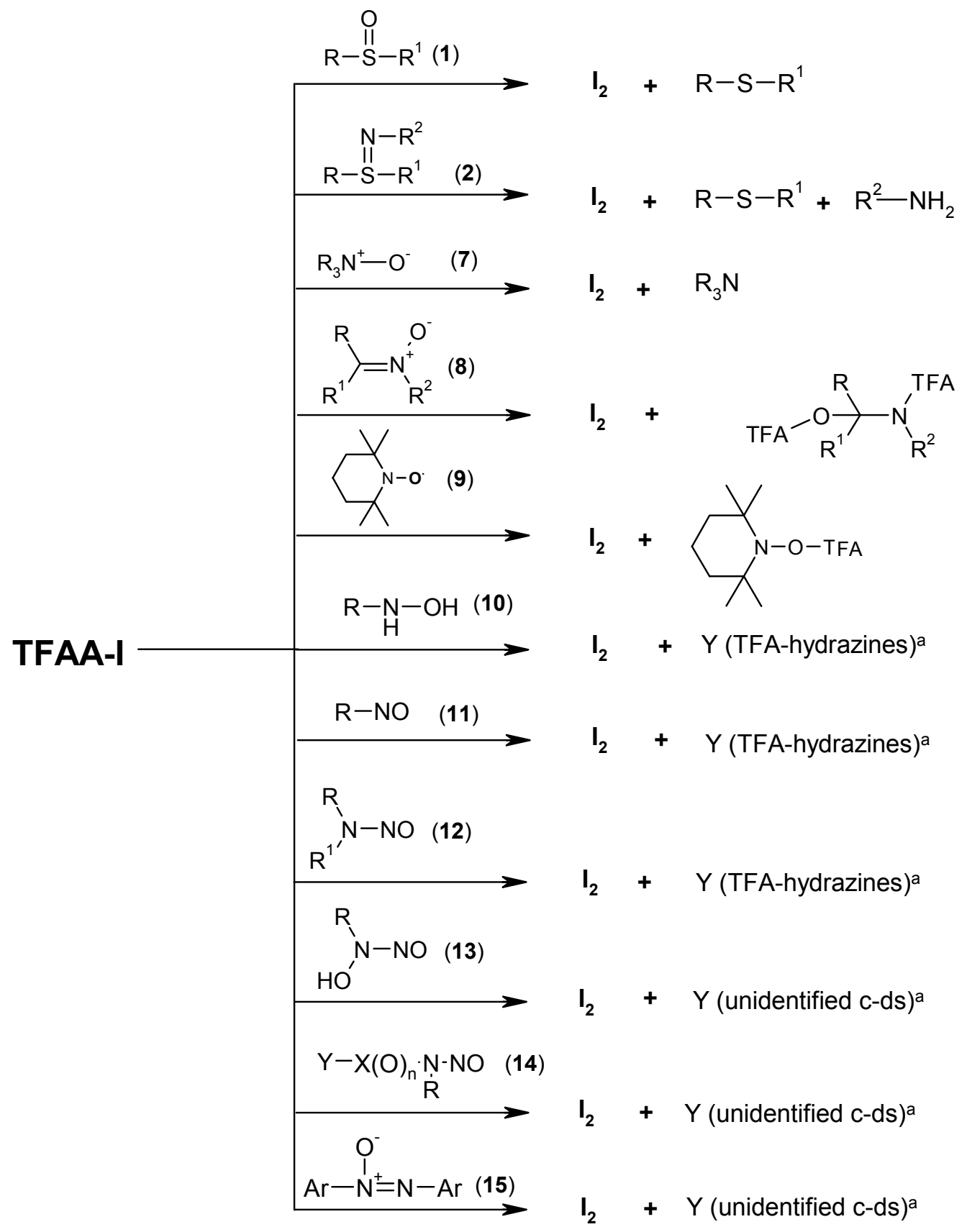

Scheme 6. ${ }^{a}$ Identification works are under investigation. 
Preliminary investigations on the reaction of TFAA-I with organophosphorus compounds containing $P$ - $O$ bond have also been presented. ${ }^{17}$

\section{Reaction of TFAA-I with $S$-oxo compounds}

The reaction of TFAA-I with sulphoxides and sulphimides present quantitative character both in respect to conversion to sulphides as well as to quantity of the iodine release. These reactions can be rationalized accordingly with Schemes 7 and 8 .

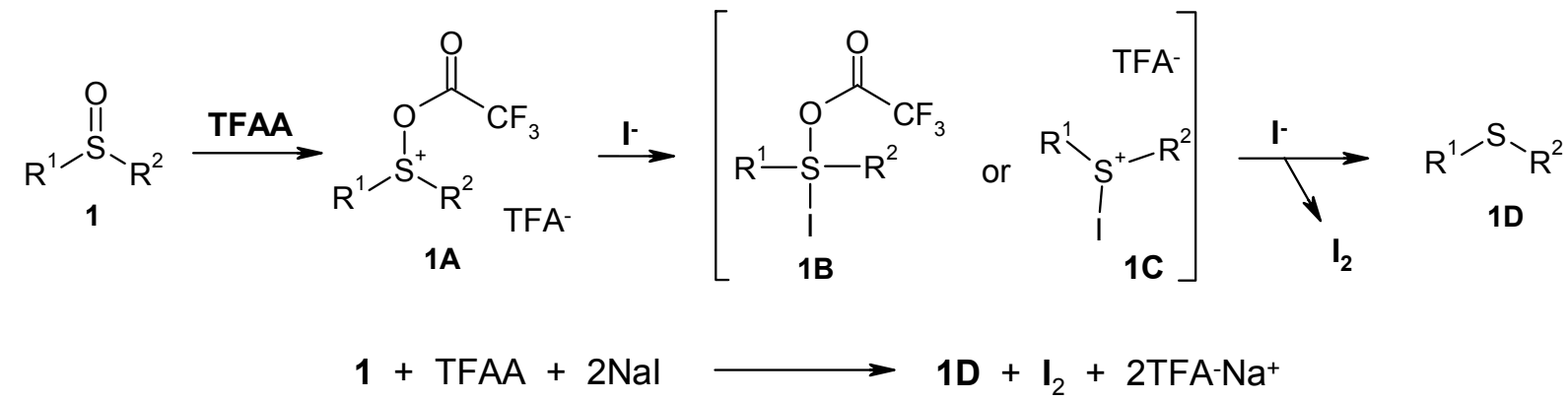

\section{Scheme 7}

The first step of the reaction is undoubtedly the acylation of the sulphoxide $\mathbf{1}$ by means of TFAA-I with formation of the acyloxysulphonium salt 1A. In the subsequent step the salt $\mathbf{1 A}$ reacts with iodide anion to form either the sulphonium $\mathbf{1 C}$ or sulphurane $\mathbf{1 B}$ intermediates. Decomposition of $\mathbf{1 A} / \mathbf{1 B}$ by another iodide anion leads to the final product $1 \mathrm{D}$.

The reaction reduction of sulphimides by means of TFAA-I can be rationalized accordingly with Scheme 8.

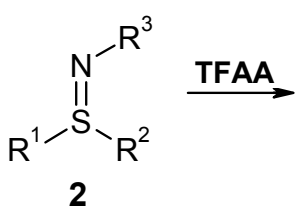

2

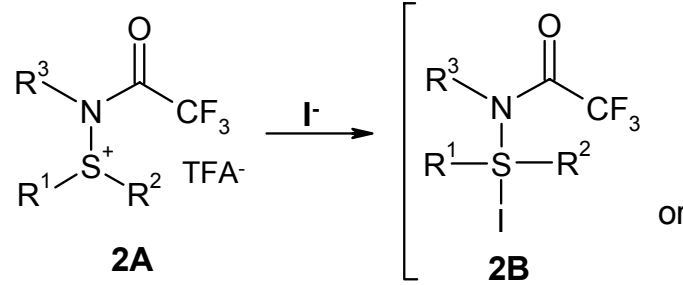

2A

2B

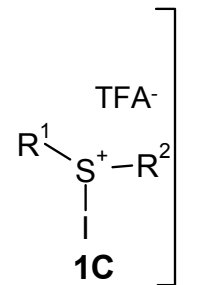<smiles>[R]S[R]</smiles>

$$
2+\mathrm{TFAA}+2 \mathrm{Nal} \longrightarrow 1 \mathrm{D}+\mathrm{I}_{2}+2 \mathrm{TFA}^{-\mathrm{Na}^{+}+} \mathrm{R}_{\mathrm{H}}^{3} \mathrm{H}_{\mathrm{CF}_{3}}
$$

\section{Scheme 8}


The first step of the reaction presents the acylation of sulphimide with TFAA to form aminosulphonium salt $\mathbf{2 A}$. The salt $\mathbf{2 A}$ reacts then with iodide anion to form either the sulphonium 1C or sulphurane 2B intermediates. These in turn decompose upon iodide anion action affording sulphide 1D, trifluoroacetamide derivatives and iodine.

The TFAA-I reagent exhibits no reactivity towards sulphones $\mathbf{1 6}$ and sulphoximides $\mathbf{1 7}$, (Table 1) probably due to low redox potential of intermediates 16A (and/or corresponding 17A, respectively), insufficient to oxidize iodide anion (Scheme 9).

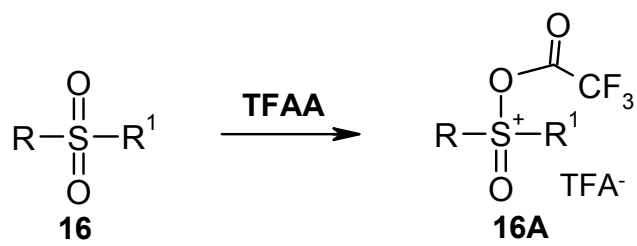

\section{Scheme 9}

Table 1. Course of the reactions of TFAA-I with compounds containing semipolar $S-O$ and $S$ - $N$ bonds

\begin{tabular}{|c|c|c|c|c|c|c|c|c|}
\hline \multicolumn{5}{|c|}{ Substrate } & \multirow[t]{2}{*}{$\begin{array}{l}\text { Taken } \\
(\mu m o l)\end{array}$} & \multicolumn{3}{|c|}{$\begin{array}{c}\text { Amount of iodine }(\mu \mathrm{mol}) \\
\text { released in time }\end{array}$} \\
\hline No & Structure & $\mathrm{R}^{1}$ & $\mathrm{R}^{2}$ & $\mathrm{R}^{3}$ & & $1 \mathrm{~min}$ & $20 \mathrm{~min}$ & $60 \mathrm{~min}$ \\
\hline $1 \mathrm{a}$ & 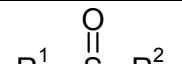 & $\mathrm{Me}$ & $\mathrm{Me}$ & & 50.0 & 49.9 & 49.9 & 49.9 \\
\hline 1c & & $n-\mathrm{Bu}$ & $n-\mathrm{Bu}$ & & 50.0 & 49.9 & 49.9 & 49.9 \\
\hline $1 \mathrm{~h}$ & & $\mathrm{Ph}$ & $\mathrm{Ph}$ & & 50.0 & 49.9 & 49.9 & 49.9 \\
\hline $2-2 c$ & $-R^{3}$ & $\mathrm{Me}$ & $n-\mathrm{Bu}$ & $\mathrm{Ph}$ & 50.0 & 25.0 & 49.0 & 49.0 \\
\hline $2-2 e$ & $\mathrm{R}-\mathrm{1}-\mathrm{S}-\mathrm{R}^{2}$ & $\mathrm{Me}$ & $\mathrm{Ph}$ & $\mathrm{Ph}$ & 50.0 & 15.0 & 26.9 & 49.0 \\
\hline $16 \mathrm{c}$ & $\begin{array}{ll} & \text { Oll } \\
& \end{array}$ & $n-\mathrm{Bu}$ & $n-\mathrm{Bu}$ & & 50.0 & 0.0 & 0.0 & 0.0 \\
\hline $16 h$ & $R-S-R^{2}$ & $\mathrm{Ph}$ & $\mathrm{Ph}$ & & 50.0 & 0.0 & 0.0 & 0.0 \\
\hline 17-1e & $N-R^{3}$ & $\mathrm{Me}$ & $\mathrm{Ph}$ & $\mathrm{H}$ & 50.0 & 0.0 & 0.0 & 0.0 \\
\hline 17-1f & $R^{1}-\|_{O}^{S}-R^{2}$ & $n-\mathrm{Bu}$ & $\mathrm{Ph}$ & $\mathrm{H}$ & 50.0 & 0.0 & 0.0 & 0.0 \\
\hline
\end{tabular}

In contrast to sulphones 16 and sulphoxyimides 17, the reaction of TFAA-I with sulphonic acids 3, according to Numata, Amato and $\mathrm{Oae}^{10}$, afforded the mixture of the corresponding thiols 3K, thioloesters 3J and disulphides $\mathbf{3 L}$. 

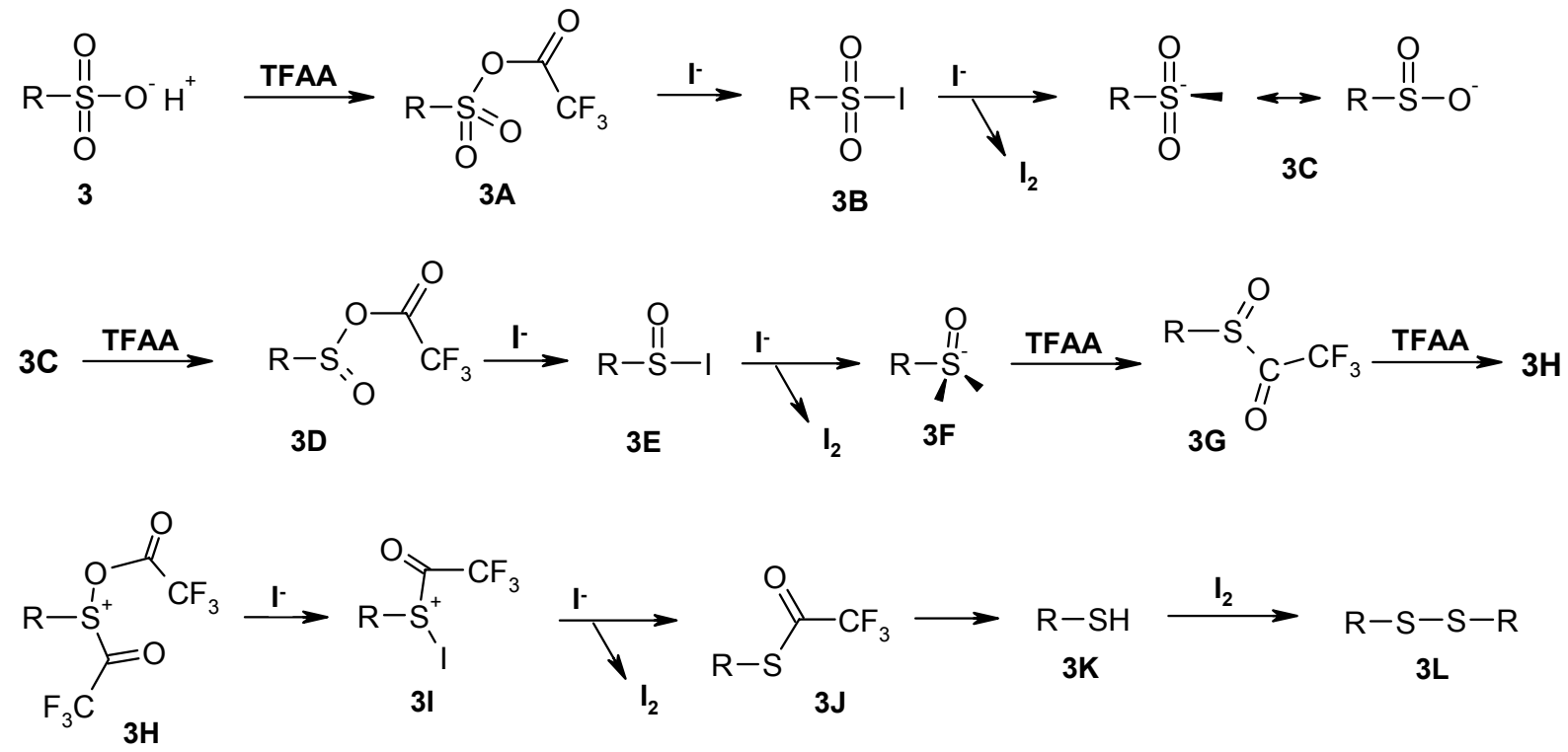

\section{Scheme 10}

The stoichiometry of iodine release in this reaction was not investigated in detail. Taking into account the already discussed general mechanism of the reaction of TFAA-I with $X$-oxo compounds, and also the types of final products of the deoxygenation of sulphonic acids by TFAA-I, this redox reaction can be considered to follow the reaction sequence presented in Scheme 10.

\subsection{Synthetic application of TFAA-I for reduction of $S$-oxo compounds}

\subsubsection{Reduction of sulphoxides}

Deoxygenation of sulphoxides to sulphides has been the subject of extensive research ${ }^{27,28}$. A survey of the literature indicates that sulphoxides can be reduced under various conditions and many preparatively useful methods have been reported (Table 2). However, only a few of them can accomplish the reduction quickly in high yields under mild conditions with common laboratory reagents. The extraordinary conditions are offered by the method elaborated by Drabowicz and Oae, based on the deoxygenation of sulphoxide $\mathbf{1}$ in reaction with TFAA-I (Scheme 11) ${ }^{7}$.<smiles>[R]S([R])=O</smiles>

1

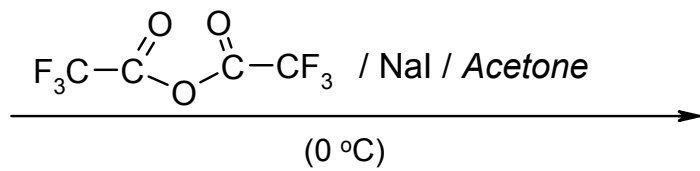

Scheme 11 
Table 2. Representative methods of reduction of sulphoxides to sulphides

\begin{tabular}{|c|c|c|c|c|c|c|c|}
\hline \multirow{2}{*}{$\begin{array}{c}\text { Meth. } \\
\text { No }\end{array}$} & \multicolumn{2}{|c|}{$\mathrm{R}^{1}-\mathrm{S}(\mathrm{O})-\mathrm{R}^{2}$} & \multicolumn{3}{|c|}{ Reaction Conditions } & \multirow{2}{*}{$\begin{array}{l}\text { Yields } \\
(\%)\end{array}$} & \multirow[t]{2}{*}{ Ref. } \\
\hline & $\mathrm{R}^{1}$ & $\mathrm{R}^{2}$ & Reagents Molar Ratio $^{a}$ & $\begin{array}{l}\text { Temp. } \\
\left({ }^{o} C\right)\end{array}$ & $\begin{array}{c}\text { Time } \\
(h)\end{array}$ & & \\
\hline \multirow[t]{3}{*}{1} & $n$-Bu & $n$-Bu & $\mathrm{R}^{1} \mathrm{~S}(\mathrm{O}) \mathrm{R}^{2} / \mathrm{RSO}_{3} \mathrm{H} / \mathrm{NaI}(1: 3: 3)$ & r. t. & 0.5 & 100 & 29 \\
\hline & $n-\operatorname{Pr}$ & $\mathrm{Ph}$ & in acetone & & 1.0 & 91 & \\
\hline & $\mathrm{Ph}$ & $\mathrm{Ph}$ & & & 1.0 & 90 & \\
\hline \multirow[t]{3}{*}{2} & $i-\operatorname{Pr}$ & $i-\operatorname{Pr}$ & $\mathrm{R}^{1} \mathrm{~S}(\mathrm{O}) \mathrm{R}^{2} /$ Silica gel $/ \mathrm{SOCl}_{2}{ }^{\mathrm{b}}$ & r. t. & 0.2 & 73 & 30 \\
\hline & $\mathrm{Bn}$ & $\mathrm{Bn}$ & & & 0.2 & 90 & \\
\hline & $\mathrm{Ph}$ & $\mathrm{Ph}$ & & & 0.05 & 81 & \\
\hline \multirow[t]{3}{*}{3} & $\mathrm{Me}$ & $\mathrm{Ph}$ & $\begin{array}{l}\mathrm{R}^{1} \mathrm{~S}(\mathrm{O}) \mathrm{R}^{2} / \mathrm{Mg} / \text { cat. } \mathrm{HgCl}_{2}(1: 4) \\
\text { in EtOH }\end{array}$ & r. t. & 3.0 & 98 & 31 \\
\hline & $\mathrm{Ph}$ & $\mathrm{Ph}$ & $\begin{array}{l}\mathrm{R}^{1} \mathrm{~S}(\mathrm{O}) \mathrm{R}^{2} / \mathrm{Mg}(1: 3) \\
\quad \text { in } \mathrm{MeOH} / \mathrm{THF}\end{array}$ & -43 & 3.0 & 99 & \\
\hline & Bn & $\mathrm{Ph}$ & $\begin{array}{l}\mathrm{R}^{1} \mathrm{~S}(\mathrm{O}) \mathrm{R}^{2} / \mathrm{Mg}(1: 6) \\
\text { in } \mathrm{MeOH}\end{array}$ & -43 & 5.0 & 99 & \\
\hline \multirow[t]{2}{*}{4} & $\mathrm{Me}$ & $\mathrm{Ph}$ & $\mathrm{R}^{1} \mathrm{~S}(\mathrm{O}) \mathrm{R}^{2} / \mathrm{Cp}_{2} \mathrm{TiCl}_{2} / \mathrm{Sm}(1: 2: 1)$ & r. t. & 1.0 & 87 & 32 \\
\hline & $\mathrm{Ph}$ & $\mathrm{Ph}$ & in THF & & & 82 & \\
\hline \multirow[t]{3}{*}{5} & $\mathrm{Me}$ & $\mathrm{Ph}$ & $\mathrm{R}^{1} \mathrm{~S}(\mathrm{O}) \mathrm{R}^{2} / \mathrm{TiCl}_{4} / \mathrm{Sm}(1: 4: 2)$ & r. t. & 0.5 & 87 & 33 \\
\hline & $\mathrm{Ph}$ & $\mathrm{Bn}$ & in THF & & & 80 & \\
\hline & $\mathrm{Ph}$ & $\mathrm{Ph}$ & & & & 75 & \\
\hline 6 & \multicolumn{2}{|c|}{$\begin{array}{l}\text { Met }[\mathrm{S}(\mathrm{O})] \text { in } \\
\text { peptides }\end{array}$} & $\begin{array}{c}\mathrm{R}^{1} \mathrm{~S}(\mathrm{O}) \mathrm{R}^{2} / \mathrm{NH}_{4} \mathrm{I}(1: 5-15) \\
\text { in } \mathrm{THF}\end{array}$ & 0 & $\begin{array}{c}0.5- \\
1.0\end{array}$ & 99 & 34 \\
\hline \multirow[t]{3}{*}{7} & $n$-Bu & $n$-Bu & $\mathrm{R}^{1} \mathrm{~S}(\mathrm{O}) \mathrm{R}^{2} / \mathrm{TsOH} / \mathrm{KI}(1: 3: 3)$ & 30 & 0.25 & 73 & 35 \\
\hline & $\mathrm{Me}$ & $\mathrm{Ph}$ & in solid state & & 4.0 & 97 & \\
\hline & $\mathrm{Ph}$ & $\mathrm{Ph}$ & & & 4.0 & 76 & \\
\hline \multirow[t]{3}{*}{8} & $n$-Bu & $n$-Bu & $\mathrm{R}^{1} \mathrm{~S}(\mathrm{O}) \mathrm{R}^{2} / \mathrm{Ac}_{2} \mathrm{O} / \mathrm{DMAP} / \mathrm{Zn}$ & r. t. & 24 & 81 & 36 \\
\hline & $\mathrm{Me}$ & $\mathrm{Ph}$ & $(1: 2: 0.1: 10)$ & & 12 & 95 & \\
\hline & Tol & Tol & in $\mathrm{CH}_{3} \mathrm{CN}$ & & 20 & 97 & \\
\hline \multirow[t]{3}{*}{9} & $n$-Bu & $n$-Bu & $\mathrm{R}^{1} \mathrm{~S}(\mathrm{O}) \mathrm{R}^{2} / \mathrm{DHPy}(2: 1)$ & 80 & 5.0 & 98 & 37 \\
\hline & $\mathrm{Ph}$ & $\mathrm{Ph}$ & in $\mathrm{CH}_{3} \mathrm{CN}$ & & 14 & 24 & \\
\hline & $\mathrm{Bn}$ & $\mathrm{Bn}$ & & & 4.0 & 98 & \\
\hline \multirow[t]{3}{*}{10} & $\mathrm{Me}$ & $\mathrm{Me}$ & $\mathrm{R}^{1} \mathrm{~S}(\mathrm{O}) \mathrm{R}^{2} / \mathrm{WCl}_{6} / \mathrm{NaI}(1: 0.5: 3)$ & r. t. & 5.0 & 98 & 38 \\
\hline & $\mathrm{Me}$ & $\mathrm{Ph}$ & in $\mathrm{CH}_{3} \mathrm{CN}$ & & 5.0 & 90 & \\
\hline & $\mathrm{Ph}$ & $\mathrm{Ph}$ & & & 35 & 95 & \\
\hline \multirow[t]{3}{*}{11} & $n$-Hex & $n$-Hex & $\mathrm{R}^{1} \mathrm{~S}(\mathrm{O}) \mathrm{R}^{2} / \mathrm{TiI}_{4}(2: 3)$ & 0 & 0.25 & 85 & 39 \\
\hline & $\mathrm{Bn}$ & $\mathrm{Bn}$ & in $\mathrm{CH}_{3} \mathrm{CN}$ & & & 85 & \\
\hline & $\mathrm{Ph}$ & $\mathrm{Ph}$ & & & & 93 & \\
\hline
\end{tabular}




\begin{tabular}{|c|c|c|c|c|c|c|c|}
\hline \multirow[t]{3}{*}{12} & $n-\mathrm{Bu}$ & $n-\mathrm{Bu}$ & $\mathrm{R}^{1} \mathrm{~S}(\mathrm{O}) \mathrm{R}^{2} / 3-\mathrm{MPA} / \mathrm{TMCS}(1: 2.1: 0.1)$ & r. t. & 0.5 & 96 & 40 \\
\hline & $\mathrm{Me}$ & $\mathrm{Ph}$ & in $\mathrm{CH}_{3} \mathrm{CN}$ & & 1.0 & 93 & \\
\hline & $\mathrm{Ph}$ & $\mathrm{Ph}$ & & & 48 & 58 & \\
\hline \multirow[t]{4}{*}{13} & $n-\mathrm{Bu}$ & $n-\mathrm{Bu}$ & $\mathrm{R}^{1} \mathrm{~S}(\mathrm{O}) \mathrm{R}^{2} / \mathrm{PhSiH}_{3} / \mathrm{MoO}_{2} \mathrm{Cl}_{2}$ & 67 & 7 & 92 & 41 \\
\hline & $\mathrm{Me}$ & $\mathrm{Ph}$ & $(1: 1: 0.05)$ in THF & & 2 & 97 & \\
\hline & $\mathrm{Ph}$ & $\mathrm{Ph}$ & & & 2 & 97 & \\
\hline & $\mathrm{Bn}$ & $\mathrm{Bn}$ & & & 20 & 96 & \\
\hline \multirow[t]{2}{*}{14} & $\mathrm{Me}$ & $\mathrm{Ph}$ & $\mathrm{R}^{1} \mathrm{~S}(\mathrm{O}) \mathrm{R}^{2} / \mathrm{PhSiH}_{3} / \mathrm{MoO}_{2} \mathrm{Cl}_{2}\left(\mathrm{H}_{2} \mathrm{O}\right)_{2}$ & & 1.5 & 95 & \\
\hline & $\mathrm{Bn}$ & $\mathrm{Bn}$ & $(1: 1: 0.05)$ in THF & & 20 & 95 & \\
\hline
\end{tabular}

${ }^{\mathrm{a}}$ Abbreviations: DMAP = 2-dimethylaminopyridine; DHPy = 2,6-dihydroksypyridine; 3-MPA =

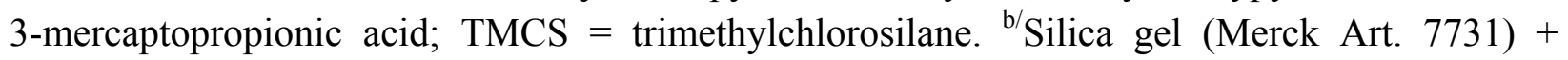
$\mathrm{SOCl}_{2} \rightarrow$ silica chloride ( $0.9 \mathrm{~g} \mathrm{Cl} / \mathrm{g}$ silica).

The results of deoxygenation of representative sulphoxides 1 using TFAA-I are given in Table 3.

Table 3. Reduction of representative sulphoxides 1 to sulphides $1 \mathbf{D}$ using TFAA-I ${ }^{7}$

\begin{tabular}{llllll}
\hline & \multicolumn{2}{c}{$\mathrm{R}^{1}-\mathrm{S}(\mathrm{O})-\mathrm{R}^{2}$} & \multicolumn{2}{c}{ Reaction Conditions } & \multicolumn{2}{c}{$\begin{array}{c}\text { Yield of sulphides } \\
\text { No }\end{array}$} & $\mathrm{R}^{1}$ & $\mathrm{R}^{2}$ & $\begin{array}{l}\text { Reagents Molar Ratio } \\
\mathrm{R}^{1}-\mathrm{S}(\mathrm{O})-\mathrm{R}^{2}: \text { TFAA }: \text { NaI }\end{array}$ & $\begin{array}{l}\text { Time }^{\mathrm{a}} \\
(\mathrm{min})\end{array}$ & \multicolumn{1}{c}{$(\%)$} \\
\hline $\mathbf{1 a}$ & $\mathrm{Me}$ & $\mathrm{Me}$ & $1: 1.2: 2.4$ & 10 & $(100)^{\mathrm{c}}$ \\
$\mathbf{1 c}$ & $n-\mathrm{Bu}$ & $n-\mathrm{Bu}$ & $1: 1.2: 2.4$ & 1 & $93(100)^{\mathrm{c}}$ \\
$\mathbf{1 d}$ & $\mathrm{Bn}$ & $\mathrm{Bn}$ & $1: 1.9: 2.4$ & 1 & $92(100)^{\mathrm{c}}$ \\
$\mathbf{1 e}$ & $\mathrm{Me}$ & $\mathrm{Ph}$ & $1: 1.5: 2.4$ & 1 & $94(100)^{\mathrm{c}}$ \\
$\mathbf{1 h}$ & $\mathrm{Ph}$ & $\mathrm{Ph}$ & $1: 2.3: 2.4$ & 1 & $95(100)^{\mathrm{c}}$ \\
$\mathbf{1 j}$ & $p$-Cl-Ph & $p$-Cl-Ph & $1: 2.6: 2.4$ & 30 & 68 \\
$\mathbf{1} \mathbf{k}^{42}$ & Ferrocene & $p-\mathrm{Tol}$ & $1: 2.6: 2.4$ & & \\
\hline
\end{tabular}

${ }^{a}$ Reactions were run at room temperature. ${ }^{b, c /}$ Yields: ${ }^{b}$ isolated compounds or ${ }^{c /}$ determined by TLC or GLC and given in parentheses.

\section{Deoxygenation of Sulphoxides ${ }^{7}$ :}

A round-bottom flask was charged with acetone $(25 \mathrm{~mL})$, sulphoxide $(5 \mathrm{mmol})$, and sodium iodide $(12 \mathrm{mmol})$. The flask was immersed in an ice bath $\left(0{ }^{\circ} \mathrm{C}\right)$ and an acetone solution of trifluoroacetic anhydride was slowly added with stirring; one to ten minutes after the addition (Table 3), the sulphoxides were quantitatively reduced. After acetone was evaporated, water was added and the mixture was extracted with ether $(70 \mathrm{~mL})$, and ether extract was washed with 
sodium thiosulphate solution and water. Upon evaporation of the solvent, residual sulphide was purified by filtration through short silica column with $n$-hexane as an eluent.

\subsubsection{Reduction of sulphimides}

The chemistry of sulphimides is a subject of substantial interest, focused on their synthetic applications as well as pharmacological properties ${ }^{43-45}$. Less attention has been paid to the reduction of sulphimides to sulphides, although a few reagents have been used to achieve this reduction satisfactorily (Table 4).

Table 4. Representative methods of reduction of sulphimides to sulphides

\begin{tabular}{|c|c|c|c|c|c|c|c|c|}
\hline \multirow{2}{*}{$\begin{array}{l}\text { Meth. } \\
\text { No }\end{array}$} & \multicolumn{3}{|c|}{$\mathrm{R}^{1}-\mathrm{S}\left(=\mathrm{N}-\mathrm{R}^{3}\right)-\mathrm{R}^{2}$} & \multicolumn{3}{|c|}{ Reaction Conditions $^{\mathrm{a}}$} & \multirow[b]{2}{*}{$\begin{array}{l}\text { Yields } \\
(\%)^{\mathrm{b}, \mathrm{c}}\end{array}$} & \multirow[b]{2}{*}{ Ref } \\
\hline & $\mathrm{R}^{1}$ & $\mathrm{R}^{2}$ & $\mathrm{R}^{3}$ & Reagents Molar Ratio & $\begin{array}{l}\text { Temp. } \\
\left({ }^{o} C\right)\end{array}$ & $\begin{array}{c}\text { Time } \\
(h)\end{array}$ & & \\
\hline \multirow[t]{2}{*}{1} & $\mathrm{Bu}$ & $\mathrm{Ph}$ & Tos & $\mathrm{R}_{2} \mathrm{~S}=\mathrm{NR} / \mathrm{H}_{2} /(1 \mathrm{at}) / \mathrm{Pd} /$ Norite & r. t. & & 75 & \multirow{2}{*}{46} \\
\hline & $\mathrm{Ph}$ & $\mathrm{Ph}$ & Tos & $(1: 0.1)$ in $\mathrm{EtOH}$ & r. t. & & 71 & \\
\hline 2 & $\mathrm{Ph}$ & $\mathrm{Ph}$ & Tos & $\begin{array}{c}\mathrm{R}_{2} \mathrm{~S}=\mathrm{NR} / \mathrm{Bu}_{3} \mathrm{SnH} / \mathrm{AIBN}(1: 5: 1) \\
\text { in THF }\end{array}$ & rf. t. & & 30 & 47 \\
\hline \multirow[t]{2}{*}{3} & $\mathrm{Me}$ & $\mathrm{Me}$ & Tos & $\mathrm{R}_{2} \mathrm{~S}=\mathrm{NR} / \mathrm{Sn} / \mathrm{HCl}_{\mathrm{aq}}$ & 100 & 0.75 & $95^{\mathrm{d}}$ & \multirow{2}{*}{48} \\
\hline & $\operatorname{Pr}$ & $\operatorname{Pr}$ & Tos & & 100 & 4 & $73^{d}$ & \\
\hline \multirow[t]{2}{*}{4} & $\mathrm{Me}$ & $\mathrm{Me}$ & Tos & $\mathrm{R}_{2} \mathrm{~S}=\mathrm{NR} / \mathrm{MeCS}_{2} \mathrm{H}(1: 2)$ & r. t. & & $(100)^{\mathrm{c}}$ & \multirow{2}{*}{49} \\
\hline & $\mathrm{Ph}$ & $\mathrm{Ph}$ & Tos & & r. t. & & $(100)^{\mathrm{c}}$ & \\
\hline \multirow[t]{2}{*}{5} & $\mathrm{Me}$ & $\mathrm{Ph}$ & Tos & $\mathrm{R}_{2} \mathrm{~S}=\mathrm{NR} / \mathrm{H}_{2} \mathrm{NC}(\mathrm{NH}) \mathrm{SO}_{2}{ }^{-} / \mathrm{NaOH}_{\mathrm{aq}} /$ & 70 & 6 & 93 & \multirow[b]{2}{*}{50} \\
\hline & $\mathrm{Ph}$ & $\mathrm{Ph}$ & Tos & $\begin{array}{c}\mathrm{R}_{4} \mathrm{P}^{+} \mathrm{Br}^{-} \\
(1: 1.8: 3.6: 0.02)\end{array}$ & 70 & 4 & 28 & \\
\hline \multirow[t]{3}{*}{6} & $\mathrm{Me}$ & $\mathrm{Me}$ & Tos & $\mathrm{R}_{2} \mathrm{~S}=\mathrm{NR} / \mathrm{P}_{4} \mathrm{~S}_{10}(2: 1)$ & 25 & 4 & 77 & \multirow{3}{*}{51} \\
\hline & $\mathrm{Ph}$ & $\mathrm{Ph}$ & $\mathrm{H}$ & in $\mathrm{CH}_{2} \mathrm{Cl}_{2}$ & 25 & 4 & 86 & \\
\hline & $\mathrm{Ph}$ & $\mathrm{Ph}$ & Tos & & rf. t. & 15 & 98 & \\
\hline \multirow[t]{3}{*}{7} & $\mathrm{Me}$ & $\mathrm{Bu}$ & PHS & $\mathrm{R}_{2} \mathrm{~S}=\mathrm{NR} / \mathrm{TiCl}_{4} / \mathrm{Zn}(1: 2: 2)$ & 20 & 1 & $(75)^{\mathrm{c}}$ & \multirow{3}{*}{7} \\
\hline & $\mathrm{Me}$ & $\mathrm{Ph}$ & PHS & in ether & 20 & 1 & $92(100)^{c}$ & \\
\hline & $\mathrm{Ph}$ & $\mathrm{Ph}$ & $\mathrm{Bn}$ & $(1: 1.8: 1.8)$ & 20 & 1 & $(100)^{\mathrm{c}}$ & \\
\hline
\end{tabular}

${ }^{\mathrm{a} /}$ Abbreviations: PHS $=$ Phenylsulphonyl; Tos - $p$-tosyl; AIBN = azobisisobutyronitrile; r. t. $=$ room temperature; rf. t. $=$ reflux temperature. ${ }^{\text {b,c/ }}$ Yields: ${ }^{b}$ isolated compounds or ${ }^{\mathrm{c} /}$ determined by TLC or GLC and given in parentheses. ${ }^{\mathrm{d} /}$ Isolated as $\mathrm{R}_{2} \mathrm{~S} \times \mathrm{HgCl}_{2}$.
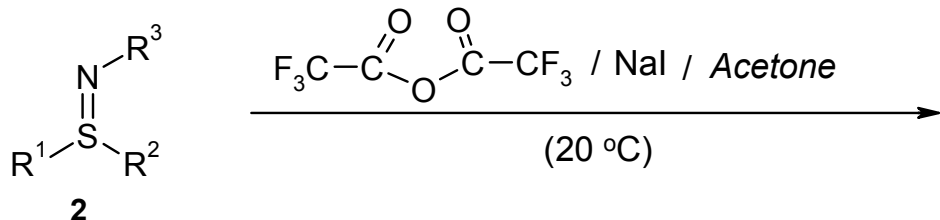

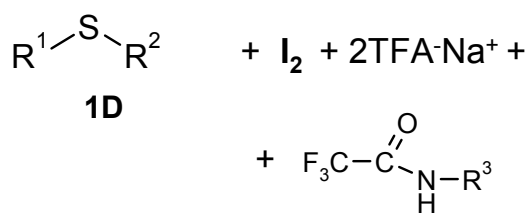

Scheme 12 
The procedure of the reduction of sulphimides by means of the TFAA-I reagent (Scheme 12, Table 5), compare favorably with known methods (Table 4) for the same purpose in terms of yields, and simplicity of performance and work up. Further, only common laboratory chemicals are used.

Table 5. Reduction of sulphimides 2 to sulphides $1 \mathrm{D}$ using TFAA-I $^{7}$

\begin{tabular}{|c|c|c|c|c|c|c|}
\hline \multicolumn{4}{|c|}{$\mathrm{R}^{1}-\mathrm{S}\left(=\mathrm{N}-\mathrm{R}^{3}\right)-\mathrm{R}^{2}$} & \multicolumn{2}{|c|}{ Reaction Conditions } & \multirow{2}{*}{$\begin{array}{l}\text { Yields of } \\
\text { sulfides } \mathrm{c}, \mathrm{c} \\
\quad(\%)\end{array}$} \\
\hline No & $\mathrm{R}^{1}$ & $\mathrm{R}^{2}$ & $\mathrm{R}^{3 / \mathrm{a}}$ & $\mathrm{R}_{2} \mathrm{~S}(=\mathrm{NR}): \mathrm{TFAA}: \mathrm{NaI}$ & $\begin{array}{c}\text { Time }^{\mathrm{b}} \\
(h)\end{array}$ & \\
\hline $2-3 c$ & $\mathrm{Me}$ & $n$-Bu & PHS & $1: 2: 2$ & 0.5 & $(98)^{\mathrm{d}}$ \\
\hline 2-3d & $\mathrm{Bn}$ & $\mathrm{Bn}$ & PHS & $1: 2: 2$ & 1 & 86 \\
\hline $2-3 e$ & $\mathrm{Me}$ & $\mathrm{Ph}$ & PHS & $1: 2: 2$ & 1 & $82(85)^{d}$ \\
\hline $2-3 g$ & $\mathrm{Me}$ & $p$-Tol & PHS & $1: 2: 2$ & 1 & $68(80)^{\mathrm{d}}$ \\
\hline $2-4 e$ & $\mathrm{Me}$ & $\mathrm{Ph}$ & Tos & $1: 2: 2$ & 1 & $87(93)^{\mathrm{d}}$ \\
\hline $2-4 h$ & $\mathrm{Ph}$ & $\mathrm{Ph}$ & Tos & $1: 2: 2$ & 5 & $67(90)^{\mathrm{d}}$ \\
\hline
\end{tabular}

${ }^{\mathrm{a} /}$ Abbreviations: PHS = phenylsulphonyl; Tos $=p$-tolylsulphonyl. ${ }^{\mathrm{b} /}$ Temperature $20{ }^{\circ} \mathrm{C} .{ }^{\mathrm{c}, \mathrm{d} /}$ Yields: ${ }^{\mathrm{c}}$ isolated compounds or ${ }^{\mathrm{d} /}$ determined by GLC and given in parentheses.

\subsubsection{Reduction of sulphonic acids and derivatives}

Results on the reduction of sulphonic acids by TFAA-I are presented in Table 6, and sulphonic and sulphinic acids and derivatives in Table 7.

The results of reduction of sulphonic acids by TFAA-I, presented in Table 7, show that yields are only moderate. Taking into account rather tedious procedure the deoxygenation of sulphonic acids by TFAA-I can be considered more as part of pure than applied chemistry.

The use of sodium iodide instead of tetrabutylammonium iodide results in a sharp decrease of yields in the reduction of sulphonic acids (for TosOH: $81 \%$ vs 6\%), probably caused by solubility of $\mathrm{NaI}$ and $\mathrm{TosOH}(\mathrm{TosOH}+\mathrm{NaI} \rightarrow \mathrm{TosNa}+\mathrm{HI})$ in methylene chloride. The results of the reduction of sulphinic acids illustrate efficiency of the reaction and probably, its quantitative character. 
Table 6. Representative results of TFAA-I reaction with representative sulphonic acids $\mathbf{3}^{10}$

\begin{tabular}{|c|c|c|c|c|c|c|c|}
\hline \multirow{2}{*}{\multicolumn{2}{|c|}{$\begin{array}{l}\text { Sulphonic acids } \\
\text { No } \quad \mathrm{R}_{-}-\mathrm{SO}_{3} \mathrm{H}^{\mathrm{a}}\end{array}$}} & \multicolumn{3}{|c|}{ Reaction Conditions } & \multicolumn{3}{|c|}{ Products $^{\mathrm{a}}(\%)$} \\
\hline & & $\begin{array}{l}\mathrm{R}-\mathrm{SO}_{3} \mathrm{H} / \mathrm{TFAA} / \mathrm{I} \\
\left(\text { in } \mathrm{CH}_{2} \mathrm{Cl}_{2}\right)^{\mathrm{b}}\end{array}$ & $\begin{array}{l}\text { Time }^{\mathrm{c}} \\
(h)\end{array}$ & Meth. ${ }^{\mathrm{d}}$ & $\mathrm{RSH}$ & RSTFA & $\mathrm{RS}_{2} \mathrm{R}$ \\
\hline $3 \mathbf{a}$ & $n-\mathrm{Am}_{-} \mathrm{SO}_{3} \mathrm{H}$ & $1: 15: 10$ & 23 & $\mathrm{C}$ & & & 36 \\
\hline $\mathbf{3 b}$ & $n$-Oct- $\mathrm{SO}_{3} \mathrm{H}$ & $1: 20: 10$ & 23 & $\mathrm{C}$ & & & 31 \\
\hline \multirow[t]{2}{*}{$3 c$} & $\mathrm{Ph}-\mathrm{SO}_{3} \mathrm{H}$ & $1: 20: 8$ & 22 & $\mathrm{~B}$ & 59 & & \\
\hline & & $1: 15: 9$ & 19 & $\mathrm{C}$ & & & 81 \\
\hline \multirow[t]{3}{*}{ 3d } & Tol- $\mathrm{SO}_{3} \mathrm{H}$ & $1: 10: 10$ & 20 & $\mathrm{~A}$ & 11 & 78 & \\
\hline & & $1: 15: 8.5$ & 22 & $\mathrm{~B}$ & 81 & & \\
\hline & & $1: 15: 8.5$ & 22 & $\mathrm{C}$ & & & 93 \\
\hline \multirow[t]{2}{*}{$3 e$} & $\mathrm{Cl}-\mathrm{Ph}-\mathrm{SO}_{3} \mathrm{H}$ & $1: 15: 8.5$ & 22 & $\mathrm{C}$ & & & 85 \\
\hline & & $1: 15: 8.5$ & 22 & $\mathrm{~B}$ & 70 & & \\
\hline
\end{tabular}

${ }^{\mathrm{a} /}$ Abbreviations: RSTFA $=$ thiolotrifluoroacetate; $\mathrm{Cl}-\mathrm{Ph}=p$-chlorophenyl. ${ }^{\mathrm{b} / \text { Iodide anion } \text { was }}$ introduced in form of $\mathrm{Bu}_{4} \mathrm{NI}$. ${ }^{\mathrm{c}}$ Room temperature. ${ }^{\mathrm{d} /}$ Methods of the reaction quenching: A - a reaction mixture was neutralized; $\mathrm{B}$ - a reaction mixture after alkalization was kept overnight and $\mathrm{C}$ - products mixture of thiols and aryl thiotrifluoroacetates was treated with $\mathrm{MeOH} / \mathrm{NaOH}$.

Table 7. Results of reaction of TFAA-I with sulphonic acid derivatives ${ }^{10}$

\begin{tabular}{ccccccc}
\hline \multirow{2}{*}{ No } & Substrate & \multicolumn{2}{c}{ Reaction Conditions } & \multicolumn{2}{c}{ Product } \\
& & R-S $(\mathrm{O})_{\mathrm{n}}-\mathrm{R}^{1} / \mathrm{TFAA} / \mathrm{NaI}$ & Temp. & Time & Structure & Yield \\
& & $($ in acetone $)$ & $\left({ }^{\circ} \mathrm{C}\right)$ & $(h)$ & & \\
\hline $\mathbf{3 d}$ & TosOH & $1: 3: 7$ & 20 & 13 & Tol- $\mathrm{S}_{2}-\mathrm{Tol}$ & $6 \%$ \\
$\mathbf{4 a}$ & $\mathrm{Tos}-\mathrm{Cl}$ & $1: 3: 10$ & 20 & 0.25 & Tol- $\mathrm{S}_{2}-\mathrm{Tol}$ & $66 \%$ \\
$\mathbf{5 a}$ & $\mathrm{Ph}-\mathrm{S}(\mathrm{O}) \mathrm{OH}$ & $1: 4: 10$ & -78 & 0.1 & $\mathrm{Ph}-\mathrm{S}_{2}-\mathrm{Ph}$ & $83 \%$ \\
$\mathbf{6 a}$ & $\mathrm{Ph}-\mathrm{S}(\mathrm{O})_{2}-\mathrm{S}-\mathrm{Ph}$ & $1: 3.6: 7.1$ & -78 & 1.5 & $\mathrm{Ph}_{-}-\mathrm{S}_{2}-\mathrm{Ph}$ & $58 \%$ \\
\hline
\end{tabular}

\subsection{Analytical application of TFAA-I for determination and detection of $S$-oxo compounds}

Sulphoxides and sulphimides are important reagents and/or intermediates in organic chemistry ${ }^{43-}$ 45,52,53. Moreover, this group of organo-sulphur compounds also shows very interesting biological and/or pharmacological activity (Table 8$)^{45,54,55}$. For this reason their determination and/or detection are of interest ${ }^{56-58}$. 
Table 8. Representative $S$-oxo compounds occurring in living organisms and/or presenting biological or pharmacological activity

garlic) (flavour ingredient of

\subsubsection{Determination of sulphoxides}

Although in the last decades GLC methods have been used extensively for the determination of volatile sulphoxides $^{56,57}$ - the non-volatile and unstable sulphoxides are still determined by classical methods.

Thus, the first of these procedures were based on reduction with stannous ${ }^{59}$ or titanous ${ }^{60,61}$ salts and back titration of the excess of reducing agent with a standard ferric solution. The sulphoxides have also been reduced with iodide in hydrochloric acid ${ }^{62,63}$, or acetic acid-acetyl chloride mixtures ${ }^{64}$ with subsequent determination of the iodine released.

Later, methods based on oxidation of sulphoxides by potassium permanganate ${ }^{65}$ or dichromate $^{66}$, and chloramines ${ }^{67,68}$, were introduced. The sulphoxides were also determined by potentiometric titration with perchloric acid in anhydrous dioxane-acetic anhydride solution ${ }^{69,70}$. Several methods of titrimetric determinations of sulphoxides were experimentally verified by Moravek and Vlacil ${ }^{71}$ (Table 9). 
Table 9. Comparison of the representative methods of titrimetric determination of sulphoxides

\begin{tabular}{|c|c|c|c|c|c|c|}
\hline No & Method & $\begin{array}{l}\text { Time } \\
(\min )\end{array}$ & $\begin{array}{l}\text { Range } \\
(\mathrm{mmol})\end{array}$ & $\begin{array}{c}\text { Accur. } \\
(\%)\end{array}$ & $\begin{array}{c}\text { Stand. } \\
\text { used }\end{array}$ & Lit. \\
\hline 1 & $\begin{array}{l}\mathrm{RS}(\mathrm{O}) \mathrm{R}+\mathrm{Ac}_{2} \mathrm{O} \rightarrow \mathrm{R}_{2} \mathrm{~S}^{+}-\mathrm{O}-\mathrm{Ac}+\mathrm{AcO}^{-} \\
\mathrm{AcO}^{-}+\mathrm{H}^{+} \mathrm{ClO}_{4}^{-} \rightarrow \mathrm{AcOH}+\mathrm{ClO}_{4}^{-} \\
\text {Potentiometric titration of sulphoxide with stand. } \\
\text { solution of } \mathrm{HClO}_{4} \text { in } \mathrm{Ac}_{2} \mathrm{O} / \text { dioxane solution. }\end{array}$ & 30 & 1.0 & $\begin{array}{l}99.5 \pm 0.1 \\
99.2 \pm 0.2 \\
99.7 \pm 0.4\end{array}$ & $\begin{array}{l}\text { DMSO } \\
\text { DPSO } \\
\text { DBSO }\end{array}$ & $\begin{array}{l}69 \\
71\end{array}$ \\
\hline 2 & $\begin{array}{l}\mathrm{RS}(\mathrm{O}) \mathrm{R}+\mathrm{Cr}_{2} \mathrm{O}_{7}^{2-}\left(\mathrm{H}^{+}\right) \rightarrow \mathrm{RS}(\mathrm{O})_{2} \mathrm{R}+\mathrm{Cr}^{3+} \\
\mathrm{Cr}_{2} \mathrm{O}_{7}^{2-}\left(\mathrm{H}^{+}\right)+\mathrm{Fe}^{2+} \rightarrow \mathrm{Cr}^{3+}+\mathrm{Fe}^{3+} \\
\text { Oxidation of sulphoxide with excess of stand. } \\
\text { solution of } \mathrm{K}_{2} \mathrm{Cr}_{2} \mathrm{O}_{7} \text { in } \mathrm{H}_{2} \mathrm{SO}_{4} \text {. Redox back-titration } \\
\text { with } 0.1 M \mathrm{Fe}(\mathrm{II}) \mathrm{SO}_{4} \text {. }\end{array}$ & 45 & $0.5-1.5$ & $\begin{array}{l}99.9 \pm 0.1 \\
99.9 \pm 0.1 \\
95.7 \pm 7.4\end{array}$ & $\begin{array}{l}\text { DMSO } \\
\text { DPSO } \\
\text { DBSO }\end{array}$ & 66 \\
\hline 3 & $\begin{array}{l}\mathrm{RS}(\mathrm{O}) \mathrm{R}+\mathrm{MnO}_{4}^{-}\left(\mathrm{H}^{+}\right) \rightarrow \mathrm{RS}(\mathrm{O})_{2} \mathrm{R}+\mathrm{Mn}^{2+} \\
\mathrm{MnO}_{4}^{-}\left(\mathrm{H}^{+}\right)+\mathrm{Fe}^{2+} \rightarrow \mathrm{Mn}^{2+}+\mathrm{Fe}^{3+} \\
\text { Oxidation of sulphoxide with excess of stand. } \\
\text { solution of } \mathrm{KMnO}_{4} \text { in } \mathrm{H}_{2} \mathrm{SO}_{4} \text {. Redox back-titration } \\
\text { with } 0.1 M \mathrm{Fe}(\mathrm{II}) \mathrm{SO}_{4} \text {. }\end{array}$ & 35 & 4.0 & $\begin{array}{l}99.5 \pm 0.1 \\
99.5 \pm 0.1\end{array}$ & $\begin{array}{l}\text { DMSO } \\
\text { DPSO }\end{array}$ & 64 \\
\hline 4 & $\begin{array}{l}\mathrm{RS}(\mathrm{O}) \mathrm{R}+\mathrm{Ar}-\mathrm{S}(\mathrm{O})_{2} \mathrm{~N}(\mathrm{Na}) \mathrm{Cl} \rightarrow \mathrm{RS}(\mathrm{O})_{2} \mathrm{R} \\
\mathrm{ArS}(\mathrm{O})_{2} \mathrm{~N}(\mathrm{Na}) \mathrm{Cl}+2 \mathrm{I}^{-}+2 \mathrm{H}^{+} \rightarrow \operatorname{ArS}(\mathrm{O})_{2} \mathrm{NH}_{2}+\mathrm{I}_{2}+ \\
\mathrm{NaCl} \\
\text { Oxidation of sulphoxide with excess of stand. } \\
\text { solution of chloramine- } \mathrm{T}^{67} \text {, or chloramine- } \mathrm{B}^{68} \text {. } \\
\text { Iodometric determination of chloramine excess } \\
\left(0.05 M \mathrm{Na}_{2} \mathrm{~S}_{2} \mathrm{O}_{3}\right) .\end{array}$ & $5-10$ & $0.2-1.0$ & $\begin{array}{l}99.5 \pm 0.1 \\
99.5 \pm 0.1\end{array}$ & $\begin{array}{l}\text { DMSO } \\
\text { DMSO }\end{array}$ & $\begin{array}{l}67 \\
68\end{array}$ \\
\hline 5 & $\begin{array}{l}\mathrm{RS}(\mathrm{O}) \mathrm{R}+\mathrm{SnCl}_{2}+2 \mathrm{HCl} \rightarrow \mathrm{RSR}+\mathrm{SnCl}_{4}+\mathrm{H}_{2} \mathrm{O} \\
\mathrm{Sn}^{2+}+2 \mathrm{Fe}^{3+} \rightarrow \mathrm{Sn}^{4+}+2 \mathrm{Fe}^{2+} \\
\text { Reduction of sulphoxide with excess of stand. } \\
\text { solution of } \mathrm{SnCl}_{2} . \text { Redox back-titration of } \mathrm{SnCl}_{2} \text { with } \\
0.1 M \mathrm{Fe}(\mathrm{III}) \mathrm{SO}_{4} \text {. }\end{array}$ & 80 & $2.5-6.0$ & $98.8 \pm 1.0$ & DBSO & 71 \\
\hline 6 & $\begin{array}{l}\mathrm{RS}(\mathrm{O}) \mathrm{R}+2 \mathrm{TiCl}_{3}+2 \mathrm{HCl} \rightarrow \mathrm{RSR}+2 \mathrm{TiCl}_{4}+\mathrm{H}_{2} \mathrm{O} \\
\mathrm{Ti}^{3+}+\mathrm{Fe}^{3+} \rightarrow \mathrm{Ti}^{4+}+\mathrm{Fe}^{2+} \\
\text { Reduction of sulphoxide with excess of stand. } \\
\text { solution of } \mathrm{TiCl}_{3} \text {. Redox back-titration of } \mathrm{TiCl}_{3} \text { with } \\
0.1 \mathrm{M} \mathrm{Fe}(\mathrm{III}) \mathrm{SO}_{4} \text {. }\end{array}$ & 95 & $2.0-5.0$ & $99.3 \pm 4.9$ & DBSO & 71 \\
\hline 7 & $\begin{array}{l}\mathrm{RS}(\mathrm{O}) \mathrm{R}+2 \mathrm{I}^{-}+2 \mathrm{H}^{+} \rightarrow \mathrm{RSR}+\mathrm{I}_{2}+\mathrm{H}_{2} \mathrm{O} \\
\text { Reduction of sulphoxide with excess of } \mathrm{KI} \text {. } \\
\text { Iodometric titration with } 0.05 \mathrm{M} \mathrm{Na}_{2} \mathrm{~S}_{2} \mathrm{O}_{3} \text {. }\end{array}$ & $5-10$ & 0.5 & $99.7 \pm 0.3$ & AMSP & 63 \\
\hline 8 & $\begin{array}{l}\mathrm{RS}(\mathrm{O}) \mathrm{R}+\mathrm{AcCl} \rightarrow \mathrm{R}_{2} \mathrm{~S}^{+}-\mathrm{OAc}+\mathrm{Cl}^{-} \\
\mathrm{R}_{2} \mathrm{~S}^{+}-\mathrm{OAc}+2 \mathrm{I}^{-} \rightarrow \mathrm{RSR}+\mathrm{I}_{2}+\mathrm{AcO}^{-} \\
\text {Acylation-reduction with } \mathrm{AcCl} / \mathrm{AcOH} / \mathrm{NaI} \text { mixture. } \\
\text { Iodometric titration with } 0.1 \mathrm{M} \mathrm{Na} \mathrm{S}_{2} \mathrm{O}_{3} \text {. }\end{array}$ & 20 & $0.5-1.0$ & $\begin{array}{l}100.2 \\
\pm 1.3\end{array}$ & DBSO & 71 \\
\hline
\end{tabular}


The more sensitive methods developed more recently, are either spectrophotometric or based on the formation of chelate-type derivatives. In contrast to the simple sulphoxides, which are nearly transparent in the 200-240 nm, derivatives which contain unsaturated groups have much stronger molar absorptivity in this region ${ }^{72}$. Strongly absorbing compounds are also formed by complexation between the sulphinyl oxygen atom and transition metal ions, and can be used for the spectrophotometric determination of sulphoxides. Thus, complex formation with $\mathrm{Fe}(\mathrm{III})(\lambda=$ $410 \mathrm{~nm})^{73}$ and aquapentacyanoferrate(II) $(\lambda=658 \mathrm{~nm})^{74}$ have been used for spectrophotometric determination of sulphoxide. Sulphoxides can also be determined by reduction with leucocompounds derived from trypthophan and glyoxalic acid $^{75}$, or $p$-dimethylaminobenzaldehyde ${ }^{76}$, to form strongly absorbing dyes. A few sulphoxides have also been by HPLC analyzed with post-column derivatization with hexachloroplatinate ${ }^{77}$.

2.2.1.1. Determination of sulphoxides by means of TFAA-I. The method of determinations of sulphoxides by application TFAA-I is characterized by the results summarized in Table 10. The reductive deoxygenation of sulphoxides is very fast and affords stoichiometric amount of iodine over the broad range of sulphoxide concentration from $10^{-3}$ to $0.1 \mathrm{M}$. Sulphoxide concentrations as low as $10^{-6} M$ can be determined with ultraviolet spectrophotometric determination of the iodine released.

The sensitivity of the method results from the final determination system, namely the thiosulphate titration of iodine with starch as indicator in the presence of excess of iodide to enhance the colour change. This system allows determination of sulphoxides at $\mu$ mol level (20$100 \mu \mathrm{mol}$ in the titrated sample) with visual detection of the end-point. The low acidity of the reaction mixture ( $0.4 \mathrm{mmol}$ of TFAA, 4 -20-fold molar ratio of TFAA to sulphoxide) practically eliminates the side-reaction of aerial oxidation of iodide, and the need for a blank titration (though this can always be performed). In comparison, the Allenmark procedure ${ }^{64}$, involving titration in $1 \mathrm{M}$ hydrochloric acid medium, gives a blank about $5 \mu \mathrm{mol}$, for which a correction must be applied.

The selectivity of the TFAA-I method is illustrated by the results exhibiting no interference by sulphides and sulphones. Thus, the determination of diphenyl sulphoxide $(50 \mu \mathrm{mol})$ alone or in mixture with diphenyl sulphide $(50 \mu \mathrm{mol})$ or diphenyl sulphone $(50 \mu \mathrm{mol})$, under the prescribed conditions, always gave the same results. 
Table 10. Results for determinations of representative sulphoxides 1 using TFAA-I ${ }^{13,14}$

\begin{tabular}{|c|c|c|c|c|c|c|c|c|}
\hline \multicolumn{3}{|c|}{$\mathrm{R}^{1}-\mathrm{S}(\mathrm{O})-\mathrm{R}^{2}$} & \multirow[t]{2}{*}{ Method $^{\mathrm{a}}$} & \multicolumn{2}{|c|}{ Taken } & \multicolumn{2}{|c|}{ Found } & \multirow{2}{*}{$\begin{array}{l}\mathrm{RSD}^{\mathrm{h}} \\
\times 10^{3} \\
\end{array}$} \\
\hline No & $\mathrm{R}^{1}$ & $\mathrm{R}^{2}$ & & $\mu m o l$ & nmol & $\mu m o l$ & nmol & \\
\hline \multirow[t]{12}{*}{$1 \mathrm{a}$} & $\mathrm{Me}$ & $\mathrm{Me}$ & & 20.0 & & 19.9 & & 5.0 \\
\hline & & & $\mathrm{A}_{1}$ & 50.0 & & 49.9 & & 2.0 \\
\hline & & & & 90.0 & & 89.7 & & 2.2 \\
\hline & & & & 20.0 & & 19.94 & & 5.0 \\
\hline & & & $\mathrm{A}_{2}$ & 50.0 & & 49.9 & & 2.0 \\
\hline & & & & 90.0 & & 89.8 & & 1.1 \\
\hline & & & & & 50.0 & & 48.0 & 44 \\
\hline & & & $\mathrm{B}_{1}$ & & 100.0 & & 99.0 & 19 \\
\hline & & & & & 500. & & 502. & 90 \\
\hline & & & & & 10.0 & & 10.5 & 40 \\
\hline & & & $\mathrm{B}_{2}$ & & 30.0 & & 31.0 & 40 \\
\hline & & & & & 50.0 & & 49.0 & 28 \\
\hline \multirow[t]{4}{*}{ 1c } & $n-\mathrm{Bu}$ & $n-\mathrm{Bu}$ & $\mathrm{A}_{1}$ & 50.0 & & 49.9 & & 2.0 \\
\hline & & & & & 50.0 & & 51.0 & 45 \\
\hline & & & $\mathrm{B}_{1}$ & & 100.0 & & 101.0 & 40 \\
\hline & & & & & 500. & & 492 & 23 \\
\hline \multirow[t]{3}{*}{ 1d } & $\mathrm{Bn}$ & $\mathrm{Bn}$ & & & 50.0 & & 49.0 & 48 \\
\hline & & & $\mathrm{B}_{1}$ & & 100.0 & & 102.0 & 36 \\
\hline & & & & & 500. & & 502. & 20 \\
\hline \multirow[t]{3}{*}{ 1h } & $\mathrm{Ph}$ & $\mathrm{Ph}$ & & & 50.0 & & 50.5 & 41 \\
\hline & & & $\mathrm{B}_{1}$ & & 100.0 & & 99.0 & 41 \\
\hline & & & & & 500. & & 497. & 20 \\
\hline \multirow[t]{4}{*}{$1 \mathrm{i}$} & $\mathrm{Ph}$ & $p$-Tol & $\mathrm{A}_{1}$ & 50.0 & & 49.7 & & 2.0 \\
\hline & & & & & 50.0 & & 48.0 & 48 \\
\hline & & & $\mathrm{B}_{1}$ & & 100.0 & & 102.0 & 36 \\
\hline & & & & & 500. & & 492. & 20 \\
\hline \multirow[t]{2}{*}{11} & \multirow{2}{*}{\multicolumn{2}{|c|}{$\operatorname{EtS}(\mathrm{O}) \mathrm{hcys}^{\mathrm{P} / \mathrm{c}}$}} & $\mathrm{A}_{2}$ & 50.0 & & 49.8 & & 6.0 \\
\hline & & & & 100.0 & & 99.0 & & 3.0 \\
\hline
\end{tabular}

a/The determinations of iodine (A - iodometric and/or B - spectrophotometric) were performed after addition to the nitroxide radical solutions the following amounts of reagents:

$\mathrm{A}_{1}: 0.4 \mathrm{mmol}$ of TFAA and $0.5 \mathrm{mmol}$ of $\mathrm{NaI}$ in acetone (exposition time $=1-30 \mathrm{~min}$ );

$\mathrm{A}_{2}: 0.5 \mathrm{mmol}$ of $\mathrm{NaI}$ in $\mathrm{AcOH}-\mathrm{Ac}_{2} \mathrm{O}(5 \%)$ (exposition time $\left.=0.5 \mathrm{~min}\right)$;

$\mathrm{B}_{1}: 0.05 \mathrm{mmol}$ of TFAA and $0.5 \mathrm{mmol}$ of $\mathrm{NaI}$ (exposition time $=2 \mathrm{~min} ; 1=1 \mathrm{~cm}$ );

$\mathrm{B}_{2}: 0.05 \mathrm{mmol}$ of TFAA and $0.5 \mathrm{mmol}$ of $\mathrm{NaI}$ (exposition time $=2 \mathrm{~min} ; 1=5 \mathrm{~cm}$ ).

${ }^{\mathrm{b}} /$ For $\mathrm{n}=6$.

${ }^{\mathrm{c}} \mathrm{EtS}(\mathrm{O})$ hcys $^{\mathrm{P}}$ - sulphoxide of $S$-ethylphosphonohomocysteine. 


\section{Procedure $\mathrm{A}^{13}$ :}

A known volume of sample solution (containing 20-100 $\mu \mathrm{mol}$ of the sulphoxide) was placed in a $100-\mathrm{ml}$ Erlenmeyer flask and $1 \mathrm{~mL}$ of $0.5 \mathrm{M}$ solution of sodium iodide was acetone is added, followed by $0.5 \mathrm{~mL}$ of TFAA in acetone. Iodine was immediately formed. After gentle swirling for $0.5 \mathrm{~min}$, the mixture was diluted with $20 \mathrm{~mL}$ of $0.1 \mathrm{M}$ potassium iodide and titrated at once with $0.02 M$ sodium thiosulphate. Starch indicator was added towards the end of titration.

\section{Procedure $\mathbf{B}^{14}$ :}

For calibration, known amounts of sulphoxide (containing $20-1000 \mu \mathrm{L}$ of $5 \times 10^{-4} \mathrm{M}$ solution of the sulphoxide in acetone) were transferred into $10-\mathrm{mL}$ standard flasks and $1 \mathrm{~mL}$ of the $0.5 \mathrm{M}$ sodium iodide and $0.1 \mathrm{~mL}$ of TFAA $0.5 \mathrm{M}$ solution (in acetone) were added, to each, and the mixtures were diluted with acetone to the mark. After $2 \mathrm{~min}$, the absorbances at $362 \mathrm{~nm}$ were measured in fused-silica cuvettes $(5-\mathrm{cm}$ path-length for $10-50 \mathrm{nmol}$ of sulphoxide, 1-cm pathlength for 50-500 nmol, at $20{ }^{\circ} \mathrm{C}$, against acetone). A reagent blank was similarly prepared and measured. The absorbances were corrected for the reagent blank and plotted against amount sulphoxide taken. The calibration graph was used for interpretation of the absorbances of sample solutions similarly prepared."

The relatively high molar absorptivity of iodine $\left(\varepsilon=2.5 \times 10^{4} \mathrm{~mol} \mathrm{~L}^{-1} \mathrm{~cm}^{-1}\right.$ at $362 \mathrm{~nm}$ in acetone) allows the determination of 10-500 nmol of sulphoxide. In principle, the reaction of TFAA and iodide with sulphoxides requires a 1:2 molar ratio of these two reagents. For determination of $\mu \mathrm{mol}$ amounts of sulphoxides we used a minimum of a four-fold molar ratio of TFAA and 2.5 molar ratio of sodium iodide to sulphoxide ${ }^{13}$.

In the spectrophotometric procedure a 100-fold molar ratio of TFAA and 1000-molar ratio of NaI to sulphoxide are used ${ }^{14}$. This high excess of iodide leads to a strong increase in the absorbance, apparently because of formation of tri-iodide anion which has a higher molar absorptivity. Such a high iodide : sulphoxide ratio, however, results in some oxidation of the excess of iodide which necessitates a reagent blank measurement. Estimation of the release of iodine as a function of time showed that the reduction of the sulphoxide is completed in a few seconds, after mixing of the solutions, and is followed by a slow increase in the iodine level because of oxidation of the iodide excess (the absorbance increases by $0.02-0.03$ in 20 min). For this reason the reagent blank is run separately and its absorbance is subtracted from that for the sulphoxide determinations. The very low molecular absorptivity of dialkyl or diaryl sulphides and sulphoxides in acetone, in the wavelength region of interest, practically eliminates the need for additional correction for the presence of these species. The method is not affected by the presence of sulphides and sulphones.

\subsubsection{Detection of $\boldsymbol{S}$-oxo compounds}

Although in the last decade mainly GLC techniques have been introduced for the determination of volatile sulphoxides, these and also the non-volatile and unstable derivatives can be detected and quantitated using TLC methods combined with chemoselective spraying indicators. Thus, 
hydroiodic $\operatorname{acid}^{78}$, iodobismuthate solution ${ }^{79}$, and 2,3-dichloro-5,6-dicyano-1,4-benzoquinone (DDQ) solution ${ }^{80}$ were introduced as spray reagents for certain sulphoxides. Later, acetic acidchromium trioxide solution $^{81}$ and Dragendorff reagent ${ }^{82}$ were applied. These reagents, however, present, mediocre sensitivity and poor selectivity.

2.2.2.1. Detection of $\boldsymbol{S}$-oxo compounds by means of TFAA-I. The results of the application TFAA-I for visualization of sulphoxides $\mathbf{1}$ and sulphimides $\mathbf{2}$ on TLC plates are summarized in Table 11.

Table 11. Detection limits for representative sulphoxides $\mathbf{1}$ and sulphimides $\mathbf{2}$ using TFAA-I as the detection reagent ${ }^{15}$

\begin{tabular}{cccccc}
\hline No & $\mathrm{R}^{1}$ & $\begin{array}{c}\mathrm{R}^{1}-\mathrm{S}(\mathrm{X})-\mathrm{R}^{2} \\
\mathrm{R}^{2}\end{array}$ & $\mathrm{X}$ & $\begin{array}{c}\mathrm{TLC}^{\mathrm{a}} \\
\text { Detection Limits } \\
\mu g(\text { nmol) per spot }]\end{array}$ & $\mathrm{R}_{\mathrm{F}}$ \\
\hline $\mathbf{1 a}$ & $\mathrm{Me}$ & $\mathrm{Me}$ & $\mathrm{O}$ & $0.30(4)$. & 0.10 \\
$\mathbf{1 c}$ & $n-\mathrm{Bu}$ & $n-\mathrm{Bu}$ & $\mathrm{O}$ & $0.9(5)$. & 0.52 \\
$\mathbf{1 d}$ & $\mathrm{Bn}$ & $\mathrm{Bn}$ & $\mathrm{O}$ & $1.08(5)$. & 0.64 \\
$\mathbf{1 e}$ & $\mathrm{Me}$ & $\mathrm{Ph}$ & $\mathrm{O}$ & $0.7(5)$. & 0.33 \\
$\mathbf{1 g}$ & $\mathrm{Me}$ & $p-\mathrm{Tol}$ & $\mathrm{O}$ & $1.6(9)$. & 0.50 \\
$\mathbf{1 h}$ & $\mathrm{Ph}$ & $\mathrm{Ph}$ & $\mathrm{O}$ & $5.0(25)$. & 0.58 \\
$\mathbf{1 i}$ & $\mathrm{Ph}$ & $p-\mathrm{Tol}$ & $\mathrm{O}$ & $1.8(8)$. & 0.64 \\
$\mathbf{1 j}$ & $\mathrm{Cl}-\mathrm{Ph}$ & $\mathrm{Cl}-\mathrm{Ph}$ & $\mathrm{O}$ & $2.8(7.5)$ & 0.62 \\
$\mathbf{2 - 4}$ & $\mathrm{Me}$ & $\mathrm{Me}$ & $\mathrm{N}-\mathrm{S}(\mathrm{O})_{2}-p-\mathrm{Tol}$ & $2.8(10)$. & 0.57 \\
$\mathbf{2 - 4}$ & $\mathrm{Me}$ & $p-\mathrm{Tol}$ & $\mathrm{N}-\mathrm{S}(\mathrm{O})_{2}-p-\mathrm{Tol}$ & $9.4(30)$. & 0.61 \\
\hline
\end{tabular}

${ }^{\mathrm{a} /}$ Acetone/Silica.

\section{TLC Detection Procedure ${ }^{15}$ :}

The plates $(10 \mathrm{~cm} \times 5 \mathrm{~cm})$ were spotted with the appropriate amount of compounds; developed for $8 \mathrm{~cm}$ distance with acetone, air dried and sprayed with sodium iodide solution and subsequently with TFAA solution. Sulphoxides and sulphimides appeared almost immediately as brown spots on a white background, and are stable for more than $20 \mathrm{~min}$.

The detection of these compounds on TLC plates after reaction with TFAA-I is very rapid; the spots of iodine being formed immediately after spraying with the reagent. The corresponding detection limits (Table 11) were found to be dependent on the structures: thus dialkyl sulphides at 4-9 nmol and diaryl sulphoxides at 10-25 nmol. The detection limits of sulphimides 2 were in the range 10-25 nmol. 
Table 12. Results of the reaction of TFAA-I with diphenyl sulphide, sulphoxide, sulphimide, sulphone and sulphoximide on TLC plates ${ }^{15}$

\begin{tabular}{|c|c|c|c|c|c|c|c|c|c|c|}
\hline \multicolumn{2}{|c|}{ Compounds } & \multirow{2}{*}{$\begin{array}{l}\text { Amount } \\
(\mu g / \text { spot })\end{array}$} & \multicolumn{4}{|c|}{ Detection on alumina $^{\mathrm{a}}$} & \multicolumn{4}{|c|}{ Detection on silica $^{a}$} \\
\hline No & Structure & & $\mathrm{R}_{\mathrm{F}}^{\mathrm{b}}$ & $U^{c}$ & $\mathrm{I}_{2}$ & $\begin{array}{l}\text { TFAA } \\
-\mathrm{I}^{\mathrm{d}}\end{array}$ & $\mathrm{R}_{\mathrm{F}}^{\mathrm{b}}$ & $\mathrm{UV}^{\mathrm{c}}$ & $\mathrm{I}_{2}$ & $\begin{array}{l}\text { TFAA- } \\
\mathrm{I}^{\mathrm{d}}\end{array}$ \\
\hline \multirow[t]{2}{*}{ 1Dh } & $\mathrm{Ph}-\mathrm{S}-\mathrm{Ph}$ & 50.0 & 0.77 & + & + & - & 0.70 & + & + & - \\
\hline & & 100. & & + & ++ & - & & + & ++ & - \\
\hline \multirow[t]{2}{*}{$1 \mathrm{~h}$} & $\mathrm{O}_{11}^{\mathrm{O}}$ & 5.0 & 0.66 & - & - & + & 0.58 & - & - & + \\
\hline & $\mathrm{Ph}-\mathrm{S}-\mathrm{Ph}$ & 10.0 & & - & - & ++ & & - & - & ++ \\
\hline \multirow[t]{2}{*}{$2-4 e$} & $\mathrm{Ph}-\mathrm{S}-\mathrm{Me}$ & 5.0 & 0.68 & - & - & $+/-$ & 0.61 & - & - & $+/-$ \\
\hline & $\mathrm{N}-\mathrm{Tos}$ & 10.0 & & + & + & + & & + & + & + \\
\hline \multirow[t]{3}{*}{$16 h$} & O & 25.0 & 0.77 & + & + & - & 0.68 & + & + & - \\
\hline & $\mathrm{Ph}-\mathrm{S}_{\Perp}-\mathrm{Ph}$ & 50.0 & & + & + & - & & + & + & - \\
\hline & & 100. & & + & + & - & & + & ++ & $-\left(+^{e}\right)$ \\
\hline \multirow{3}{*}{$\begin{array}{l}17- \\
1 \mathrm{e}\end{array}$} & O & 25.0 & 0.52 & - & + & - & 0.39 & - & + & - \\
\hline & $\mathrm{Ph}-\underset{\text { SI }}{\mathrm{S}}-\mathrm{Me}$ & 50.0 & & - & + & $-\left(+^{f}\right)$ & & - & + & - \\
\hline & & 100. & & - & + & $-\left(+^{\mathrm{f}}\right)$ & & - & + & - \\
\hline
\end{tabular}

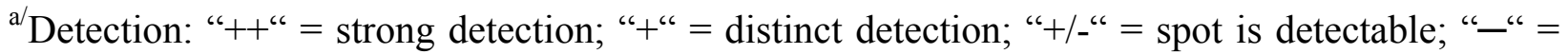
not detected. ${ }^{b /}$ Eluent: acetone. ${ }^{c /} \mathrm{UV}: 352 \mathrm{~nm} .{ }^{\mathrm{d} /}$ Brown spots on white background. ${ }^{\mathrm{e}, \mathrm{f} /} \mathrm{A}$ spot of iodine appeared after ${ }^{\mathrm{e} /} 1 \mathrm{~h}$ or ${ }^{\mathrm{f} /} 2 \mathrm{~h}$.

Table 13. Comparison of reagents applied for detection of sulphoxides 1 on TLC

\begin{tabular}{|c|c|c|c|c|c|c|}
\hline \multicolumn{2}{|c|}{ Compound } & \multirow{2}{*}{$\begin{array}{l}\text { Amount } \\
\text { applied } \\
(\mu g / s p o t)\end{array}$} & \multicolumn{2}{|c|}{ Detection reagent ${ }^{\mathrm{a}-\mathrm{c}}$} & \multirow[b]{2}{*}{$\begin{array}{l}\mathrm{CrO}_{3^{-}} \\
-\mathrm{AcOH}^{\mathrm{b} /[81]}\end{array}$} & \multirow[b]{2}{*}{$\begin{array}{l}\text { TFAA- } \\
-\mathrm{I}^{\mathrm{c} /[15]}\end{array}$} \\
\hline No & Structure & & $\begin{array}{l}\mathrm{Bi}(\mathrm{III})- \\
-\mathrm{KI}^{\mathrm{a} /[79]}\end{array}$ & $\begin{array}{l}\text { DDQ- } \\
-\mathrm{BH}_{3}{ }^{\mathrm{a}}[80]\end{array}$ & & \\
\hline \multirow[t]{4}{*}{$1 a$} & \multirow{4}{*}{$\stackrel{\mathrm{O}}{\mathrm{Me}-\mathrm{I}}-\mathrm{Me}$} & 1.0 & - & - & - & + \\
\hline & & 25.0 & - & - & - & + \\
\hline & & 100. & - & - & + & + \\
\hline & & 200. & - & - & + & + \\
\hline \multirow[t]{4}{*}{ 1d } & \multirow{4}{*}{$\stackrel{\mathrm{O}}{\mathrm{B} n-\mathrm{II}-\mathrm{Bn}}$} & 1.0 & - & - & - & + \\
\hline & & 25.0 & - & - & - & + \\
\hline & & 100. & + & + & + & + \\
\hline & & 200 . & + & - & + & + \\
\hline \multirow[t]{4}{*}{$1 \mathrm{~h}$} & \multirow{4}{*}{$\stackrel{\mathrm{O}}{\mathrm{Ph}-\mathrm{II}-\mathrm{Ph}}$} & 1.0 & - & - & - & $+/-$ \\
\hline & & 25.0 & $+/-$ & - & - & + \\
\hline & & 100. & + & - & + & + \\
\hline & & 200 . & + & - & + & + \\
\hline
\end{tabular}

${ }^{a}$ Brown spots. ${ }^{b /}$ Green spots. ${ }^{~ c / B r o w n ~ s p o t s ~ o n ~ w h i t e ~ b a c k g r o u n d . ~}$ 
The results collected in Table 12 clearly indicate that this procedure allows on the selective detection of sulphoxides and sulphimides in the presence of sulphides, sulphones and sulphoximides. Thus, diphenyl sulphides, diphenyl sulphones and phenyl methyl sulphoximide do not react with the reagent and do not interfere in the test, even at the level of $100 \mu \mathrm{g}$ of compound in the spot.

The TFAA-I reagent (Table 13) has proved to be significantly more sensitive than the previously reported sprays for the detection of sulphoxides.

\section{Reaction of TFAA-I with $N$-oxo compounds}

Several $N$-oxo compounds were found to react with TFAA-I (Scheme 6) in terms of redox reaction with release of elemental iodine. The results of reaction of TFAA-I with various $N$-oxo compounds are summarized in Table 14.

Comparison of reactivities exhibited by TFAA-I towards representative amine $N$-oxides, nitrones and nitroxide radicals is presented in Table 15.

Table 14. Reaction of TFAA-I with various $N$-oxo compounds ${ }^{18,20,23}$

\begin{tabular}{|c|c|c|c|c|c|}
\hline No & $\begin{array}{l}N \text {-oxo compound } \\
\text { Structure }\end{array}$ & $\begin{array}{l}\text { Amount } \\
(\mu m o l)\end{array}$ & $\begin{array}{c}\text { Iodine } \\
\text { released } \\
(\mu \mathrm{mol})\end{array}$ & $\begin{array}{l}\text { Method } \\
\text { of iodine } \\
\text { determ. }^{\mathrm{a}, \mathrm{b}}\end{array}$ & $\begin{array}{c}N_{O / I}{ }^{c} \\
\left(n_{I 2} / m_{N-O}\right)\end{array}$ \\
\hline $7 a$ & $\mathrm{Me}_{3} \mathrm{~N}^{+}-\mathrm{O}^{-}$ & 50.0 & 0.0 & M1 & 0.0 \\
\hline $7 \mathbf{b}$ & $n-\mathrm{Pr}_{3} \mathrm{~N}^{+}-\mathrm{O}^{-}$ & 50.0 & 0.0 & M1 & 0.0 \\
\hline $7 \mathrm{c}$ & & 50.0 & 49.6 & M1 & 1.0 \\
\hline $7 d$ & & 50.0 & 49.9 & M1 & 1.0 \\
\hline $7 e$ & & 50.0 & 98.7 & M1 & 1.98 \\
\hline $\mathbf{8 a}$ & & 50.0 & 50 & M1 & 1.00 \\
\hline $8 b$ & $\mathrm{Ph}$ & 50.0 & 50 & M1 & 1.00 \\
\hline
\end{tabular}


8c<smiles>[O-]/[N+](=C\Pc1ccccc1)c1ccccc1</smiles>

9a

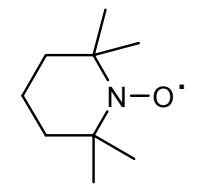

$9 b$

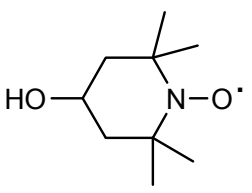

9c
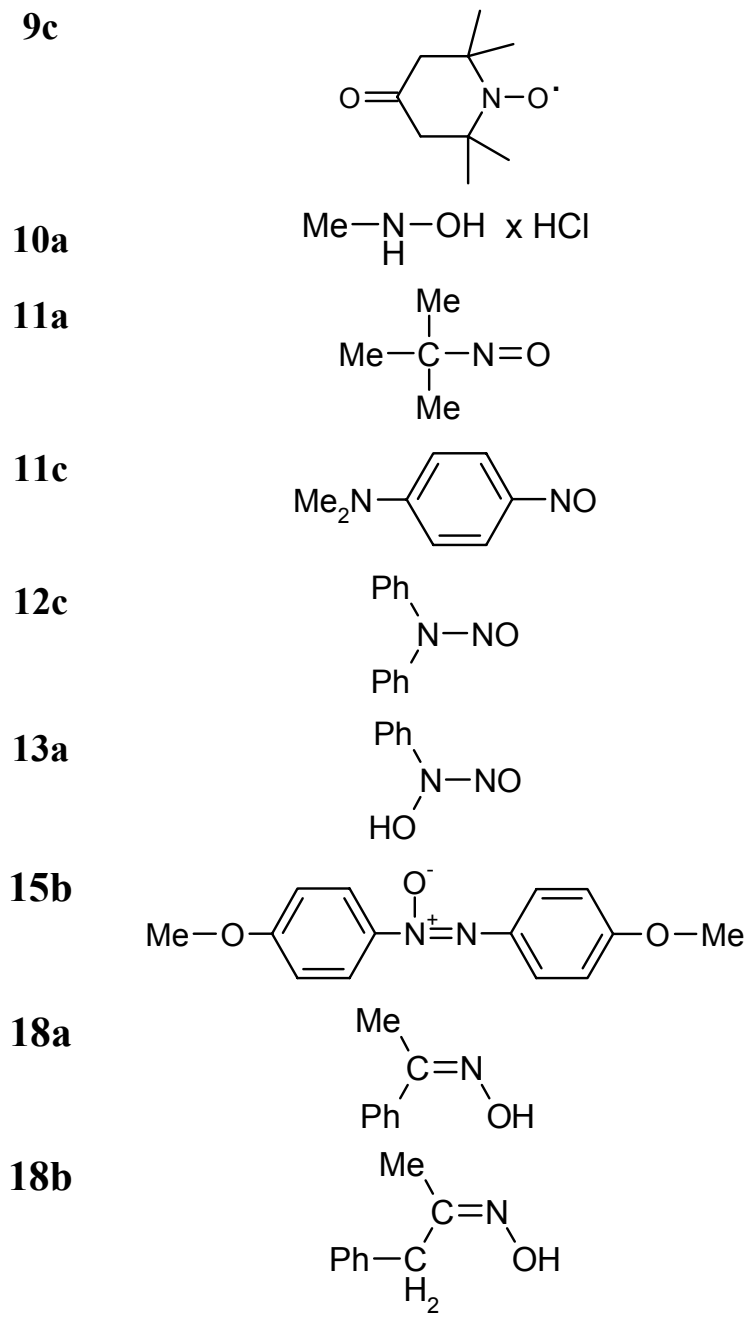

50.0

50.0

50.0

50.0

50.0

50.0

50.0

50.0

50.0

50.0

50.0

50.0

50.0

50.0
50

24.85

25.5

24.85

49.6

78.0

74.0

105.1

M1

M1

M1

M2

1.48

19a

$$
\mathrm{Me}-\mathrm{N}^{1 / \mathrm{N}^{+}}
$$

19b<smiles>CC[N+](=O)[O-]</smiles>

50

0.0

M1

0.0

0.0

M1

0.0

0.0

M1

0.0

0.0

M1

0.0 
19c

20a

$21 \mathrm{a}$

$21 b$

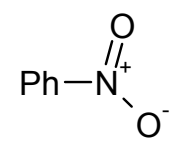

50.0

50.0

50.0

$\mathrm{Ph}-\mathrm{N}=\mathrm{C}=\mathrm{S}$

Tol- $\mathrm{N}=\mathrm{C}=\mathrm{S}$

50.0

0.0

M1

0.0

a,b/Methods: ${ }^{\mathrm{a} /} \mathrm{M} 1$ - Iodine was determined by iodometric titration in standard conditions (room temperature, reaction time $30 \mathrm{~min}$ ); ${ }^{\mathrm{b} /} \mathrm{M} 2$ - Iodine was determined by potentiometric titration. ${ }^{\mathrm{c} /}$ Factors $\left(N_{O / I}=n_{I 2} / m_{N-O}\right)$ were determined as ratios of numbers of $\mu$ moles $\left(m_{N-O}\right)$ of $N$-oxo compounds applied in the reaction with TFAA-I reagent, and numbers of $\mu$ moles $\left(n_{I 2}\right)$ of iodine released in the reaction.

The results revealed two main factors influencing the reaction course of the TFAA-I reagent with $\mathrm{N}$-oxo compounds. One of these factors examined was the influence of the activity of acylation reagents related to TFAA. The results, summarized in Table 16, clearly reveal the change in reactivity in the following order: TFAA $>\mathrm{AcCl}>\mathrm{BzCl}>\mathrm{Ac}_{2} \mathrm{O}$, which is in agreement with their acylation power.

The results in Tables 15 and 16 show that nitrones react faster than amine $N$-oxides and the reactivities of both nitrones and amine $N$-oxides are strongly dependent on the nature of the substituents. Thus, trialkylamine $N$-oxide treated with TFAA-I do not release iodine at all, whereas heterocyclic amine $N$-oxides react with nearly stoichiometric formation of iodine, showing the following reaction rate-structure dependence: quinoline $N$-oxide $>$ quinoxaline $N$ oxide $>$ pyridine $N$-oxide $\sim$ picoline $N$-oxides. Similar differences are observed in reactions of TFAA-I with nitrones: cyclic nitrones seem to be less reactive than acyclic, especially when bearing aryl substituents ${ }^{20}$.

Supplemental identification of organic products formed in the reactions of the TFAA-I with $\mathrm{N}$-oxo compounds, in conjunction with stoichiometry of iodine release (Table 14; $\mathrm{N}_{\mathrm{O} / \mathrm{I}}$ ) and analogy to mechanism of deoxygenation of sulphoxides by TFAA-I, enables to propose their mechanism. Thus, $\mathrm{N}$-heteroarene $\mathrm{N}$-oxides 7 undergo quantitative deoxygenation to amines $\mathbf{7 C}$ in accordance with Scheme 13. 
Table 15. Comparison of the reaction course of TFAA-I with amine $N$-oxides 7 , nitrones 8 and nitroxide radicals $\mathbf{9}^{18,20,23}$

\begin{tabular}{|c|c|c|c|c|c|c|c|c|}
\hline \multicolumn{3}{|c|}{ Compound applied } & \multicolumn{5}{|c|}{$\begin{array}{l}\text { Iodine determined }(\mu \mathrm{mol}) \text { after } \\
\text { indicated reaction time }(\mathrm{min})\end{array}$} & \multirow[t]{2}{*}{$\begin{array}{l}\text { Conditions } \\
\text { applied }\end{array}$} \\
\hline No & Structure & $\begin{array}{l}\text { Amount } \\
(\mu m o l)\end{array}$ & $\begin{array}{c}1 \\
\min \end{array}$ & $\begin{array}{c}2 \\
\min \end{array}$ & $\begin{array}{c}20 \\
\min \end{array}$ & $\begin{array}{c}30 \\
\min \end{array}$ & $\begin{array}{c}90 \\
\min \end{array}$ & \\
\hline $7 \mathbf{a}$ & $\mathrm{R}_{3} \mathrm{~N}^{+}-\mathrm{O}^{-}$ & 50.0 & - & - & - & - & - & TFAA/NaI/AcMe \\
\hline $7 b$ & $(\mathrm{R}=\mathrm{Me}, n-\mathrm{Pr})$ & & - & - & - & - & - & $\mathrm{Ac}_{2} \mathrm{O} / \mathrm{NaI} / \mathrm{AcOH}$ \\
\hline $7 c$ & & 50.0 & 24 & 49.5 & 49.6 & & & TFAA/NaI/AcMe \\
\hline & & & 24 & 49.5 & 49.6 & & & $\mathrm{Ac}_{2} \mathrm{O} / \mathrm{NaI} / \mathrm{AcOH}$ \\
\hline $7 d$ & & 50.0 & 25.0 & 45.0 & 45.0 & & & TFAA/NaI/AcMe \\
\hline $7 e$ & & 50.0 & 50.0 & 80.0 & 91.0 & 91.0 & & TFAA/NaI/AcMe \\
\hline $8 \mathbf{a}$ & & 50.0 & 49.8 & 49.8 & 49.8 & & & TFAA/NaI/AcMe \\
\hline $\mathbf{8 b}$ & & 50.0 & 49.8 & 49.8 & 49.8 & & & TFAA/NaI/AcMe \\
\hline 8d & & 50.0 & 46.0 & 47.8 & 48.0 & 48.0 & 48.0 & TFAA/NaI/AcMe \\
\hline $9 \mathbf{a}$ & & 50.0 & 24.8 & 24.8 & 24.9 & & & TFAA/NaI/AcMe \\
\hline $9 c$ & & 50.0 & 20.0 & 24.8 & 24.9 & & & TFAA/NaI/AcMe \\
\hline 9d & & 50.0 & 10.0 & 14.8 & 23.4 & 24.4 & & TFAA/NaI/AcMe \\
\hline
\end{tabular}


The results of supplementary investigations on the reaction course of representative amine $N$ oxides, nitrones and nitroxide radicals with other acylation agent-iodide systems, including $\mathrm{Ac}_{2} \mathrm{O}-\mathrm{NaI}$, AcCl-NaI, BzCl-NaI, MesCl-NaI and TosCl-NaI, respectively are presented in Table 16.

Table 16. Comparison of the reaction course (moles of released iodine as a function of time) of various acylating agent - sodium iodide systems with amine $N$-oxides 7 , nitrones 8 and nitroxide radicals $9^{18,20,23}$

\begin{tabular}{|c|c|c|c|c|c|c|c|c|c|c|}
\hline \multirow[t]{4}{*}{ No } & \multirow{4}{*}{$\begin{array}{c}\text { Structure } \\
\text { of } N \text {-oxo substrate }\end{array}$} & \multirow{4}{*}{$\begin{array}{l}\text { Amount } \\
(\mu m o l)\end{array}$} & \multicolumn{8}{|c|}{ Iodine determined $(\mu \mathrm{mol})$ after indicated reaction time } \\
\hline & & & \multicolumn{2}{|c|}{$\mathrm{Ac}_{2} \mathrm{O}-\mathrm{NaI}$} & \multicolumn{2}{|c|}{ AcCl-NaI } & \multicolumn{2}{|c|}{$\mathrm{BzCl}-\mathrm{NaI}$} & \multicolumn{2}{|c|}{ TFAA-NaI } \\
\hline & & & 1 & 30 & 1 & 30 & 1 & 30 & 1 & 30 \\
\hline & & & $\min$ & $\min$ & $\min$ & $\min$ & $\min$ & $\min$ & $\min$ & $\min$ \\
\hline $7 c$ & & 50.0 & - & - & 2.5 & 18.0 & - & - & 12.0 & 47.0 \\
\hline $7 d$ & & 50.0 & - & - & 1.0 & 15.0 & - & - & 40.0 & 40.0 \\
\hline $8 \mathbf{a}$ & & 50.0 & - & - & 6.5 & 23.0 & 10.0 & 22.5 & 49.8 & 49.8 \\
\hline $\mathbf{8 b}$ & & 50.0 & - & - & 8.5 & 26.0 & 15.0 & 28.5 & 49.8 & 49.8 \\
\hline $8 e$ & & 50.0 & - & - & 0.9 & 1.7 & - & 0.5 & 20.0 & 26.5 \\
\hline $9 a$ & & 50.0 & - & - & 25.0 & 25.0 & 3.5 & 19.0 & 24.8 & 24.9 \\
\hline $9 c$ & & 50.0 & - & - & 24.9 & 25.0 & 0.75 & 12.5 & 20.0 & $24 . .9$ \\
\hline $9 d$ & & 50.0 & - & - & 24.0 & 24.4 & 0.5 & 10.0 & 10.0 & 24.0 \\
\hline
\end{tabular}




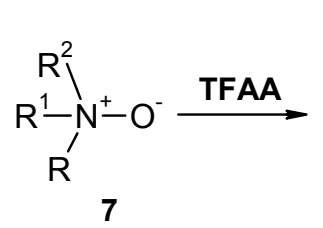

$7+\mathrm{TFAA}+2 \mathrm{Nal}$

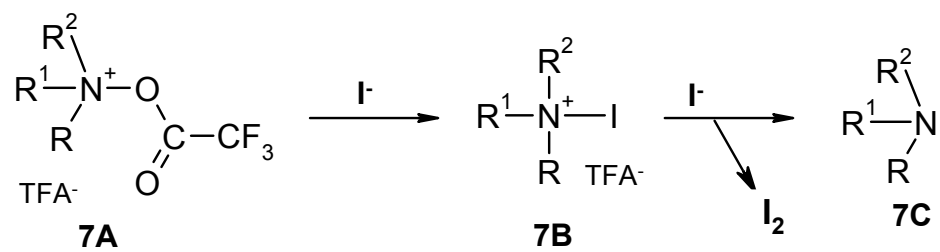

$$
7 \mathrm{C}+\mathrm{I}_{2}+2 \mathrm{TFA}-\mathrm{Na}^{+}
$$

Scheme 13. $\left(\mathrm{N}_{\mathrm{O} / \mathrm{I}}=1\right)$

Similar effect of the iodine release in reactions of TFAA-I with amine N-oxides 7 and nitrones $8\left(\mathrm{~N}_{\mathrm{O} / \mathrm{I}}=1\right)$ suggested similar mechanism for both reactions, based on the $N$ deoxygenation of common $\mathrm{N}-\mathrm{O}$ group (Scheme 14; path $\boldsymbol{A}$ ).

However, an analysis of organic products of the reaction of TFAA-I with nitrones 8 (TLC, GCMS) did not reveal any presence of the expected imines 8D. Instead of these, we isolated and identified $O$-trifluoroacetates of corresponding amidoesters 8B, suggesting path $\boldsymbol{B}$ of Scheme 14, as major course of the reactions ${ }^{20}$.

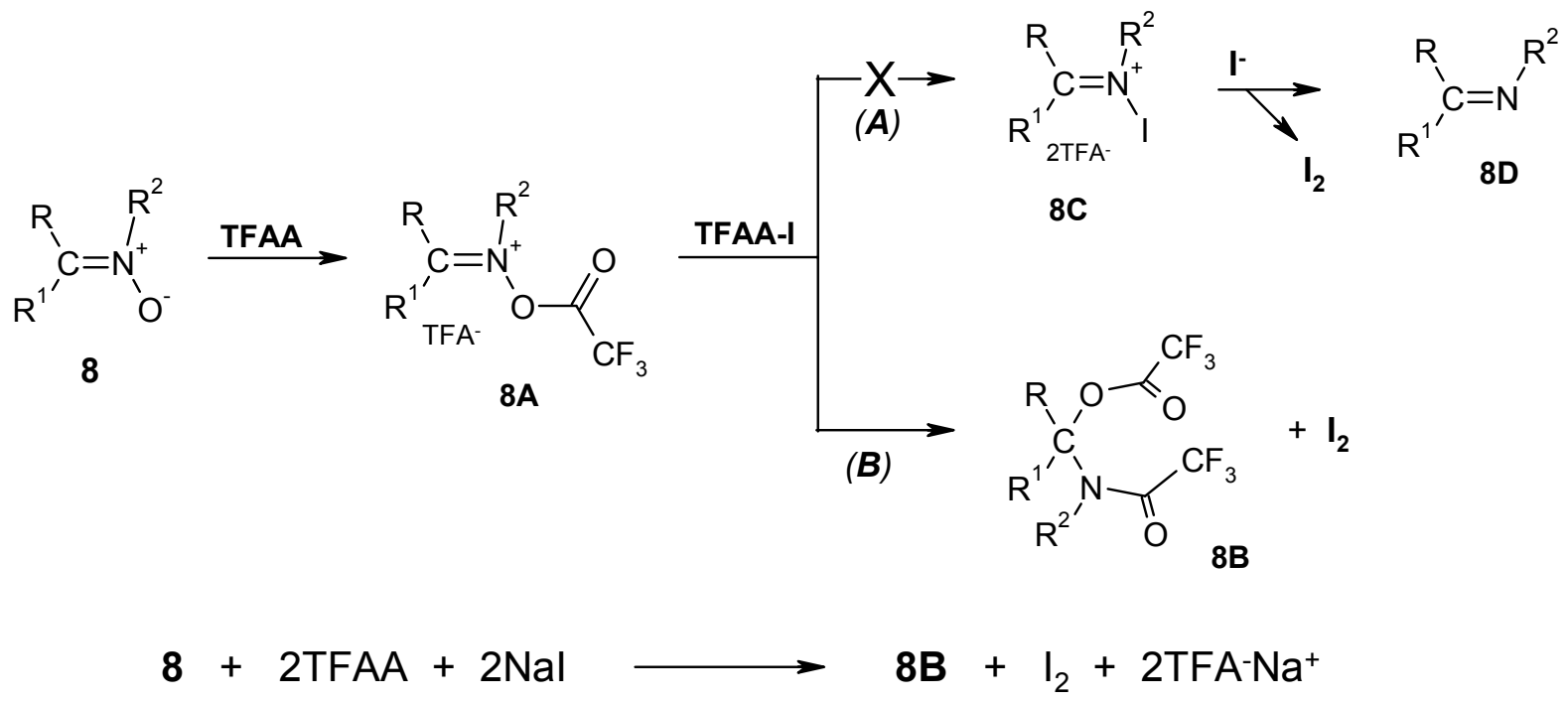

Scheme 14. $\left(\mathrm{N}_{\mathrm{O} / \mathrm{I}}=1\right)$

In continuation, the systematic studies of the reaction of aldonitrones with the TFAA-I system were performed (Scheme 15) ${ }^{24-26}$. 


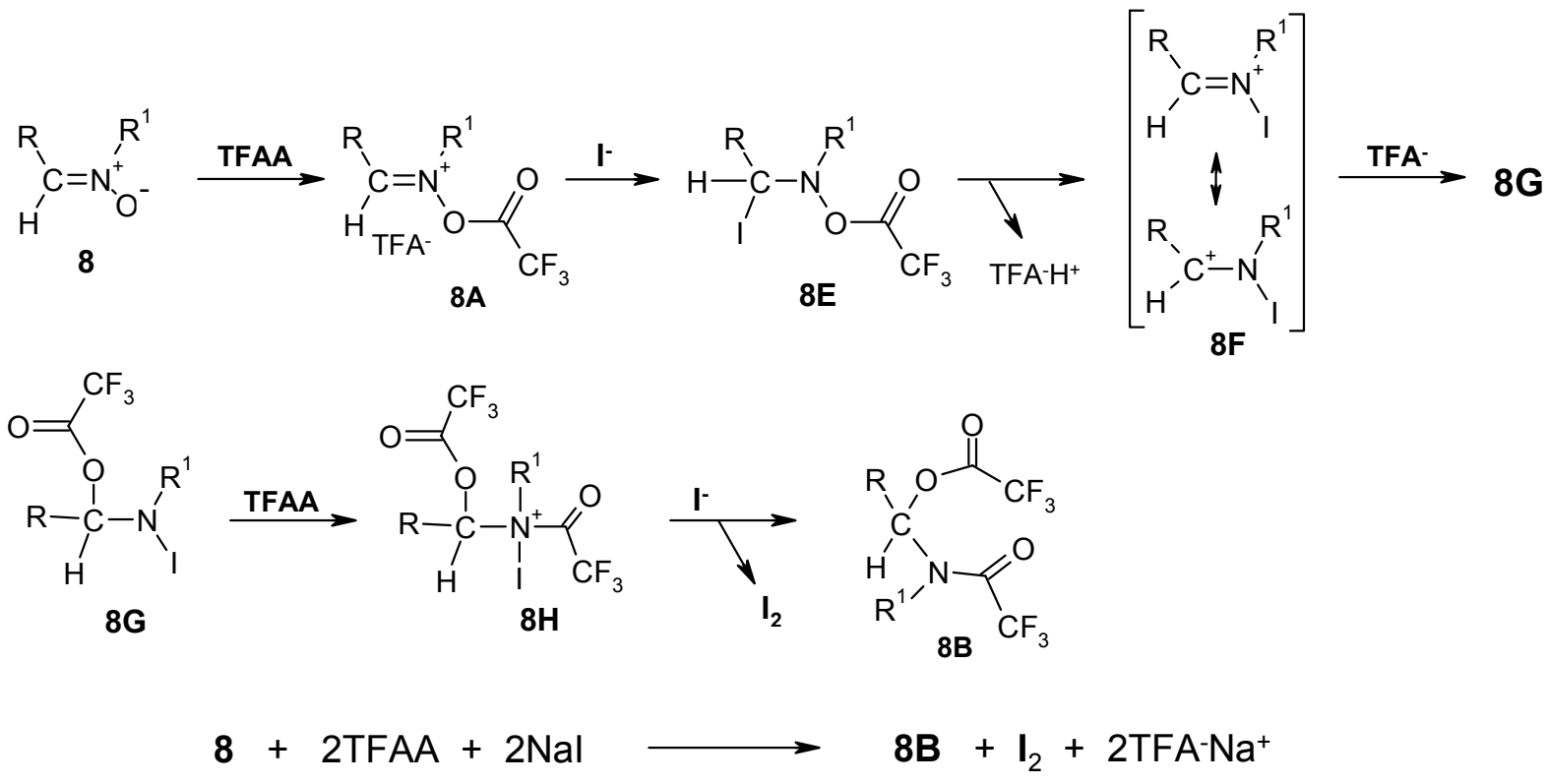

\section{Scheme 15}

The reaction engaged was recognized as a previously known process, so called "the Beckmann rearrangement of nitrones". Some mechanistic considerations on these transformations and competitive nucleophilic additions were presented in order to explain the origin of the iodine release and its observed stoichiometry as well as of some products' isolation. The intermediacy of $C$-and $N$-iodo species (including iodonium cations) in the presence of iodide anions, was postulated ${ }^{24}$.

It should be noted that the order of reagent addition strongly influences the reaction course, and consequently iodine formation. Thus, if the nitrones $\mathbf{8}$ solution is first treated with TFAA and sodium iodide is added to this mixture later, only a small amount of iodine is formed. This suggests that in the absence of iodide, acylated nitrones intermediate $\mathbf{8 A}$ rearrange to imides $8 \mathbf{L}$ (identified by GCMS), which are totally unreactive in further iodide oxidation (Scheme 16).

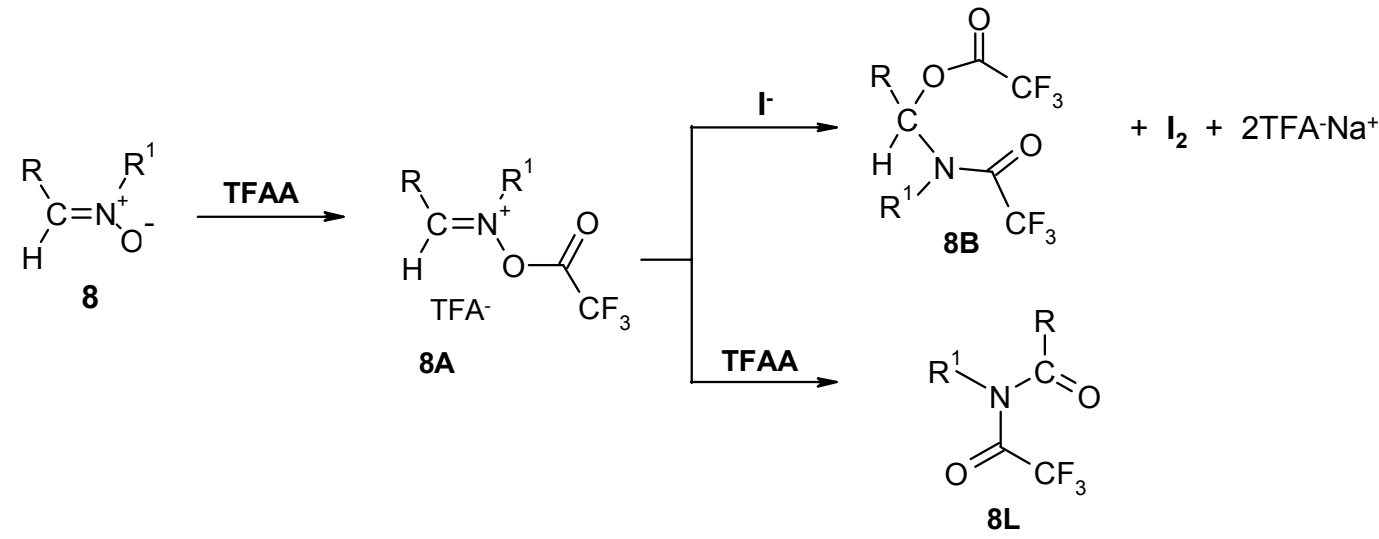

Scheme 16 
Nitroxide radicals 9 react with TFAA-I with release of only half of expected amounts of the iodine (Scheme 18; $\mathrm{N}_{\mathrm{O} / \mathrm{I}}=0.5$ ), with rate strongly influenced by nitroxide radical structure (TEMPO vs PROXYL radicals).

Additionally, GCMS analysis of organic products of the reaction exhibited the presence of corresponding $N$-trifluoroacetoxyamines 9B (products of reduction of nitroxide radicals) as major organic component. These facts enable us to propose the mechanism of the reaction, illustrated by Scheme 17.

In reaction of TFAA-I with $N$-methylhydroxylamine 10a similar release of iodine was found to occur $\left(\mathrm{N}_{\mathrm{O} / \mathrm{I}}=0.5\right)$ (Table 14). Since GCMS analysis of the reaction mixture revealed the presence of $N, N$ '-bistrifluoroacetylhydrazide 10Da, we proposed for the reaction the mechanistic course illustrated in Scheme 18.

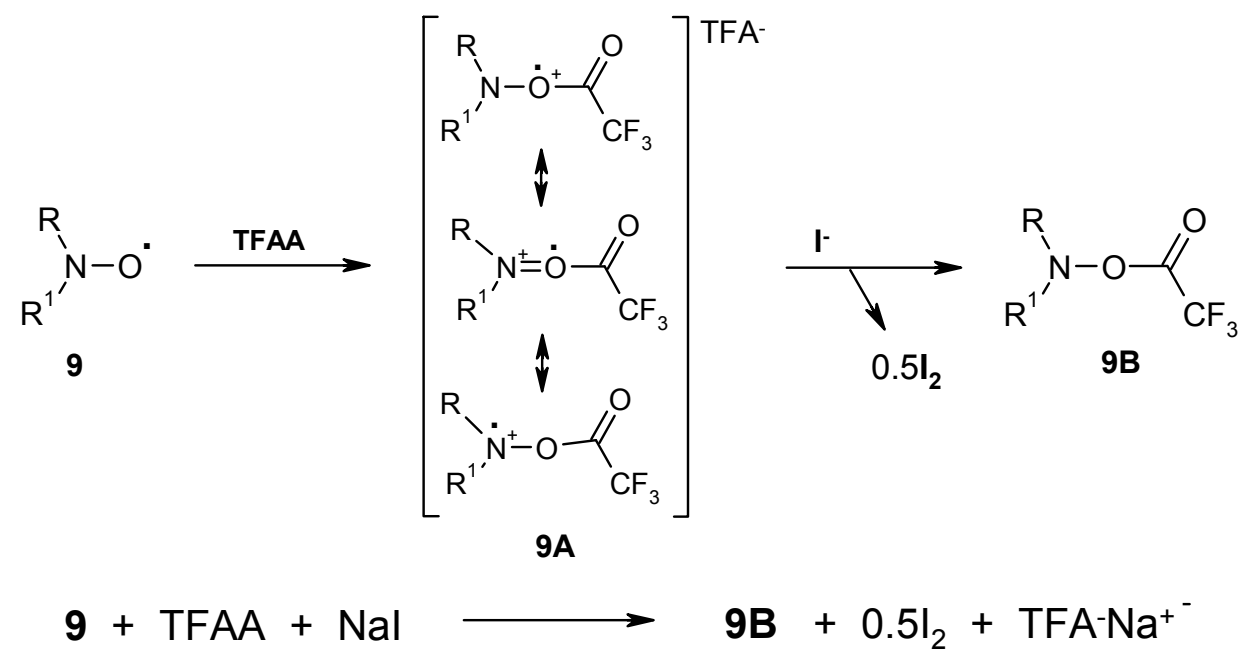

Scheme 17. $\left(\mathrm{N}_{\mathrm{O} / \mathrm{I}}=0.5\right)$

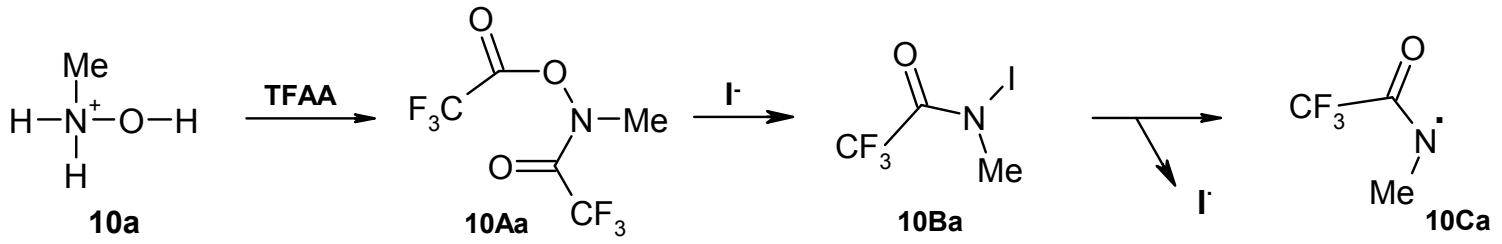

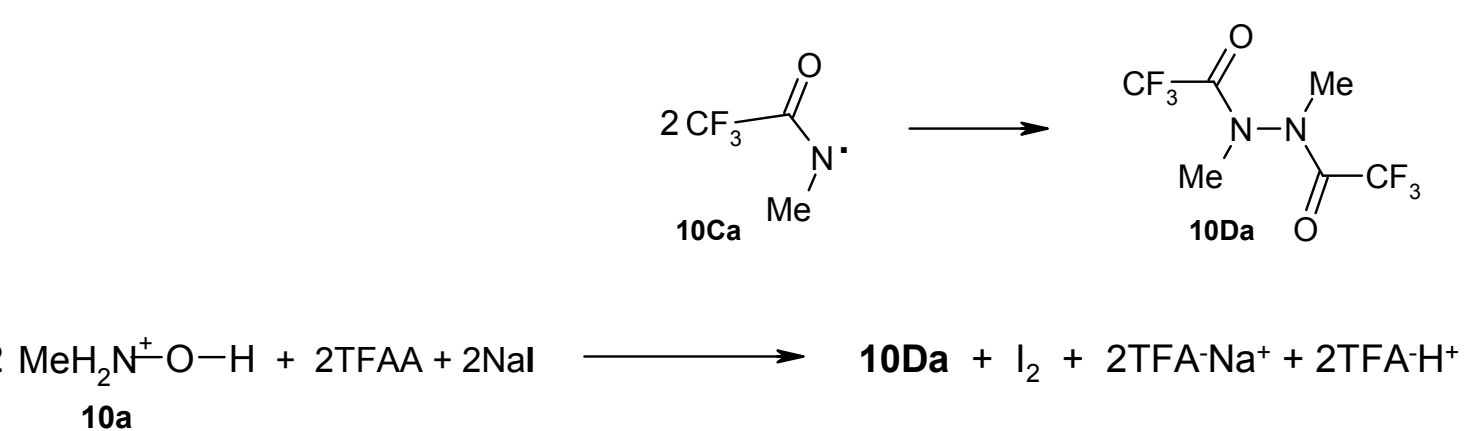

Scheme 18. $\left(\mathrm{N}_{\mathrm{O} / \mathrm{I}}=0.5\right)$ 
For reaction of TFAA-I with $C$-nitroso- 11 and $N$-nitroso- 12-14, and also $N$-azoxy compounds 15, we propose the mechanisms presented in Schemes 19-22.

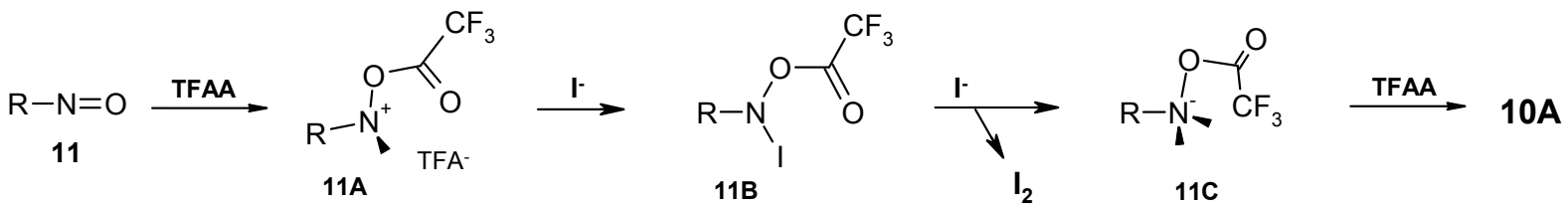

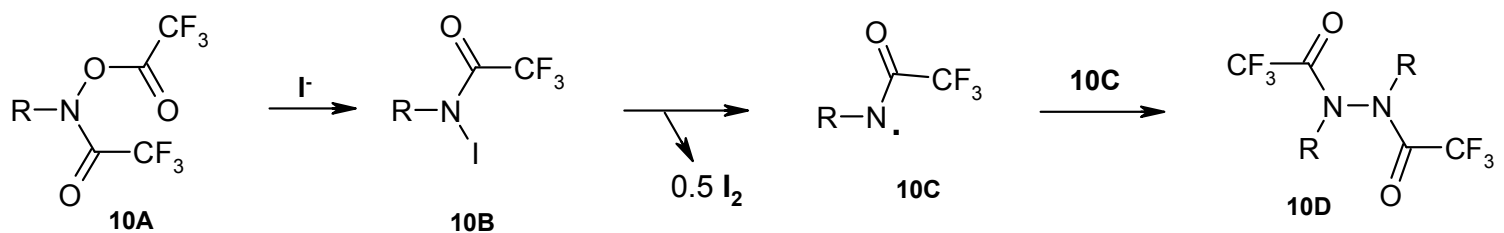

$2 \mathrm{R}-\mathrm{N}=\mathrm{O}+4 \mathrm{TFAA}+6 \mathrm{Nal} \longrightarrow 10 \mathrm{D}+3 \mathrm{I}_{2}+6 \mathrm{TFA}^{-} \mathrm{Na}^{+}$

11

Scheme 19. $\left(\mathrm{N}_{\mathrm{O} / \mathrm{I}}=1.5\right)$

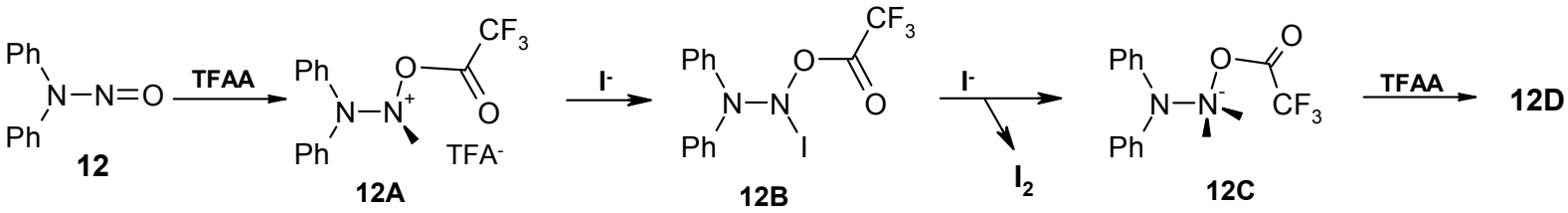<smiles>CC(C)(F)C(=O)N(OC(=O)C(F)(F)F)C(=O)C(F)(F)F</smiles>

$12+3$ TFAA $+4 \mathrm{NaI} \longrightarrow 12 \mathrm{G}+2 \mathrm{I}_{2}+4 \mathrm{TFA}-\mathrm{Na}^{+}$

Scheme 20. $\left(\mathrm{N}_{\mathrm{O} / \mathrm{I}}=2\right)$ 


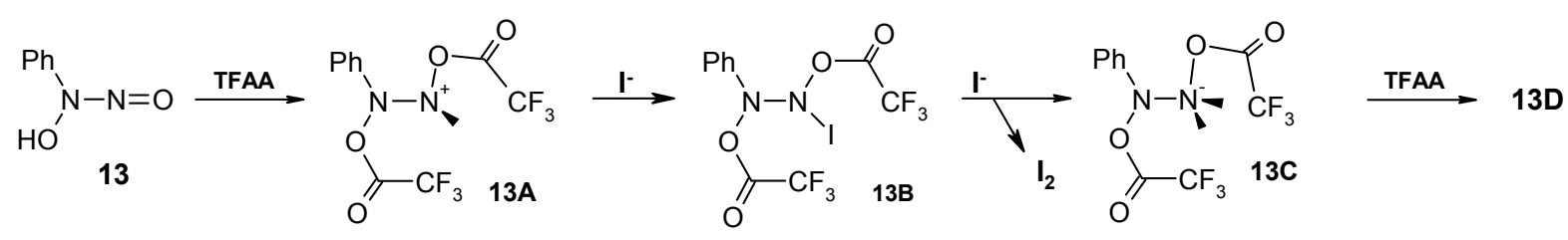

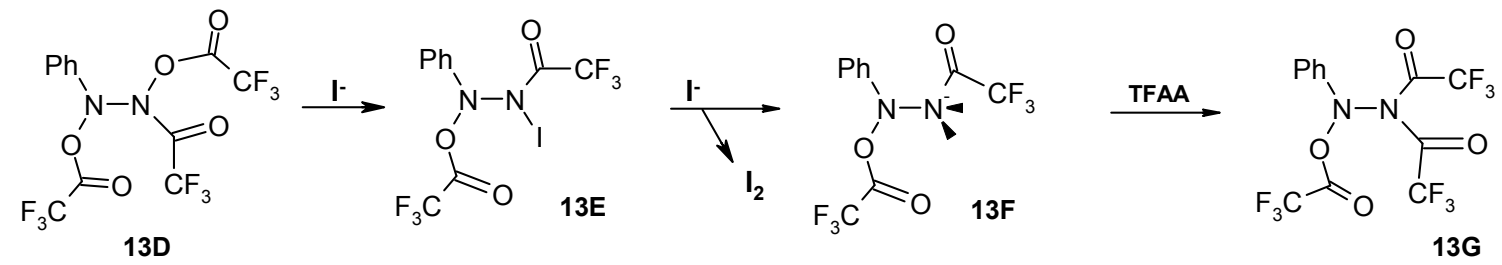
$13+4 \mathrm{TFAA}+4 \mathrm{Nal} \longrightarrow 13 \mathrm{G}+2 \mathrm{I}_{2}+\mathrm{TFA}^{-} \mathrm{H}^{+}+4 \mathrm{TFA}^{-\mathrm{Na}^{+}}$

Scheme 21. $\left(\mathrm{N}_{\mathrm{O} / \mathrm{I}}=2\right)$<smiles>COc1ccc(N=[N+]([O-])c2ccc(OC)cc2)cc1</smiles>

15Ba
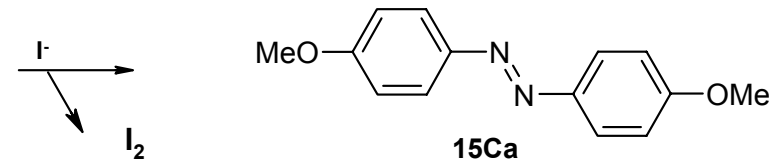

$15 a+\mathrm{TFAA}+2 \mathrm{Nal}$

$15 \mathrm{Ca}+\mathrm{I}_{2}+2 \mathrm{TFA}^{-} \mathrm{Na}^{+}$

Scheme 22. $\left(\mathrm{N}_{\mathrm{O} / \mathrm{I}}=1\right)$

The tentative results of chromatographic analysis (GCMS, TLC) of described reaction mixtures confirmed presence of majority of the final products depicted on Schemes 19-22.

\subsection{Synthetic application of TFAA-I for deoxygenation of $\mathrm{N}$-oxo compounds}

\subsubsection{Deoxygenation of amine $\boldsymbol{N}$-oxides and nitrones}

Deoxygenation of amine $\mathrm{N}$-oxides and nitrones in the presence of other functional groups presents a valuable transformation in the synthesis of nitrogenous aromatic heterocycles ${ }^{82-88}$. Survey of the literature reveals that this can be affected by various reagents, listed in Table 17. 
Table 17. Comparison of representative methods applied for deoxygenation of amine $N$-oxides 7 and nitrones $\mathbf{8}$

\begin{tabular}{|c|c|c|c|c|c|c|}
\hline Meth. & Structures $^{\mathrm{a}}$ & $\begin{array}{c}\text { Reagents } \\
\text { (Reagents Molar Ratio) }\end{array}$ & $\begin{array}{l}\text { Temp. } \\
\left({ }^{\circ} C\right)\end{array}$ & $\begin{array}{l}\text { Time } \\
(h)\end{array}$ & $\begin{array}{l}\text { Yields } \\
(\%)\end{array}$ & Ref. \\
\hline \multirow[t]{3}{*}{1} & $\mathrm{PicO}$ & $\mathrm{R}_{3} \mathrm{~N}-\mathrm{O} / \mathrm{HCO}_{2} \mathrm{NH}_{4} / \mathrm{Pd} / \mathrm{C}$ & 20 & 0.2 & $90-94$ & 90 \\
\hline & QuinO & in $\mathrm{MeOH}$ & 40 & 0.3 & 88 & \\
\hline & AcrO & & 50 & 0.5 & 85 & \\
\hline \multirow[t]{4}{*}{2} & $\mathrm{Et}_{3} \mathrm{~N}^{+}-\mathrm{O}^{-} \times \mathrm{H}_{2} \mathrm{O}$ & $\mathrm{R}_{3} \mathrm{~N}-\mathrm{O} / \mathrm{TiCl}_{4} / \mathrm{NaI}$ & 20 & 0.1 & 55 & 91 \\
\hline & $\mathrm{Ph} \underset{\mathrm{N}^{+}}{\mathrm{Me}}$ & $(1: 1: 3)$ in $\mathrm{MeCN}$ & 20 & 0.1 & 90 & \\
\hline & QuinO & & 30 & 0.2 & 90 & \\
\hline & $\mathrm{PhenO}_{2}$ & $\begin{array}{l}\mathrm{R}_{3} \mathrm{~N}-\mathrm{O} / \mathrm{TiCl}_{4} / \mathrm{NaI} \\
(1: 2: 6) \text { in } \mathrm{MeCN}\end{array}$ & 20 & 0.05 & 90 & \\
\hline \multirow[t]{2}{*}{3} & 2-Cl-PyO & $\mathrm{R}_{3} \mathrm{~N}-\mathrm{O} / \mathrm{TiCl}_{4} / \mathrm{SnCl}_{2}$ & r. t. & 0.25 & 90 & 92 \\
\hline & 2-Cl-QuinO & $(1: 1: 1)$ in $\mathrm{THF}$ & r. t. & 0.25 & 94 & \\
\hline 4 & $\mathrm{PyO}$ & $\begin{array}{l}\mathrm{R}_{3} \mathrm{~N}-\mathrm{O} / \mathrm{TiCl}_{4} / \mathrm{Mg} \\
(1: 1: 2) \text { in } \mathrm{THF}\end{array}$ & r. t. & 0.25 & 90 & 93 \\
\hline \multirow[t]{3}{*}{5} & QuinO & $\mathrm{R}_{3} \mathrm{~N}-\mathrm{O} / \mathrm{TiCl}_{4} / \mathrm{LiAlH}_{4}$ & r. t. & 0.25 & 95 & \\
\hline & AcrO & $(1: 1: 0.6)$ in $\mathrm{THF}$ & & & 97 & \\
\hline & $\mathrm{PhenO}_{2}$ & $\begin{array}{c}\mathrm{R}_{3} \mathrm{~N}-\mathrm{O} / \mathrm{TiCl}_{4} / \mathrm{LiAlH}_{4} \\
(1: 2: 1.2) \text { in } \mathrm{THF}\end{array}$ & r. t. & 0.25 & 96 & \\
\hline \multirow[t]{2}{*}{6} & $n-\mathrm{Bu}_{3} \mathrm{~N}^{+}-\mathrm{O}^{-}$ & $\mathrm{R}_{3} \mathrm{~N}-\mathrm{O} / \mathrm{Bu}_{6} \mathrm{Sn}_{2}$ & 50 & 1 & 84 & 94 \\
\hline & $\mathrm{Me}_{2} \mathrm{PhN}^{+}-\mathrm{O}^{-}$ & $(1: 1)$ in $\mathrm{THF}$ & & & 83 & \\
\hline 7 & 2-Cl-PyO & $\begin{array}{c}\mathrm{R}_{3} \mathrm{~N}-\mathrm{O} / \mathrm{Bu}_{4} \mathrm{Cl}_{2} \mathrm{Sn}_{2} \\
(1: 1) \text { in } \mathrm{THF}\end{array}$ & rf. t. & 1 & 75 & \\
\hline \multirow[t]{2}{*}{8} & $\mathrm{PyO}$ & $\mathrm{R}_{3} \mathrm{~N}-\mathrm{O} / \mathrm{Pr}-\mathrm{O}-\mathrm{S}-\mathrm{O}-\mathrm{Pr}(1: 1)$ & r. t. & 3 & 96 & 95 \\
\hline & $\mathrm{PicO}$ & & rf. t. & 0.5 & 70 & \\
\hline \multirow[t]{2}{*}{9} & $\mathrm{PyO}$ & $\mathrm{R}_{3} \mathrm{~N}-\mathrm{O} / \mathrm{Ph}_{3} \mathrm{P}$ & $\sim 230$ & 0.5 & 90 & 96 \\
\hline & QuinO & $(1: 1)$ & $\sim 270-$ & 0.3 & 89 & \\
\hline \multirow[t]{3}{*}{10} & PyO & $\mathrm{R}_{3} \mathrm{~N}-\mathrm{O} / \mathrm{Ph}_{3} \mathrm{P} / \mathrm{MoO}_{2} \mathrm{Cl}_{2}(\mathrm{dmf})_{2}$ & rf. t. & 1 & 80 & 97 \\
\hline & QuinO & $(1: 1.03: 0.01)$ in THF & rf. t. & 1 & 85 & \\
\hline & $\stackrel{\mathrm{Ph}}{{ }^{2} \mathrm{~N}^{+}} \underset{\mathrm{N}^{+}}{\mathrm{CH}_{2} \mathrm{Ph}}$ & & rf. t. & 2 & 84 & \\
\hline \multirow[t]{2}{*}{11} & 3-PicO & $\mathrm{R}_{3} \mathrm{~N}-\mathrm{O} / \mathrm{PhSiH}_{3} / \mathrm{MoO}_{2} \mathrm{Cl}_{2}$ & 67 & 3 & 85 & 41 \\
\hline & 4-PicO & $(1: 1.03: 0.05)$ in $\mathrm{THF}$ & & 3 & 85 & \\
\hline \multirow[t]{2}{*}{12} & 3-PicO & $\mathrm{R}_{3} \mathrm{~N}-\mathrm{O} / \mathrm{PhSiH}_{3} / \mathrm{MoO}_{2} \mathrm{Cl}_{2} \times \mathrm{H}_{2} \mathrm{O}$ & & 3 & 83 & \\
\hline & 4-PicO & $(1: 1.03: 0.05)$ in $\mathrm{THF}$ & & 3 & 84 & \\
\hline
\end{tabular}




\begin{tabular}{|c|c|c|c|c|c|c|}
\hline 13 & QuinO & $\begin{array}{l}\mathrm{R}_{3} \mathrm{~N}-\mathrm{O} / \mathrm{SmI}_{2}(1: 2.2) \\
\text { in } \mathrm{THF} / / \mathrm{HMPA}\end{array}$ & 20 & 1 & 96 & 98 \\
\hline \multirow[t]{3}{*}{14} & $n-\mathrm{Bu}_{3} \mathrm{~N}^{+}-\mathrm{O}^{-}$ & $\mathrm{R}_{3} \mathrm{~N}-\mathrm{O} / \mathrm{In}(1: 1.2)$ & rf. t. & 3 & 85 & 99 \\
\hline & $\mathrm{PyO}$ & in $\mathrm{NH}_{4} \mathrm{Cl} / \mathrm{H}_{2} \mathrm{O} / \mathrm{EtOH}$ & rf. t. & 4 & 93 & \\
\hline & QuinO & & rf. t. & 4 & 88 & \\
\hline \multirow[t]{4}{*}{15} & $\mathrm{Me}_{2} \mathrm{PhN}^{+}-\mathrm{O}^{-}$ & $\mathrm{R}_{3} \mathrm{~N}-\mathrm{O} /\left(\mathrm{BnNEt}_{3}\right) \mathrm{MoS}_{4}(1: 1.2)$ & 25 & 2 & 67 & 100 \\
\hline & & in $\mathrm{MeCN}$ & 25 & 72 & 74 & \\
\hline & & & 25 & 21 & 83 & \\
\hline & & & 25 & 22 & 60 & \\
\hline \multirow[t]{2}{*}{16} & $\begin{array}{c}\mathrm{R}-\mathrm{PyO} \\
(\mathrm{R}=\mathrm{Me}, \mathrm{Cl}, \mathrm{CN}, \mathrm{HO})\end{array}$ & $\begin{array}{c}\mathrm{R}_{3} \mathrm{~N}-\mathrm{O} / \mathrm{FeCl}_{3} / \mathrm{In} \\
(1: 4: 2) \text { in } \mathrm{MeOH} / \mathrm{H}_{2} \mathrm{O}\end{array}$ & r. t. & $3-7$ & $88-92$ & 101 \\
\hline & QuinO & Under ultrasonication & r. t. & 5 & 91 & \\
\hline 17 & $\mathrm{Ph}$ & $\begin{array}{c}\text { Nitrone/ } \mathrm{RuCl}_{3} \times \mathrm{H}_{2} \mathrm{O} \\
(1: 1) \text { in } \mathrm{MeCN}\end{array}$ & 80 & 0.4 & 94 & 102 \\
\hline 18 & 'o. & $\begin{array}{c}\text { Nitrone } / \mathrm{TiO}_{2} / \mathrm{N}_{2} / \mathrm{UV} \\
(350 \mathrm{~nm})(2: 1) \text { in } \mathrm{MeCN}\end{array}$ & r. t. & 0.5 & 88 & 103 \\
\hline 19 & & $\begin{array}{l}\text { Nitrone/Li/DTBB } \\
(1: 8: 0.1) \text { in THF }\end{array}$ & r. t. & 2 & 57 & 104 \\
\hline
\end{tabular}

a/ Abbreviations:

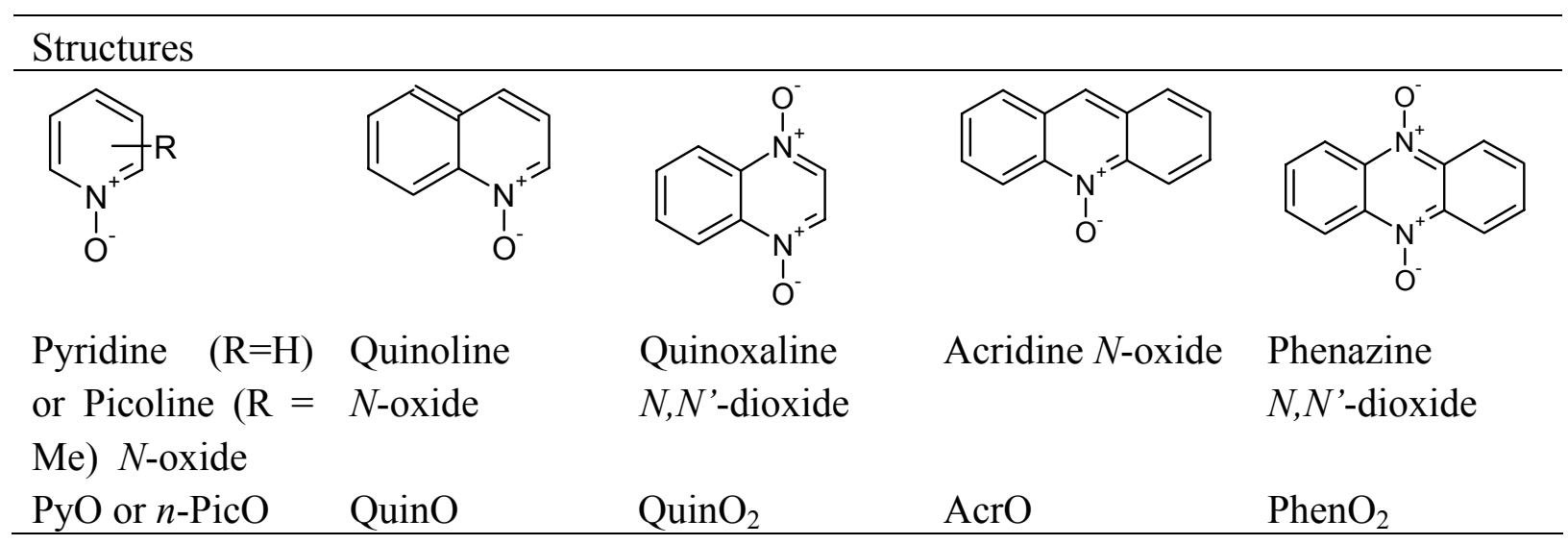

Many of these methods suffer a few drawbacks such as: low yields, expensive or not readily available reagents, severe reaction conditions, or difficulties with isolation of the products. 
3.1.1.1. Deoxygenation of quinoxaline $N, N^{\prime}$-dioxides using TFAA-I. Deoxygenation of several derivatives of quinoxaline $N, N$ '-dioxides by means of the TFAA-I reagent (Scheme 23) was performed by Homaidan and Issidores ${ }^{9}$.

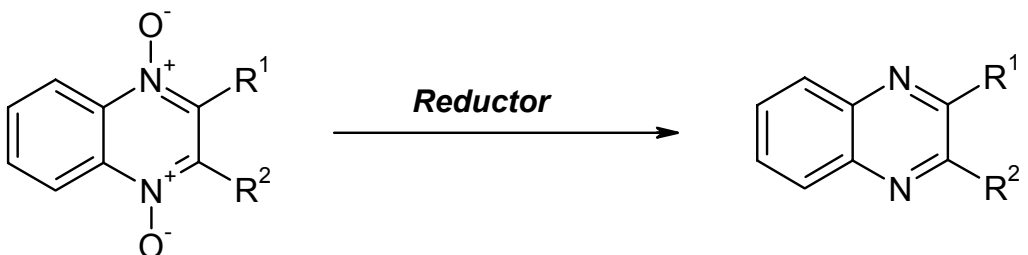

\section{Scheme 23}

Comparison of the results of deoxygenation using trimethyliodosilane, TFAA-I and $\mathrm{TiCl}_{4} / \mathrm{Zn}$, performed by these Authors, are presented in Table 18.

Table 18. Comparison of deoxygenation results of quinoxaline $N, N$ '-dioxides using chlorosilane, trimethyliodosilane, TFAA-I and $\mathrm{TiCl}_{4} / \mathrm{Zn}$ reagent systems ${ }^{9}$

\begin{tabular}{|c|c|c|c|c|c|c|c|c|c|c|}
\hline \multirow{2}{*}{\multicolumn{3}{|c|}{$\begin{array}{l}\text { Substrate /product } \\
(\mathbf{7 / 7 C )}\end{array}$}} & \multicolumn{8}{|c|}{ Deoxygenation systems } \\
\hline & & & \multicolumn{2}{|c|}{$\begin{array}{l}\mathrm{Si}_{2} \mathrm{Cl}_{6} \\
\left(\mathrm{CHCl}_{3}\right)^{\mathrm{a}}\end{array}$} & \multicolumn{2}{|c|}{$\begin{array}{l}\mathrm{Me}_{3} \mathrm{SiI} \\
\left(\mathrm{CHCl}_{3}\right)^{\mathrm{a}}\end{array}$} & \multicolumn{2}{|c|}{$\begin{array}{l}\text { TFAA-I } \\
(\text { acetone })^{\mathrm{a}}\end{array}$} & \multicolumn{2}{|c|}{$\begin{array}{l}\mathrm{TiCl}_{4} / \mathrm{Zn} \\
(\text { ether })^{\mathrm{b}}\end{array}$} \\
\hline 7/ & $\mathbf{R}^{1}$ & $\mathbf{R}^{2}$ & Time & Yield & Time & Yield & Time & Yield & Time & Yield \\
\hline $7 \mathrm{C}$ & & & $(h)$ & $(\%)^{\mathrm{d}}$ & (h) & $(\%)^{\mathrm{d}}$ & $(h)$ & $(\%)^{\mathrm{d}, \mathrm{e}}$ & $(h)$ & $(\%)^{\mathrm{d}}$ \\
\hline $\mathbf{f}$ & Me & Me & $3-4$ & 80 & 48 & 72 & $0.5^{\mathrm{c}}$ & 49 & 1 & 53 \\
\hline $\mathbf{g}$ & $\mathbf{P h}$ & Me & $3-4$ & 45 & 48 & 76 & $0.5^{\mathrm{c}}$ & 74 & 1 & $-{ }^{f}$ \\
\hline h & Bn & $\mathbf{P h}$ & $3-4$ & 57 & 48 & 69 & $0.5^{\mathrm{c}}$ & 50 & 1 & $-{ }^{f}$ \\
\hline i & $\mathrm{CO}_{2} \mathrm{Et}$ & Me & $3-4$ & 74 & 48 & 85 & $0.5^{\mathrm{c}}$ & 74 & 1 & 47 \\
\hline $\mathbf{j}$ & $\mathrm{C}(\mathrm{O}) \mathrm{Me}$ & Me & $3-4$ & 48 & 48 & 56 & $0.5^{\mathrm{c}}$ & 63 & 1 & 54 \\
\hline
\end{tabular}

a,b/Temperature: ${ }^{\mathrm{a} /}$ room temperature or ${ }^{\mathrm{b} /} 0{ }^{\circ} \mathrm{C}$. ${ }^{\mathrm{c} /}$ Estimated by authors. ${ }^{\mathrm{d} /}$ Yields refer to isolated and chromatographically pure quinoxalines $\mathbf{7 C}(\mathbf{7} \rightarrow \mathbf{7 C}) .{ }^{\text {e/ }}$ Quantitative by TLC. ${ }^{\mathrm{f} /}$ Intractable mixture.

\section{Deoxygenation procedure of quinoxaline dioxides 9}

The quinoxaline dioxide $(1.25 \mathrm{mmol})$ and sodium iodide $(6 \mathrm{mmol})$ were magnetically stirred with acetone $(5-7 \mathrm{~mL})$ in a round-bottom flask. An acetone solution of TFAA $(6.5 \mathrm{mmol})$ was slowly added with stirring. The extremely rapid reaction was followed by TLC and, when complete, the acetone was evaporated under reduced pressure and water was added. The mixture was then extracted with ether and the organic phase was washed first with $5 \%$ aq. sodium thiosulfate and then with water. The ether was removed from the dried extract (magnesium sulfate), and the product collected and purified. 
In view of the importance of reductive removal of the $N$-oxide oxygen in synthetic heterocyclic chemistry, the reagents described, especially the TFAA-I, offer an attractive alternative to earlier methods.

\subsection{Analytical application of TFAA-I for determination and detection of $\mathrm{N}$-oxo compounds}

\subsubsection{Determination of $N$-oxo compounds}

The $N$-oxo derivatives present abundant in number, and structurally differentiated class of organo-nitrogen compounds, possessing the $\mathrm{N}-\mathrm{O}$ unit as the common structural element. The importance of $N$-oxo compounds is connected with their technological applicability and use as pharmaceuticals (Table 19) and also as reagents in bio-organic (Table 20) and organic chemistry $^{85-88,105-115}$.

Table 19. Pharmacologically active compounds containing nitrone structure ${ }^{111}$

\section{Compounds}<smiles>CNC1=Nc2ccc(Cl)cc2C(c2ccccc2)=[N+]([O-])C1</smiles><smiles>[R2]N(C)CC[N+]([O-])=c1c2ccccc2ccc2ccccc12</smiles><smiles>[R]/C(c1ccc([N+](=O)[O-])o1)=[N+](/[R])[O-]</smiles><smiles>O=c1c[n+]([O-])cc[nH]1</smiles>

Table 20. Representative applications of spin labeled biomolecules ${ }^{113}$

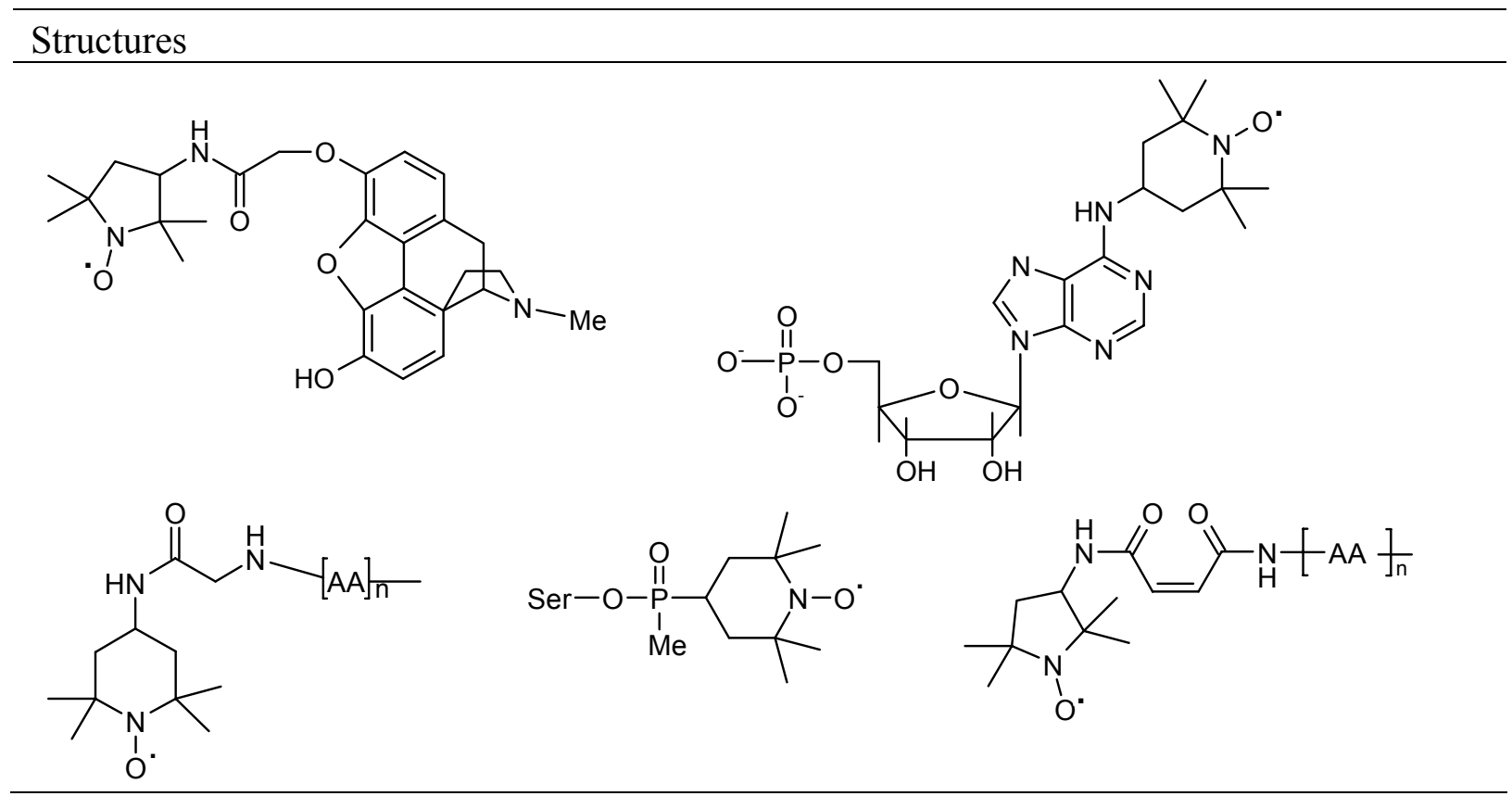


In this section, we concentrate on amine $N$-oxides ${ }^{86-88}$, nitroxide radicals and nitrones ${ }^{89,106-115}$, and also on nitroso-compounds ${ }^{116-121}$.

Nitrones are important reagents in organic synthesis ${ }^{106,107}$ and also serve as excellent spin traps in electron paramagnetic resonance techniques ${ }^{108,109}$ whereas nitroxide radicals play crucial role in spin labeling ${ }^{113-115}$. Nitroxide radicals belong to the most common classes of stable free radicals. Owing to their EPR activity, nitroxides play a crucial role in the investigations of many chemical, especially bio-organically oriented problems ${ }^{114,115}$, and are also involved in various industrial applications ${ }^{89,106}$.

In spite of such a broad applications, the selective determination and detection of $N$-oxo compounds still belongs to the problems of analytical chemistry of $N$-oxo compounds ${ }^{58,122-124}$.

\subsubsection{Determination of amine $\mathrm{N}$-oxides, nitroxide radicals and nitroso compounds.} Compilation of representative methods of determination of representative $N$-oxo compounds, including amine $N$-oxides, nitroxide radicals and $N$-nitroso compounds are given in Tables 21 , 22 and 23, respectively. Chemical methods of determination of nitrones, excluding methods based on application of the TFAA-I reagent, are absent in available chemical literature. The methods published are based on application of EPR and frequently suffer on tedious character, and/or lack of generality ${ }^{113-115}$. In contrast to them, determination and/or detection of several $\mathrm{N}$ oxy compounds can be successfully performed using the TFAA-I reagent.

Table 21. Comparison of the representative methods of determinations of amine $N$-oxides

\begin{tabular}{|c|c|c|c|}
\hline No & $\begin{array}{l}\text { Method } \\
\text { Reactions }\end{array}$ & Procedure & Ref. \\
\hline 1 & $\begin{array}{l}\mathrm{R}_{3} \mathrm{~N}^{+}-\mathrm{O}^{-}+\mathrm{Ti}^{3+} \rightarrow \mathrm{R}_{3} \mathrm{~N}+\mathrm{Ti}^{4+} \\
\mathrm{Ti}^{3+}+\mathrm{Fe}^{3+} \rightarrow \mathrm{Ti}^{4+}+\mathrm{Fe}^{2+}\end{array}$ & $\begin{array}{l}\text { Back titration of excess of } \mathrm{Ti}^{3+} \\
\text { with stand. solution of } \mathrm{Fe}(\mathrm{III}) \text {. }\end{array}$ & $\begin{array}{l}125 \\
127\end{array}$ \\
\hline 2 & $\begin{array}{l}\mathrm{R}_{3} \mathrm{~N}^{+}-\mathrm{O}^{-}+\mathrm{Ac}_{2} \mathrm{O} \rightarrow \mathrm{R}_{3} \mathrm{~N}^{+}-\mathrm{OAc}+\mathrm{AcO}^{-} \\
\mathrm{AcO}^{-}+\mathrm{H}^{+} \mathrm{ClO}_{4}^{-} \rightarrow \mathrm{AcOH}+\mathrm{ClO}_{4}^{-}\end{array}$ & $\begin{array}{l}\text { Potentiometric titration of } \\
\text { formed } \mathrm{AcO}^{-}\end{array}$ & $\begin{array}{l}128 \\
130\end{array}$ \\
\hline 3 & $\mathrm{R}_{3} \mathrm{~N}^{+}-\mathrm{O}^{-}+2 \mathrm{H}^{+}+2 \mathrm{e} \rightarrow \mathrm{R}_{3} \mathrm{~N}+\mathrm{H}_{2} \mathrm{O}$ & $\begin{array}{l}\text { Polarographic determination of } \\
\text { amine-oxides. }\end{array}$ & $\begin{array}{l}131 \\
132\end{array}$ \\
\hline 4 & $\mathrm{R}_{3} \mathrm{~N}^{+}-\mathrm{O}^{-}+$Draggendorff reagent $\rightarrow$ dye & $\begin{array}{l}\text { TLC separation/densitometric } \\
\text { determination of formed dye. }\end{array}$ & 133 \\
\hline 5 & $\begin{array}{l}\mathrm{R}_{2}(\mathrm{Me}) \mathrm{N}^{+}-\mathrm{O}^{-}+\mathrm{SO}_{2} / \mathrm{H}_{3} \mathrm{O}^{+} \rightarrow \mathrm{R}_{2}(\mathrm{Me}) \mathrm{N}^{+}-\mathrm{O}- \\
\mathrm{S}(\mathrm{O}) \mathrm{OH} \\
\mathrm{R}_{2}(\mathrm{Me}) \mathrm{N}^{+}-\mathrm{O}-\mathrm{S}(\mathrm{O}) \mathrm{OH} \rightarrow \mathrm{CH}_{2} \mathrm{O}+\mathrm{R}_{2} \mathrm{NH}+\mathrm{SO}_{2}\end{array}$ & $\begin{array}{l}\text { Determination UV/VIS of } \\
\text { released } \mathrm{CH}_{2} \mathrm{O} .\end{array}$ & 134 \\
\hline 6 & $\begin{array}{l}\mathrm{R}_{3} \mathrm{~N}^{+}-\mathrm{O}^{-}+\mathrm{TFAA}-\mathrm{I} \rightarrow \mathrm{R}_{3} \mathrm{~N}^{+}-\mathrm{O}-\mathrm{C}(\mathrm{O}) \mathrm{CF}_{3}+\mathrm{TFA}^{-} \\
\mathrm{R}_{3} \mathrm{~N}^{+}-\mathrm{O}-\mathrm{C}(\mathrm{O}) \mathrm{CF}_{3}+2 \mathrm{I}^{-} \rightarrow \mathrm{R}_{3} \mathrm{~N}+\mathrm{I}_{2}+\mathrm{TFA}^{-} \\
\mathrm{R}_{3} \mathrm{~N}^{+}-\mathrm{O}-\mathrm{C}(\mathrm{O}) \mathrm{CF}_{3}+2 \mathrm{I}^{-} \rightarrow \text { TFA(R')N-CRH- } \\
\mathrm{OTFA}+\mathrm{I}_{2}\end{array}$ & $\begin{array}{l}\text { Acylation-reduction of arene- } \\
\text { amine } N \text {-oxides and/or nitrones } \\
\text { with TFAA-I, and subsequent } \\
\text { detm. of released iodine. }\end{array}$ & $\begin{array}{l}20 \\
23\end{array}$ \\
\hline
\end{tabular}


Table 22. Comparison of the methods of determination of nitroxide radicals

\begin{tabular}{|c|c|c|c|}
\hline \multirow[t]{2}{*}{ No } & \multicolumn{2}{|c|}{ Method } & \multirow[t]{2}{*}{ Ref. } \\
\hline & Reactions & Procedure & \\
\hline 1 & $\begin{array}{l}\mathrm{R}_{2} \mathrm{~N}-\mathrm{O}+\mathrm{I}^{-}+\mathrm{AcOH} \rightarrow \mathrm{R}_{2} \mathrm{~N}-\mathrm{OH}+0.5 \mathrm{I}_{2}+ \\
\mathrm{AcO}^{-} \\
\mathrm{I}_{2}+2 \mathrm{~S}_{2} \mathrm{O}_{3}{ }^{2-} \rightarrow 2 \mathrm{I}^{-}+\mathrm{S}_{4} \mathrm{O}_{6}{ }^{2-}\end{array}$ & $\begin{array}{l}\text { Reduction of nitroxide radical with } \mathrm{KI} \\
\text { in glacial acetic acid. Titration of iodine } \\
\text { with } 0.1 \mathrm{M} \mathrm{Na}_{2} \mathrm{~S}_{2} \mathrm{O}_{3} \text {. }\end{array}$ & 135 \\
\hline 2 & $\mathrm{R}_{2} \mathrm{~N}-\mathrm{O}+\mathrm{Ce}^{4+} \rightarrow \mathrm{R}_{2} \mathrm{~N}^{+}=\mathrm{O}+\mathrm{Ce}^{3+}$ & $\begin{array}{l}\text { Amperometric titration of nitroxide } \\
\text { radical with } 0.01-0.1 \mathrm{M} \mathrm{Ce}(\mathrm{IV}) \text { sulphate. }\end{array}$ & 136 \\
\hline 3 & $\begin{array}{l}\mathrm{R}_{2} \mathrm{~N}-\mathrm{O}+\mathrm{ASC}(2 \mathrm{H}) \rightarrow \mathrm{R}_{2} \mathrm{~N}-\mathrm{OH}+\mathrm{ASC} \\
\mathrm{ASC}(2 \mathrm{H})+\mathrm{I}_{2} \rightarrow \mathrm{Asc}+2 \mathrm{I}^{-}\end{array}$ & $\begin{array}{l}\text { Reduction of nitroxide radical with } \\
\text { ascorbic acid. Redox back-titration with } \\
\text { stand. solution of iodine. }\end{array}$ & 137 \\
\hline 4 & $\begin{array}{l}\mathrm{R}_{2} \mathrm{~N}-\mathrm{O}+\text { fluorescamine } \mathrm{H} \rightarrow \\
\mathrm{R}_{2} \mathrm{~N}-\mathrm{O} \text {-fluorescamine } \mathrm{H}\end{array}$ & $\begin{array}{l}\text { HPLC separation } \mathrm{R}_{2} \mathrm{~N}-\mathrm{O} \text {-fluorescamine } \\
\text { and its } \mathrm{MS} / \mathrm{EI} \text { detm. }\end{array}$ & 138 \\
\hline 5 & $\begin{array}{l}\text { DMPO } \\
\mathrm{R}_{2} \mathrm{~N}-\mathrm{O}\end{array}$ (or $\left.\mathrm{PBN}\right)+\mathrm{R}^{\cdot}(\mathrm{HO}, \mathrm{Me}) \rightarrow$ & $\begin{array}{l}\text { HPLC separation of stable nitroxide } \\
\text { radical and its subsequent EPR detm. }\end{array}$ & 139 \\
\hline 6 & $\begin{array}{l}\mathrm{R}_{2} \mathrm{~N}-\mathrm{O}+\mathrm{TFAA}-\mathrm{I} \quad \rightarrow \quad \mathrm{R}_{2} \mathrm{~N}-\mathrm{O}-\mathrm{TFA}+ \\
0.5 \mathrm{I}_{2}\end{array}$ & $\begin{array}{l}\text { Acylation-reduction of nitroxides with } \\
\text { TFAA-I and subsequent detm. of } \\
\text { released iodine. }\end{array}$ & 23 \\
\hline
\end{tabular}

${ }^{\mathrm{a}}$ Abbreviations: ASC $=$ ascorbic acid; $\operatorname{ASC}(2 \mathrm{H})=$ ascorbic acid - reduced form; DMPO = 5,5dimethyl-1-pyrroline $N$-oxide; $\mathrm{PBN}=N$-tert-butyl- $\alpha$-phenylnitrone.

Table 23. Comparison of representative methods of analysis of nitroso compounds

\begin{tabular}{|c|c|c|c|}
\hline \multirow[t]{2}{*}{ No } & \multicolumn{2}{|c|}{ Method } & \multirow[t]{2}{*}{ Ref. } \\
\hline & Reactions $^{\mathrm{a}}$ & Procedure & \\
\hline 1 & $\mathrm{R}_{2} \mathrm{~N}-\mathrm{NO}+\mathrm{Ti}^{+3}+\mathrm{H}^{+} \rightarrow \mathrm{R}_{2} \mathrm{NH}+\mathrm{Ti}^{+4}+\mathrm{H}_{2} \mathrm{O}$ & Thermogravimetrical determination. & 140 \\
\hline 2 & $\begin{array}{l}\mathrm{R}-\mathrm{NO}+\mathrm{Fe}(\mathrm{OH})_{2} \rightarrow \mathrm{R}-\mathrm{NH}_{2}+\mathrm{Fe}^{+3} \\
\mathrm{Fe}^{+3}+\mathrm{Ti}^{+3} \rightarrow \mathrm{Fe}^{+2}+\mathrm{Ti}^{+4}\end{array}$ & $\begin{array}{l}\text { Titration of excess of Ti(III) with } \\
\text { stand. solution of Fe(III). }\end{array}$ & $\begin{array}{l}141 \\
142\end{array}$ \\
\hline 3 & $\begin{array}{l}\mathrm{R}_{2} \mathrm{~N}-\mathrm{NO}+\mathrm{SOCl}_{2} \rightarrow \mathrm{R}_{2} \mathrm{NH}+\mathrm{NO}_{2}^{-} \\
\mathrm{R}_{2} \mathrm{NH}+\mathrm{NO}_{2}^{-}+\mathrm{NEDA} \rightarrow \text { dye }\end{array}$ & $\begin{array}{l}\text { Spectrometric detm. (VIS: } 540 \mathrm{~nm} \text { ) } \\
\text { of formed dye. }\end{array}$ & 143 \\
\hline 4 & $\begin{array}{l}\mathrm{R}_{2} \mathrm{~N}-\mathrm{NO}+\mathrm{H}_{2} \mathrm{O}(\mathrm{UV}) \rightarrow \mathrm{R}_{2} \mathrm{NH}+\mathrm{NO}_{2}^{-} \\
\mathrm{R}_{2} \mathrm{NH}+\mathrm{NO}_{2}^{-}+\mathrm{NEDA}+\mathrm{SAA} \rightarrow \text { dye }\end{array}$ & $\begin{array}{l}\text { Spectrometric detm. (VIS: } 540 \mathrm{~nm} \text { ) } \\
\text { of formed dye. }\end{array}$ & 144 \\
\hline 5 & $\begin{array}{l}\mathrm{R}_{2} \mathrm{~N}-\mathrm{NO}+\mathrm{HBr} / \mathrm{AcOH} \rightarrow \mathrm{R}_{2} \mathrm{NH} \\
\mathrm{R}_{2} \mathrm{NH}+\text { Bratton-Marshall reagent } \rightarrow \text { dye }\end{array}$ & $\begin{array}{l}\text { Spectrometric detm. (VIS: } 550 \mathrm{~nm} \text { ) } \\
\text { of formed dye. }\end{array}$ & 145 \\
\hline 6 & $\mathrm{R}_{2} \mathrm{~N}-\mathrm{NO}+4 \mathrm{H}^{+}+4 \mathrm{e} \rightarrow \mathrm{R}_{2} \mathrm{~N}-\mathrm{NH}_{2}+2 \mathrm{H}_{2} \mathrm{O}$ & Polarographical reduction of NNA. & 146 \\
\hline 7 & $\mathrm{R}_{2} \mathrm{~N}-\mathrm{NO}+\mathrm{TFA}+\mathrm{H}_{2} \mathrm{O}_{2} \rightarrow \mathrm{R}_{2} \mathrm{~N}-\mathrm{NO}_{2}$ & GLC detm. of formed N-nitroamines. & 147 \\
\hline 8 & $\begin{array}{l}\mathrm{R}_{2} \mathrm{~N}-\mathrm{NO}+\mathrm{HBr} / \mathrm{AcOH} \rightarrow \mathrm{R}_{2} \mathrm{NH} \\
\mathrm{R}_{2} \mathrm{NH}+\mathrm{ClP}(\mathrm{S})(\mathrm{SEt})_{2} \rightarrow \mathrm{R}_{2} \mathrm{~N}-\mathrm{P}(\mathrm{S})(\mathrm{SEt})_{2}\end{array}$ & $\begin{array}{l}\text { Conversion of NNA to amide and its } \\
\text { detm. by GLC/FPD. }\end{array}$ & 148 \\
\hline 9 & $\begin{array}{l}\mathrm{R}_{2} \mathrm{~N}-\mathrm{NO}+\mathrm{VOSO}_{4} / \mathrm{H}^{+} \rightarrow \mathrm{R}_{2} \mathrm{~N}-\mathrm{NO}_{2}+\mathrm{V}(\mathrm{III}) \\
\mathrm{V}(\mathrm{III})+\mathrm{Fe}(\mathrm{III}) / \text { safranine } \mathrm{T} \rightarrow \mathrm{V}(\mathrm{V})+\mathrm{Fe}(\mathrm{II})\end{array}$ & $\begin{array}{l}\text { Titration of excess of V(III) with } \\
\text { stand. solution of Fe(III). }\end{array}$ & 149 \\
\hline 10 & $\mathrm{R}_{2} \mathrm{~N}-\mathrm{O}+\mathrm{TFAA}-\mathrm{I} \rightarrow \mathrm{R}_{2} \mathrm{~N}-\mathrm{N}(\mathrm{TFA})_{2}+2 \mathrm{I}_{2}$ & $\begin{array}{l}\text { Acylation-reduction of NNA with } \\
\text { TFAA-I and subsequent detm./detn. } \\
\text { of released iodine. }\end{array}$ & $\begin{array}{l}21,22 \\
25\end{array}$ \\
\hline
\end{tabular}

${ }^{\mathrm{a}}$ Abbreviations: NEDA $=N$-(1-napthyl)ethylenediamine; SAA $=$ sulphanilic acid; NNA $=N$ nitroso-amine. 
3.2.1.2. Determination of $N$-oxo compounds by means of TFAA-I. The systematic studies of reactions of amine $N$-oxides 7 , nitrones $\mathbf{8}$ and nitroxide radicals 9 with the TFAA-I system, revealed their apparent analytical feature (Scheme 6; Table 14). The results of nitrones and nitroxide radicals determinations, based on subsequent determinations of iodine released during the reaction of TFAA-I with these $N$-oxo compounds (Scheme 24), are summarized in Table 24 and 25 , respectively.

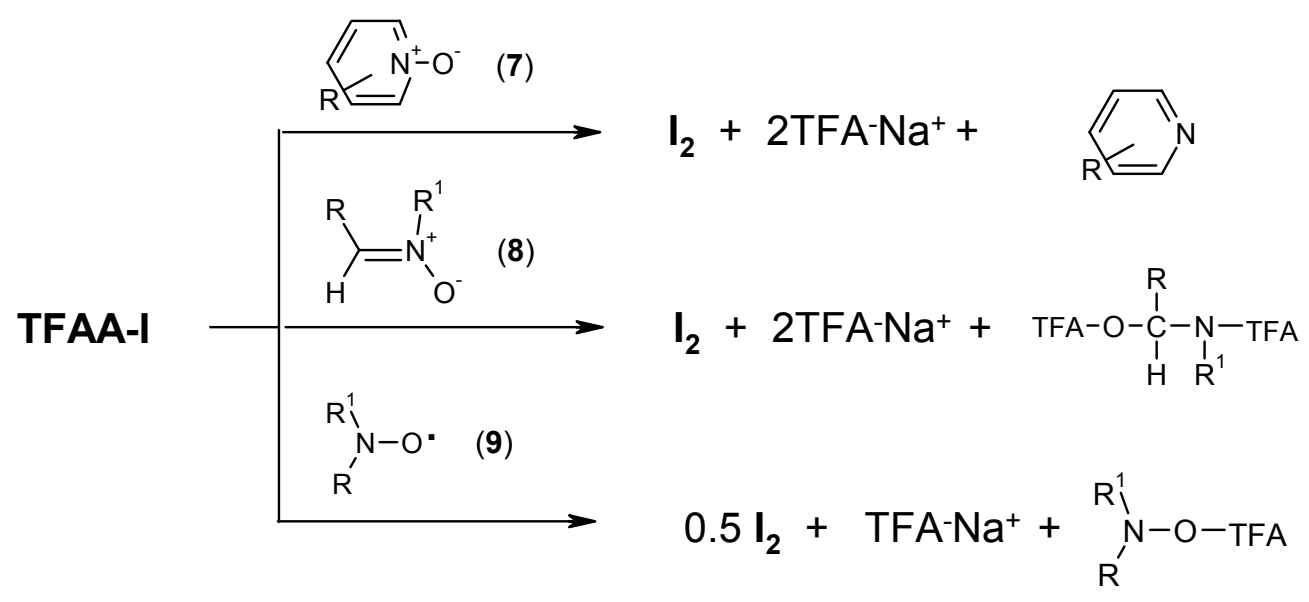

\section{Scheme 24}

The iodometric titration of iodine released permits one to determine nitrones at the 20 to 100 $\mu \mathrm{mol}$ level with an average deviation 1\% (RSD: 0.0027 to 0.0076). This system also allows spectrophotometric determination of nitrones (equivalent to released iodine) at the 50 to 500 nmol in standard $(1=1 \mathrm{~cm})$ and at the 50 to $10 \mathrm{nmol}$ level using cuvette with path light $1=5 \mathrm{~cm}$. The average deviation of these determinations is $\pm 2.8 \%$ (RSD: 0.022 to 0.066 ).

The iodometric titration of the iodine released in reaction of TFAA-I with nitroxide radicals permits one to determine 9 at the 40 -1000 $\mu$ mol level with an average deviation up to $\pm 2.8 \%$ (RSD. 0.0018-0.0094). This method is especially recommended for the fast and accurate determination of nitroxide radicals (e.g. determination of purity of $9^{23}$ ). The spectrophotometric method permits the determination of nitroxide radicals (equivalent to released iodine) at the 100$1000 \mathrm{nmol}$ level in standard $(l=10 \mathrm{~mm})$ and at the $20-100 \mathrm{nmol}$ level using cuvettes with light path $l=50 \mathrm{~mm}$. The average deviation of these determinations of 9 is $\pm 3.0 \%$ (RSD: 0.018 0.092). The sensitivity of this method is comparable with the sensitivities offered by EPR techniques, additionally presenting better versatility and simplicity of measurements. 
Table 24. The results of determination of nitrones 8 using TFAA- $\mathrm{I}^{20}$

\begin{tabular}{|c|c|c|c|c|c|c|c|c|}
\hline \multicolumn{3}{|c|}{ Nitrone } & \multirow{3}{*}{ Methods $^{\mathrm{a}}$} & \multicolumn{2}{|c|}{ Taken } & \multicolumn{2}{|l|}{ Found } & \multirow{3}{*}{$\begin{array}{l}\mathrm{RSD}^{\mathrm{b}} \\
\times 10^{3}\end{array}$} \\
\hline No & $\mathrm{R}_{\mathrm{C}}$ & $\mathrm{R}^{1}$ & & umol & nmol & umol & nmol & \\
\hline & $\mathrm{R}$ & $\mathrm{R}^{1}$ & & & & & & \\
\hline & & & A & 20.0 & & 19.9 & & 6.6 \\
\hline \multirow[t]{4}{*}{$8 \mathbf{a}$} & $\mathrm{Ph}$ & $\mathrm{Me}$ & & 100.0 & & 99.6 & & 2.7 \\
\hline & & & $\mathrm{B}_{1}$ & & 50.0 & & 51.0 & 46 \\
\hline & & & & & 500. & & 490. & 24 \\
\hline & & & A & 20.0 & & 19.9 & & 7.6 \\
\hline \multirow[t]{4}{*}{$8 b$} & $\mathrm{Ph}$ & $\mathrm{Ph}$ & & 100.0 & & 100.2 & & 3.2 \\
\hline & & & $\mathrm{B}_{1}$ & & 50.0 & & 51.0 & 46 \\
\hline & & & & & 500 . & & 486. & 22 \\
\hline & & & A & 20.0 & & 19.8 & & 7.2 \\
\hline \multirow[t]{4}{*}{$8 c$} & $m-\mathrm{Cl}-\mathrm{Ph}$ & $\mathrm{Ph}$ & & 100.0 & & 98.8 & & 3.2 \\
\hline & & & $\mathrm{B}_{1}$ & & 50.0 & & 49.0 & 44 \\
\hline & & & & & 500. & & 492. & 26 \\
\hline & & & A & 20.0 & & 19.9 & & 6.4 \\
\hline \multirow[t]{5}{*}{$8 d$} & $p$-MeO-Ph & $\mathrm{Ph}$ & & 100.0 & & 99.4 & & 3.0 \\
\hline & & & $\mathrm{B}_{1}$ & & 50.0 & & 48.0 & 56 \\
\hline & & & & & 500 . & & 510. & 30 \\
\hline & & & $\mathrm{B}_{2}$ & & $10.0^{*}$ & & 10.4 & 84 \\
\hline & & & & & $50.0^{*}$ & & 50.8 & 20 \\
\hline
\end{tabular}

${ }^{a}$ The determinations of iodine (A - iodometric and/or B - spectrophotometric) were performed after addition to the nitroxide radical solutions the following amounts of reagents:

A: $0.4 \mathrm{mmol}$ of TFAA and $0.5 \mathrm{mmol}$ of $\mathrm{NaI}$ (exposition time $=0.5 \mathrm{~min}$ );

$\mathrm{B}_{1}: 0.05 \mathrm{mmol}$ of TFAA and $0.5 \mathrm{mmol}$ of NaI (exposition time $=2 \mathrm{~min} ; 1=1 \mathrm{~cm}$ );

$\mathrm{B}_{2}: 0.05 \mathrm{mmol}$ of TFAA and $0.5 \mathrm{mmol}$ of NaI (exposition time $=2 \mathrm{~min} ; 1^{*}=5 \mathrm{~cm}$ ).

${ }^{\mathrm{b} /}$ For $\mathrm{n}=6$. 
Table 25. Results for determinations of nitroxide radicals 9 using TFAA- $\mathrm{I}^{23}$

\begin{tabular}{|c|c|c|c|c|c|c|c|c|}
\hline \multicolumn{2}{|c|}{ Nitroxide radicals } & \multirow[t]{2}{*}{ Meth. } & \multirow{2}{*}{$\begin{array}{l}\text { Time }^{\mathrm{b}} \\
(\mathrm{min})\end{array}$} & \multirow{2}{*}{$\begin{array}{l}\text { Taken } \\
\mu m o l\end{array}$} & \multirow[b]{2}{*}{ nmol } & \multirow{2}{*}{$\begin{array}{l}\text { Found } \\
\mu m o l\end{array}$} & \multirow[b]{2}{*}{ nmol } & \multirow{2}{*}{$\begin{array}{l}\mathrm{RSD}^{\mathrm{c}} \\
\times 10^{3} \\
\end{array}$} \\
\hline No & Structure & & & & & & & \\
\hline \multirow[t]{6}{*}{$9 a$} & & $\mathrm{~A}_{1}$ & 1 & 40.0 & & 39.7 & & 6.2 \\
\hline & & & & 100.0 & & 99.4 & & 3.8 \\
\hline & & & & 200.0 & & 199.0 & & 2.5 \\
\hline & & $\mathrm{B}_{1}$ & 2 & & 100.0 & & 103.0 & 36 \\
\hline & & & & & 400 & & 408. & 28 \\
\hline & & & & & 1000. & & 980. & 22 \\
\hline \multirow[t]{13}{*}{$9 b$} & & $\mathrm{~A}_{1}$ & 1 & 40.0 & & 39.7 & & 5.5 \\
\hline & & & & 100.0 & & 99.5 & & 3.0 \\
\hline & & & & 200.0 & & 199.2 & & 23 \\
\hline & & $\mathrm{A}_{2}$ & 1 & 600 & & 599. & & 26 \\
\hline & & & & 1000. & & 1000. & & 1.8 \\
\hline & & $\mathrm{B}_{1}$ & 2 & & 100.0 & & 102.0 & 37 \\
\hline & & & & & 200.0 & & 196.0 & 18 \\
\hline & & & & & 600 & & 599. & 26 \\
\hline & & & & & 1000. & & 1000. & 1.8 \\
\hline & & $\mathrm{B}_{2}$ & 2 & & 20.0 & & 19.1 & 92 \\
\hline & & & & & 40.0 & & 39.6 & 70 \\
\hline & & & & & 60.0 & & 62.0 & 45 \\
\hline & & & & & 100.0 & & 101.0 & 26 \\
\hline \multirow[t]{6}{*}{$9 c$} & & $\mathrm{~A}_{1}$ & 10 & 40.0 & & 39.6 & & 8.4 \\
\hline & & & & 100.0 & & 99.4 & & 6.5 \\
\hline & & & & 200.0 & & 199.0 & & 5.2 \\
\hline & & $\mathrm{B}_{1}$ & 2 & & 100.0 & & 97.0 & 36 \\
\hline & & & & & 400. & & 390. & 32 \\
\hline & & & & & 1000 . & & 1020. & 36 \\
\hline \multirow[t]{4}{*}{ 9d } & & $\mathrm{A}_{1}$ & 30 & 40.0 & & 39.7 & & 9.4 \\
\hline & & & & 200.0 & & 194.5 & & 7.0 \\
\hline & & $\mathrm{A}_{3}$ & 1 & 40.0 & & 39.0 & & 6.2 \\
\hline & & & & 200.0 & & 195.0 & & 5.0 \\
\hline
\end{tabular}

${ }^{\mathrm{a}}$ The determinations of iodine (A - iodometric and/or B - spectrophotometric) were performed after addition to the nitroxide radical solutions the following amounts of reagents:

$\mathrm{A}_{1}: 0.8 \mathrm{mmol}$ of TFAA and $0.5 \mathrm{mmol}$ of $\mathrm{NaI}$ (exposition time $=1-30 \mathrm{~min}$ );

$\mathrm{A}_{2}: 1.6 \mathrm{mmol}$ of TFAA and $2.0 \mathrm{mmol}$ of $\mathrm{NaI}$ (exposition time $=1 \mathrm{~min}$ );

$\mathrm{A}_{3}: 0.8 \mathrm{mmol}$ of $\mathrm{AcCl}$ and $0.5 \mathrm{mmol}$ of $\mathrm{NaI}$ (exposition time $=1 \mathrm{~min}$ );

$\mathrm{B}_{1}: 0.08 \mathrm{mmol}$ of TFAA and $0.5 \mathrm{mmol}$ of $\mathrm{NaI}$ (exposition time $=2 \mathrm{~min} ; 1=1 \mathrm{~cm}$ );

$B_{2}: 0.08 \mathrm{mmol}$ of TFAA and $0.5 \mathrm{mmol}$ of $\mathrm{NaI}$ (exposition time $=2 \mathrm{~min} ; 1=5 \mathrm{~cm}$ ).

${ }^{\mathrm{b}}$ Time of exposition. 
For kinetic reasons explained in 2.2.1.1., we have used at least four molar excess of TFAA and 2.5 molar excess of sodium iodide for determination on the $\mu \mathrm{mol}$ scale (with iodometric titration), and 100-fold excess of TFAA and 1000-fold excess of $\mathrm{NaI}$ for spectrophotometric determination on nmol level. The low acidity of the reaction mixture (0.04 mmol TFAA) involves only marginal side-reaction of aerial oxidation of iodide, thus practically eliminates the requirement of blank titration in titrimetric determinations of nitrones. However, in the spectroscopic method, blank correction is needed since the iodine from aerial iodide oxidation constitutes a perceptible part of the total released iodine. Thus, the examination of the course of iodine release as a function of time reveals that the reaction is completed in a few seconds after mixing the solutions, with slow gradual increase in iodine level caused by further air oxidation ( $A=0.02$ to 0.03 in $20 \mathrm{~min}$ ). For this reason, blank correction was determined from the separate measurement of TFAA-I absorbance (standard condition: 2 min exposure, with acetone as reference) and this value was subtracted from measurements of nitrones determinations. The very low molecular absorbance of nitrones in the analytical wavelength region practically eliminates the requirement of additional correction of absorbance measurements.

The procedures of determination of nitrones and nitroxide radicals [iodometrical (A) and spectrophotometrical (B)] are identical to these described for determination of sulphoxides.

This reaction has also been examined in respect to the addition order of sub-component of TFAA-I. Thus, if TFAA was added first (reverse mode), and after the exposure time (indicated in Table 26) followed by addition of NaI, the quantities of iodine determined decreased with prolongation of the exposure time (Table 26).

Table 26. Differentiation of nitrones 8 and nitroxide radicals 9 using the reverse order titration procedure $^{23}$

\begin{tabular}{|c|c|c|c|c|c|c|c|}
\hline \multicolumn{2}{|c|}{ Compound applied } & \multirow{2}{*}{$\begin{array}{l}\text { Amount } \\
\text { umol }\end{array}$} & \multicolumn{3}{|c|}{$\begin{array}{l}\text { Determination of iodine }(\%)^{\mathrm{a}} \\
\text { Time }(\mathrm{min})\end{array}$} & \multirow[b]{2}{*}{4} & \multirow[b]{2}{*}{5} \\
\hline No & Structure & & 1 & 2 & 3 & & \\
\hline $8 a$ & & 100.0 & 3.0 & 2.0 & 0.2 & 0.0 & 0.0 \\
\hline $8 b$ & & 100.0 & 0.2 & 0.0 & 0.0 & 0.0 & 0.0 \\
\hline $9 b$ & & 100.0 & $98.7^{\mathrm{b}}$ & $97.2^{\mathrm{b}}$ & $94.0^{\mathrm{b}}$ & $90.0^{\mathrm{b}}$ & $86.0^{\mathrm{b}}$ \\
\hline
\end{tabular}

${ }^{\mathrm{a} /}$ According to the iodometric titration-reverse procedure. ${ }^{\mathrm{b} /}$ Regarding the reaction stoichiometry. 


\section{Iodometric titration-reverse mode procedure $^{23}$ :}

A known amount of nitrone 8 or nitroxide radical $9(100 \mu \mathrm{mol}$ contained in $1 \mathrm{~mL}$ of $0.1 \mathrm{M}$ solution) was taken into a $100-\mathrm{mL}$ Erlenmeyer flask and $1 \mathrm{~mL}$ of $0.8 M$ TFAA was added. After time indicated in Table 26, $1 \mathrm{~mL}$ of $0.5 \mathrm{M} \mathrm{NaI}$ in acetone was added. After gentle mixing for 1 min the contents were diluted with $20 \mathrm{~mL}$ of $0.1 M \mathrm{KI}$ and titrated at once with sodium thiosulphate. At the end of the titration, starch was added.

Thus, if the nitrones solution is first treated with TFAA and sodium iodide is added to this mixture later, only a marginal amount of iodine is formed; namely $3 \%$ of theoretical release after $1 \mathrm{~min}, 0.2 \%$ after $3 \mathrm{~min}$ and null after $4 \mathrm{~min}$ of exposition of $\mathbf{8}$ with TFAA. This suggests that in the absence of iodide, acylated nitrone intermediates $8 \mathbf{A}$ quickly rearrange to imides $\mathbf{8 L}$ (scheme $25)$, which are totally unreactive in further iodide oxidation ${ }^{24}$.

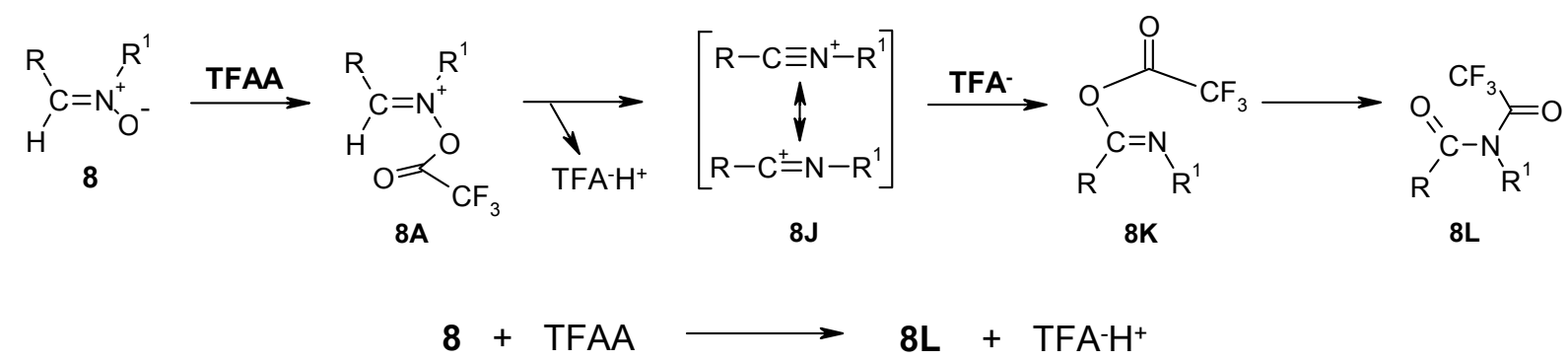

\section{Scheme 25}

In case of application of the reverse mode reaction for nitroxide radicals 9 , the rate of decrease of iodine amount, released in the reaction of 9 with TFAA-I, was substantially lower. Namely, only $1.3 \%$ (98.7\% of iodine was released) after $1 \mathrm{~min}, 2.8 \%$ after 2 min and 10\% after 4 min of exposition of 9 in solutions with TFAA.

Detailed investigations of this reaction revealed a mechanistic course illustrated in Schemes 26 and $27^{25,26}$.

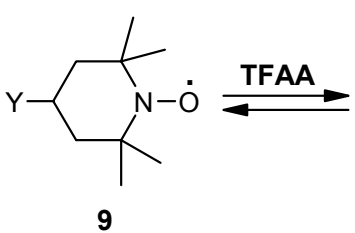

Scheme 26

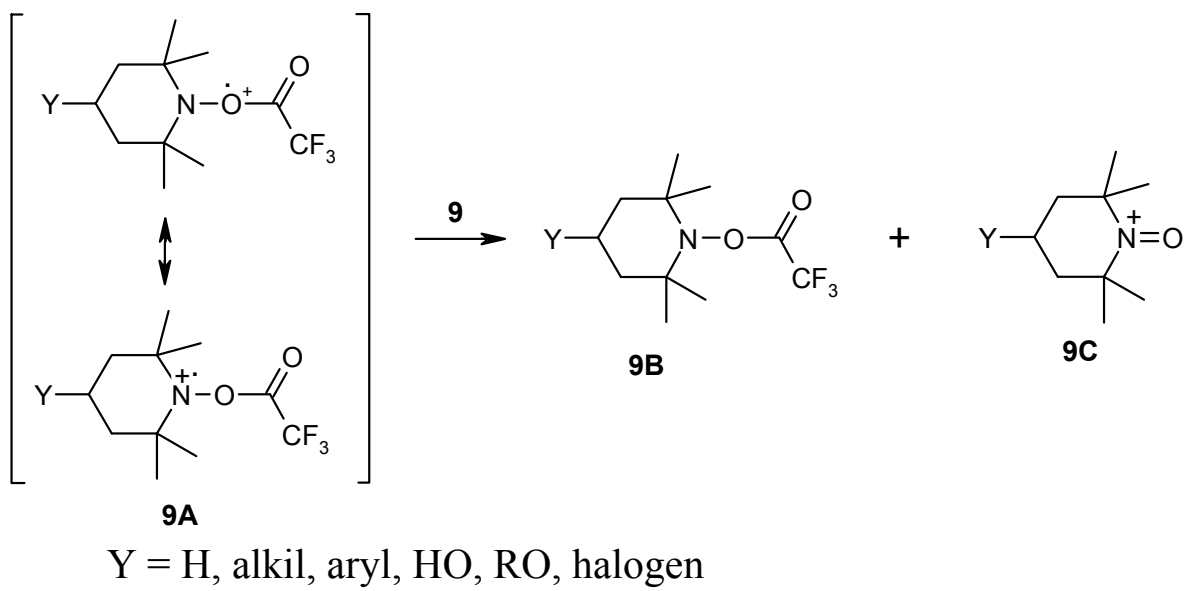


This reaction course includes the stage of disproportion of $9 \mathbf{A}$ to hydroxylamines $\mathbf{9 B}$ and aminoxyl derivatives 9C (Scheme 26), analogous to the disproportions described for protonated

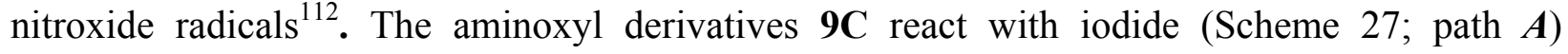
releasing equimolar amount of iodine and anion 9E (acylated directly by TFAA to 9B), and simultaneously with acetone (Scheme 27; path $\boldsymbol{B}$ ) affording hydroxylamines $\mathbf{9 F}$.
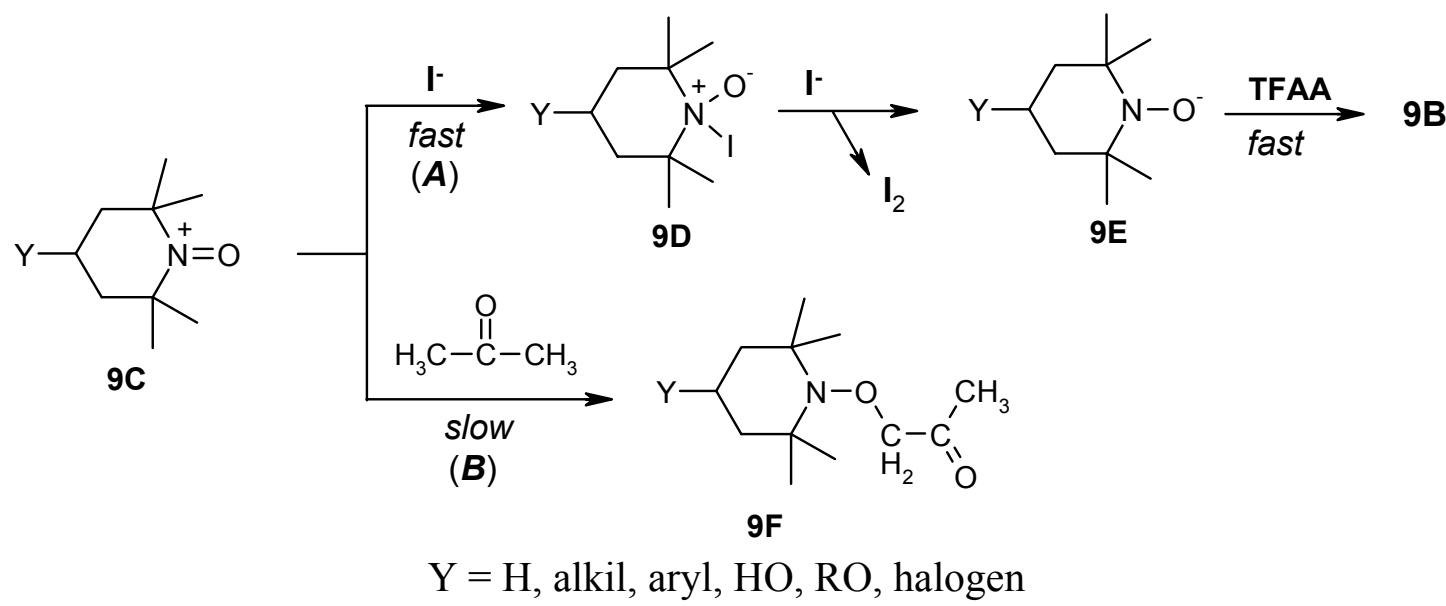

\section{Scheme 27}

The presence of imides 8L (Scheme 25) and also hydroxyloamines 9B and 9F (Scheme 27) was confirmed by GCMS measurements of the appropriate reaction mixtures ${ }^{25}$.

This slow rearrangement of derivatives 9A to inert towards iodide hydroxylamines 9F, creates a possibility for the semi-quantification of nitroxide radicals $\mathbf{9}$ and nitrones $\mathbf{8}$, in mixtures. Thus, if the reverse mode of TFAA-I procedure is applied for the analysis of mixtures of 8 and 9, their corresponding $\mathrm{N}$-O-trifluoroacetyl derivatives $\mathbf{8 A}$ and $\mathbf{9 A}$ (formed during the treatment of parent compounds by means of TFAA), rearrange at different rates to compounds devoid of oxidative properties $(\mathbf{8 C}$ vs $\mathbf{9 F}$ ). As the reactions $\mathbf{8 A} \rightarrow \mathbf{8 C}$ proceed much faster than the reactions $\mathbf{9 A} \rightarrow \mathbf{9 F}$, the application of this reverse order procedure permits semi-quantification of these types of $N$-oxo compounds in mixtures (Table 26).

\subsubsection{Detection of $N$-oxo compounds}

Since occurrence of $\mathrm{N}$-oxo compounds present significant concern their determination and/or detection was the subject of numerous methods of analysis, both classical as well as instrumental type. Generally, volatile $N$-oxy compounds are analyzed by means of GC and/or GC/MS ${ }^{122-124}$. However, frequently methods enabling selective determination/detection of these compounds in complex mixtures may present the method of choice. The representative methods of selective detection of $N$-oxo (in majority $N$-nitroso) compounds are presented in Table 27. 
Table 27. Representative methods of selective detection of $N$-oxo ( $N$-nitroso) compounds

\begin{tabular}{|c|c|c|c|}
\hline No & $\begin{array}{l}\text { Method } \\
\text { Detection reaction }^{\mathrm{a}}\end{array}$ & Procedure & Ref. \\
\hline 1 & $\begin{array}{l}\mathrm{R}_{2} \mathrm{~N}-\mathrm{NO}+\mathrm{Ph}_{2} \mathrm{NH}+\mathrm{PdCl}_{2}+\mathrm{UV} \rightarrow \\
\mathrm{R}_{2} \mathrm{~N}-\mathrm{NPh}_{2} \times \mathrm{PdCl}_{2}\end{array}$ & TLC separation/identification. & $\begin{array}{l}150 \\
151\end{array}$ \\
\hline 2 & $\begin{array}{l}\mathrm{R}_{2} \mathrm{~N}-\mathrm{NO}+\mathrm{H}_{2} \mathrm{~N}-\mathrm{Ph}-\mathrm{SO}_{2} \mathrm{NH}_{2}+\mathrm{Nph}-\mathrm{NH}_{2}+\mathrm{UV} \rightarrow \\
\text { azo-dye }\end{array}$ & TLC separation/identification. & 151 \\
\hline 3 & $\mathrm{R}_{2} \mathrm{~N}-\mathrm{NO}+$ ninhydrine $\rightarrow$ blue dye & TLC separation/identification. & $\begin{array}{l}152 \\
153\end{array}$ \\
\hline 4 & $\begin{array}{l}\mathrm{R}_{2} \mathrm{~N}-\mathrm{NO}+\mathrm{AcOH} / \mathrm{HBr} \rightarrow \mathrm{R}_{2} \mathrm{NH} \times \mathrm{HBr} \\
\mathrm{R}_{2} \mathrm{NH}+\mathrm{NBD}-\mathrm{Cl} \rightarrow \mathrm{R}_{2} \mathrm{~N}-\mathrm{NBD}\end{array}$ & $\begin{array}{l}\text { TLC separation/fluorometric } \\
\text { determination. }\end{array}$ & $\begin{array}{l}154 \\
155\end{array}$ \\
\hline 5 & $\begin{array}{l}\mathrm{R}_{2} \mathrm{~N}-\mathrm{NO}+\mathrm{AcOH} / \mathrm{HBr} \rightarrow \mathrm{R}_{2} \mathrm{NH} \times \mathrm{HBr} \\
\mathrm{R}_{2} \mathrm{NH}+\text { Dans-Cl } \rightarrow \mathrm{R}_{2} \mathrm{~N}-\text { Dans }\end{array}$ & $\begin{array}{l}\text { TLC separation/fluorometric } \\
\text { determination. }\end{array}$ & $\begin{array}{l}156 \\
157\end{array}$ \\
\hline 6 & $\begin{array}{l}\mathrm{R}_{2} \mathrm{~N}-\mathrm{NO}+\mathrm{AcOH} / \mathrm{HBr} \rightarrow \mathrm{R}_{2} \mathrm{NH} \times \mathrm{HBr} \\
\mathrm{R}_{2} \mathrm{NH}+\mathrm{MQSA} \rightarrow \mathrm{R}_{2} \mathrm{~N}-\mathrm{NH}-\mathrm{MQSA}\end{array}$ & $\begin{array}{l}\text { TLC separation/fluorometric } \\
\text { determination. }\end{array}$ & 158 \\
\hline 7 & $\begin{array}{l}\mathrm{R}_{2} \mathrm{~N}-\mathrm{NO} \rightarrow \mathrm{R}_{2} \mathrm{NH}-\mathrm{NH}_{2} \\
\mathrm{R}_{2} \mathrm{NH}-\mathrm{NH}_{2}+4-\mathrm{NAB}-4{ }^{\prime}-\mathrm{C}(\mathrm{O}) \mathrm{Cl} \rightarrow \\
4-\mathrm{NAB}-4{ }^{\prime}-\mathrm{C}(\mathrm{O})-\mathrm{NHNR}_{2}\end{array}$ & $\begin{array}{l}\text { TLC separation/fluorometric } \\
\text { determination. }\end{array}$ & 159 \\
\hline 8 & $\begin{array}{l}\mathrm{R}_{2} \mathrm{~N}-\mathrm{NO} \rightarrow \mathrm{R}_{2} \mathrm{NH}-\mathrm{NH}_{2} \\
\mathrm{R}_{2} \mathrm{~N}-\mathrm{NH}_{2}+\text { Antr-C(O)H } \rightarrow \text { Antr-C }(\mathrm{H})=\mathrm{NNR}_{2}\end{array}$ & $\begin{array}{l}\text { TLC separation/fluorometric } \\
\text { determination. }\end{array}$ & $\begin{array}{l}160 \\
161\end{array}$ \\
\hline 9 & $\begin{array}{l}\mathrm{R}_{2} \mathrm{~N}-\mathrm{NO} \rightarrow \mathrm{R}_{2} \mathrm{NNH}_{2} \\
\mathrm{R}_{2} \mathrm{~N}-\mathrm{NH}_{2}+\mathrm{HNPh}-\mathrm{C}(\mathrm{O}) \mathrm{H} \rightarrow \mathrm{HNPh}-\mathrm{C}(\mathrm{H})=\mathrm{NNR}_{2}\end{array}$ & TLC separation/identification & 162 \\
\hline
\end{tabular}

${ }^{\mathrm{a}}$ Abbreviations: NBD-Cl = 7-chloro-4-nitrobenzo-2-oxa-1,3-diazole; Dans- $\mathrm{Cl}=$ dansyl chloride; 5-dimethylamino-1-napthalenesulphonyl chloride; $\quad$ MQSA $\quad=\quad N$-(8-methoxy-5quinolinesulphonyl)aziridine; 4-NAB-4' - $\mathrm{C}(\mathrm{O}) \mathrm{Cl}=4$-nitroazobenzene-4'-carbonylchloride; Antr$\mathrm{C}(\mathrm{O}) \mathrm{H}=$ 9-antraldehyde; $\mathrm{HNPh}-\mathrm{C}(\mathrm{O}) \mathrm{H}=$ 2-hydroxy-5-nitrobenzaldehyde.

The selective detection of $N$-oxo compounds in TLC systems is limited to a narrow range of detection reagents (Table 27). Due to UV transparency of $N$-oxo group, in some procedures nitrosoamines were derivatized to compounds exhibiting higher detectability (strong absorbance or chemiluminiscence), prior to their chromatographic separation and subsequent determination. The published methods for TLC detection of amine $N$-oxides, nitrones and nitroxide radicals are based on the application of the TFAA-I reagent ${ }^{19,21,22,25,26}$. We have found that the TFAA-I reagent reacts also with various nitroso compounds with simultaneous release of iodine, creating a base of their TLC detection.

3.2.2.1. Detection of $N$-oxo compounds by means of TFAA-I. TLC detection of $N$-oxo compounds by means of the TFAA-I reagent, is based on the reactions illustrated on Scheme 6 (and also Schemes 13-21), occurring with simultaneous release of iodine. Results for the 
application of TFAA-I for the detection of representative $N$-oxo compounds are summarized in Table 28.

Table 28. Detection limits for the detection of amine $N$-oxides 7, nitrones $\mathbf{8}$, nitroxide radicals 9 and nitroso compounds 11-14, using TFAA-I as the detection reagent ${ }^{19,21,22,25,26}$

\begin{tabular}{|c|c|c|c|c|c|}
\hline \multicolumn{2}{|c|}{ Compound applied } & \multirow{2}{*}{$\begin{array}{l}\mathrm{SiO}_{2} \\
\text { Detection Limit }^{\mathrm{a}} \\
\mu g\left(\mathrm{nmol}^{d}\right) / \text { spot }\end{array}$} & \multirow[b]{2}{*}{$\mathrm{R}_{\mathrm{F}}^{\mathrm{b}, \mathrm{c}}$} & \multirow{2}{*}{$\begin{array}{l}\mathrm{Al}_{2} \mathrm{O}_{3} \\
\text { Detection Limit } \\
\mu g\left(\mathrm{nmol}^{d}\right) / \text { spot }^{\mathrm{a}}\end{array}$} & \multirow[b]{2}{*}{$\mathrm{R}_{\mathrm{F}}^{\mathrm{b}, \mathrm{c}}$} \\
\hline No & Structure & & & & \\
\hline $7 a$ & $\mathrm{Me}$ & $-{ }^{e}$ & & $-{ }^{e}$ & \\
\hline $7 d$ & & $10(69)$ & $0.56^{\mathrm{b}}$ & $10(69)$ & $0.70^{\mathrm{b}}$ \\
\hline $7 e$ & & $5.0(23)$ & $0.52^{\mathrm{b}}$ & $10(47)$ & $0.68^{\mathrm{b}}$ \\
\hline $8 a$ & & $1.0(7.7)$ & $0.26^{\mathrm{b}}$ & $2.2(18)$ & $0.62^{b}$ \\
\hline $8 \mathbf{b}$ & & $1.0(5.0)$ & $0.70^{\mathrm{b}}$ & $2.3(12)$ & $0.72^{\mathrm{b}}$ \\
\hline $8 f$ & & $5.0(31)$ & $0.05^{\mathrm{b}}$ & $7.5(45)$ & $0.07^{\mathrm{b}}$ \\
\hline & & $5.0(31)$ & $0.75^{\mathrm{c}}$ & $7.5(45)$ & $0.81^{\mathrm{c}}$ \\
\hline $9 \mathbf{a}$ & & $1.1(7)$. & $0.66^{\mathrm{b}}$ & $2.2(14)$. & $0.68^{\mathrm{b}}$ \\
\hline $9 b$ & & $1.0(5.6)$ & $0.65^{b}$ & $3.0(17.5)$. & $0.71^{b}$ \\
\hline $9 c$ & & $1.0(5.6)$ & $0.65^{\mathrm{b}}$ & $2.0(12)$. & $0.70^{\mathrm{b}}$ \\
\hline $11 b$ & & $5(41)$ & $0.69^{\mathrm{b}}$ & $10(82)$ & $0.84^{\mathrm{b}}$ \\
\hline
\end{tabular}




\begin{tabular}{|c|c|c|c|c|c|}
\hline $12 \mathbf{a}$ & $i-\mathrm{Pr}_{2} \mathrm{~N}-\mathrm{NO}$ & $50(650)$ & $0.72^{b}$ & $50(650)$ & $0.86^{\mathrm{b}}$ \\
\hline $12 b$ & & $10(88)$ & $0.52^{b}$ & $50(439)$ & $0.80^{\mathrm{b}}$ \\
\hline $12 \mathrm{c}$ & $\mathrm{Ph}(\mathrm{Me}) \mathrm{N}-\mathrm{NO}$ & $1(7.0)$ & $0.66^{\mathrm{b}}$ & $3(22)$ & $0.80^{\mathrm{b}}$ \\
\hline $12 d$ & $\mathrm{Ph}_{2} \mathrm{~N}-\mathrm{NO}$ & $1(5.1)$ & $0.58^{b}$ & $1(5.1)$ & $0.85^{\mathrm{b}}$ \\
\hline $13 a$ & & $1(6.6)$ & $0.56^{\mathrm{b}}$ & $1(6.6)$ & $0.81^{b}$ \\
\hline & $\mathrm{H}_{4} \mathrm{~N}^{+} \mathrm{O}^{-}$ & & & & \\
\hline $14 a$ & p-Tos $^{\mathrm{Me}}$ & $1(6.7)$ & $0.67^{\mathrm{b}}$ & $1(6.7)$ & $0.80^{\mathrm{b}}$ \\
\hline
\end{tabular}

${ }^{a}$ Brown spots on a white background. ${ }^{b /}$ Acetone. ${ }^{c /}$ Methanol. ${ }^{\mathrm{d} /}$ Values calculated. ${ }^{\mathrm{e} /}$ No detection up to $100 \mu \mathrm{g}$ per spot.

TLC detection procedure of $\boldsymbol{N}$-oxo compounds ${ }^{19,21,22}$ :

The plates $(10 \mathrm{~cm} \times 5 \mathrm{~cm})$ were spotted with the appropriate amount of compounds (see Table 28), developed for $8 \mathrm{~cm}$ distance with acetone, air dried and sprayed with sodium iodide solution and subsequently with TFAA solution. $N$-oxo compounds appeared almost immediately as brown spots on a white background, stable for more than 20 min.

It is evident that the detection limits of $N$-oxo compounds are strongly influenced by their structures. Thus, aliphatic amine $N$-oxides do not react at all with TFAA-I, heterocyclic amine $N$ oxides react slowly with high DL, the cyclic nitrones are detectable at 5-10 nmol and cyclic aliphatic nitrones are detectable at ca. 30-40 nmol. The detection limits (on Silica oxide or Alumina oxide) of nitroxide radicals vary from 5 to $10 \mathrm{nmol}$ (per spot). Detection limits for $N$ nitrosoamines vary 5-7 nmol for diaryl- and arylalkyl- $N$-nitrosoamines through $90-190$ for cyclic $N$-nitrosoamines and to $c a$. $650 \mathrm{nmol}$ for acyclic $N$-nitrosoamines. $N$-nitrosophenylhydroxylamine and $N$-nitrosoamides exhibit detection at ca. 7 nmol.

The results of the application of various reagents, related to TFAA-I detection systems, for the detection $N$-oxo compounds by TLC are presented in Table 29.

These results reveal that the most sensitive systems for the detection of $N$-oxo compounds is TFAA-I. However, subsequent modification of the reagent system by replacement of the halide salt or acylating agent leads to differentiation of their detection selectivity.

Results for the evaluation of TFAA-I reagent in comparison with other spray reagents representative for the detection of $N$-oxo compounds ${ }^{163}$, including Dragendorff reagent, DDQ (2,3-dichloro-5,6-dicyano-1,4-benzoquinone), DAB (N,N-dimethylaminebenzaldehyde), potassium permanganate (Mn), ninhydrine (NH), bromophenol blue (IND), sodium nitroprusside (SN) Fe(III) are given in Table 30. 
Table 29. Comparison of various acylating-halide salt systems for the detection of amine $N$ oxides $\mathbf{7}$, nitrones $\mathbf{8}$, nitroxide radicals 9 and nitroso compounds $\mathbf{1 1 - 1 4}$ 19,21,22,25,26 $^{\text {1 }}$

\begin{tabular}{|c|c|c|c|c|c|c|c|}
\hline \multicolumn{3}{|c|}{ Compound applied } & \multicolumn{5}{|c|}{ Acylating-halide salt systems } \\
\hline No & Structure & $\begin{array}{l}\text { Amount } \\
(\mu g / \text { spot })\end{array}$ & $\begin{array}{c}\mathrm{Ac}_{2} \mathrm{O} / \\
\mathrm{NaI}^{\mathrm{a}} \\
\end{array}$ & $\begin{array}{c}\mathrm{AcCl} / \\
\mathrm{NaI}^{\mathrm{a}}\end{array}$ & $\begin{array}{r}\mathrm{AcCl} / \\
\mathrm{LiBr}^{\mathrm{b}} \\
\end{array}$ & $\begin{array}{l}\text { TFAA/ } \\
\mathrm{NaBr}^{\mathrm{b}}\end{array}$ & $\begin{array}{c}\text { TFAA/ } \\
\mathrm{NaI}^{\mathrm{a}} \\
\end{array}$ \\
\hline \multirow[t]{3}{*}{$7 d$} & & 1.0 & - & - & - & - & - \\
\hline & & 10.0 & + & + & - & - & + \\
\hline & & 50. & + & + & - & - & + \\
\hline \multirow[t]{3}{*}{$7 e$} & & 1.0 & - & + & - & - & + \\
\hline & & 10.0 & $+/-$ & ++ & - & - & ++ \\
\hline & & 50. & + & ++ & - & - & ++ \\
\hline \multirow[t]{3}{*}{$8 \mathbf{a}$} & & 1.0 & $-\left(+^{\mathrm{c}}\right)$ & $-\left(+{ }^{\mathrm{d}}\right)$ & - & - & + \\
\hline & & 10.0 & $-\left(+^{c}\right)$ & $-\left(+{ }^{\mathrm{d}}\right)$ & - & - & ++ \\
\hline & & 50. & $-\left(+^{c}\right)$ & $-\left(+^{\mathrm{d}}\right)$ & - & - & ++ \\
\hline \multirow[t]{3}{*}{$\mathbf{8 f}$} & & 1.0 & - & $-\left(+^{c}\right)$ & - & - & - \\
\hline & & 10.0 & + & $-\left(+^{c}\right)$ & - & - & + \\
\hline & & 50. & + & $-\left(+^{c}\right)$ & - & - & + \\
\hline \multirow[t]{3}{*}{$9 \mathbf{a}$} & & 1.0 & - & $+/-$ & - & - & $+/-$ \\
\hline & & 10.0 & $+/-$ & + & + & + & + \\
\hline & & 50. & + & + & + & + & + \\
\hline \multirow[t]{3}{*}{$9 c$} & & 1.0 & - & + & - & - & + \\
\hline & & 10.0 & $+/-$ & + & + & + & + \\
\hline & & 50. & + & + & + & + & + \\
\hline \multirow[t]{3}{*}{$11 b$} & & 1.0 & - & + & - & - & + \\
\hline & & 10.0 & $+/-$ & + & - & - & ++ \\
\hline & & 50. & + & ++ & $+/-$ & $+/-$ & ++ \\
\hline \multirow[t]{3}{*}{$12 b$} & & 1.0 & - & - & - & - & - \\
\hline & & 10.0 & - & + & - & - & + \\
\hline & & 50. & - & + & - & - & + \\
\hline \multirow[t]{3}{*}{$12 d$} & & 1.0 & - & $+/-$ & - & - & - \\
\hline & & 10.0 & $++^{\mathrm{e}}$ & $+^{\mathrm{f}}$ & + & $+/-$ & $+^{\mathrm{e}}$ \\
\hline & $\mathrm{Ph}$ & 50 & $+{ }^{e}$ & $++^{\mathrm{f}}$ & ++ & + & $++^{e}$ \\
\hline \multirow[t]{3}{*}{$13 \mathbf{a}$} & & 1.0 & + & + & - & - & $+/-$ \\
\hline & $\mathrm{H}_{4} \mathrm{~N}^{+} \mathrm{O}^{-}$ & 10.0 & ++ & + & - & $+/-$ & + \\
\hline & & 50 & ++ & ++ & $+/-$ & + & ++ \\
\hline
\end{tabular}


$14 \mathbf{a}$

$$
p-\mathrm{Tol}-\mathrm{I}_{\mathrm{O}}^{\mathrm{O}}-\underbrace{N}_{\mathrm{Me}}
$$

$$
\begin{gathered}
+^{\mathrm{g}} \\
+^{\mathrm{g}} \\
+^{\mathrm{g}} \\
\hline
\end{gathered}
$$

$+^{\mathrm{g}}$
$+^{\mathrm{g}}$
$++^{\mathrm{g}}$

-
-
-

\begin{tabular}{ll}
- & $+^{\mathrm{g}}$ \\
- & $+^{\mathrm{g}}$ \\
- & $+^{\mathrm{g}}$ \\
\hline
\end{tabular}

${ }^{a}$ Brown spots on yellow background. ${ }^{\text {b/ }}$ Red brown spots. ${ }^{\mathrm{c} /}$ After 30 min exposure. ${ }^{\mathrm{d} /} \mathrm{A}$ spot of iodine appeared after $10 \mathrm{~min}$ exposure. ${ }^{\mathrm{e} /}$ Blue-brown spots after preheating to $c a .150{ }^{\circ} \mathrm{C}$, turning yellow after spraying with the reagent. ${ }^{\mathrm{f}}$ Blue-brown spots after preheating to $\mathrm{ca} .150{ }^{\circ} \mathrm{C}$, turning blue-navy after spraying with $\mathrm{LiBr}$, turning green after additional spraying with acetyl chloride. ${ }^{\mathrm{g} /}$ Yellow spots after spraying with sodium iodide solution.

Table 30. Comparison of reagents for the detection of representative $N$-oxo compounds by

\begin{tabular}{|c|c|c|c|c|c|c|c|c|c|}
\hline \multicolumn{3}{|c|}{ Compound applied } & \multicolumn{7}{|c|}{ Detection reagents } \\
\hline No & Structure & $\begin{array}{l}\text { Amount } \\
(\mu g / s p o t)\end{array}$ & $U^{\mathrm{a}}$ & $\mathrm{I}_{2}$ & $\begin{array}{l}\text { TFAA } \\
-I^{b}\end{array}$ & $\mathrm{Mn}^{\mathrm{c}}$ & $\mathrm{Bi}^{\mathrm{d}}$ & $\mathrm{Fe}$ & DDQ \\
\hline \multirow[t]{3}{*}{$7 d$} & & 1.0 & + & - & - & - & - & - & - \\
\hline & & 10.0 & + & + & $+/-$ & + & + & + & - \\
\hline & & 50 & + & + & + & + & + & + & - \\
\hline \multirow[t]{3}{*}{$8 b$} & & 1.0 & + & + & + & - & - & - & - \\
\hline & & 10.0 & + & + & + & + & - & - & - \\
\hline & & 50. & + & + & ++ & + & - & - & - \\
\hline \multirow[t]{3}{*}{$8 \mathbf{e}$} & & 1.0 & + & + & - & - & - & - & - \\
\hline & & 10.0 & + & + & + & + & - & - & - \\
\hline & & 50 & ++ & ++ & + & + & - & - & - \\
\hline \multirow[t]{3}{*}{$9 a$} & & 1.0 & - & - & $+/-$ & + & - & - & - \\
\hline & & 10.0 & $+/-$ & + & + & + & - & - & - \\
\hline & & 50 & + & + & ++ & + & - & - & - \\
\hline \multirow[t]{3}{*}{$11 \mathrm{~b}$} & & 1.0 & + & - & - & - & - & - & - \\
\hline & & 10.0 & + & - & + & - & - & - & - \\
\hline & & 50 & ++ & + & ++ & + & - & - & - \\
\hline \multirow[t]{3}{*}{$12 \mathrm{a}$} & & 1.0 & - & - & - & - & - & - & - \\
\hline & & 10.0 & - & - & - & - & - & - & - \\
\hline & & 50 & + & + & + & - & - & - & - \\
\hline \multirow[t]{3}{*}{$12 b$} & & 1.0 & - & - & - & - & - & - & - \\
\hline & & 10.0 & + & + & + & - & - & - & - \\
\hline & & 50 & ++ & ++ & + & - & - & - & - \\
\hline \multirow[t]{3}{*}{$12 d$} & & 1.0 & - & $+/-$ & $+/-$ & $+/-$ & - & - & $+/-$ \\
\hline & & 10.0 & + & + & + & + & - & $+^{\mathrm{f}}$ & $+^{\mathrm{g}}$ \\
\hline & $P n$ & 50. & + & + & + & + & - & $++^{\mathbf{f}}$ & $++^{\mathrm{g}}$ \\
\hline
\end{tabular}
TLC $^{19,21,22,25,26}$ 
13a

$14 a$<smiles>CN([O+])[N+](=O)[O-]</smiles>

15a<smiles>[O-]/[N+](=N\c1ccccc1)c1ccccc1</smiles>

1.0
10.0
50.
1.0
10.0
50.

1.0

10.0

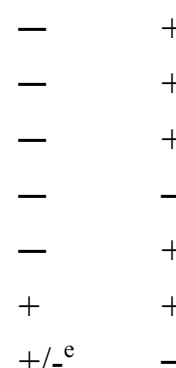

$+/-\quad+$

$+\quad+$

$++\quad++$

$++\quad+$ $\begin{array}{lll}- & - & - \\ - & +^{\mathrm{h}} & +^{\mathrm{i}} \\ - & ++^{\mathrm{h}} & ++^{\mathrm{i}}\end{array}$

$\begin{array}{lll}- & - & - \\ - & - & -\end{array}$

$++^{\mathrm{e}} \quad+/-$

$-$

th

${ }^{\mathrm{a}} \mathrm{UV}$ : $360 \mathrm{~nm} .{ }^{\mathrm{b} /}$ Brown spots on yellow background. ${ }^{\mathrm{c} /}$ Grey-green spots. ${ }^{\mathrm{d} /}$ Red spots. ${ }^{\mathrm{e} /}$ Brown spots

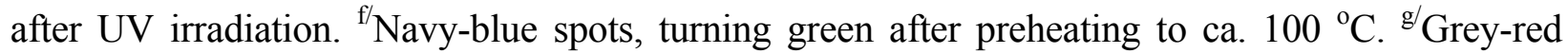
spots. ${ }^{\text {h}}$ Orange spots. ${ }^{\mathrm{i} /}$ Red-brown spots turning green after saturation with ammonia vapour. ${ }^{\mathrm{j} /}$ Orange spots after preheating to ca. $150{ }^{\circ} \mathrm{C}$.

3.2.1.1. Detection of nitrones, nitroxide radicals and $\boldsymbol{N}$-nitrosoamines in mixtures. In order to determine selectively nitrones, nitroxide radicals and nitrosoamines in the mixtures, some additional treatments are required that would allow their gradual selection, prior to the final detection with TFAA-I. Thus, nitrones and nitroxide radicals exhibit different redox properties; whereas nitrones are reduction-resistant compounds, nitroxide radicals are reduced easily with various reagents, e.g., hydroiodide acid $^{164}$, ascorbic acid $^{137}$, ethanethiol ${ }^{165}$ and rhodizonic acid and its analogue ${ }^{166}$. The corresponding amines or hydroxylamines formed in this reaction are totally inactive towards TFAA-I.

Thus, the combination of the selective pre-reduction of nitroxide radicals 9 into hydroxylamines 9G or amines $\mathbf{9 H}$ (performed in solution by means of ascorbic acid, thiols, or formate-palladium hydrogenation), with detection by means of the TFAA-I reagent of the reduction-resistant nitrones $\mathbf{8}$, allows the selective TLC detection and differentiation of these two classes of $N$-oxo compounds (Scheme 28).

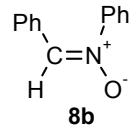

Reductor
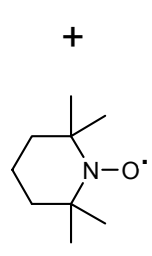

9 a
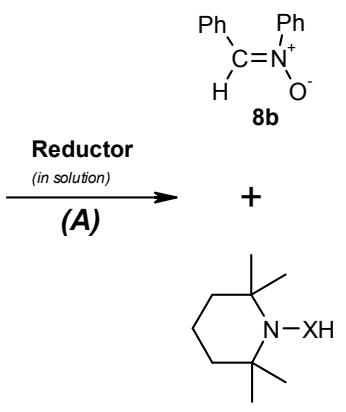

9Ga $(\mathrm{XH}=\mathrm{OH})$ or $9 \mathrm{Ha}(\mathrm{XH}=\mathrm{H})$

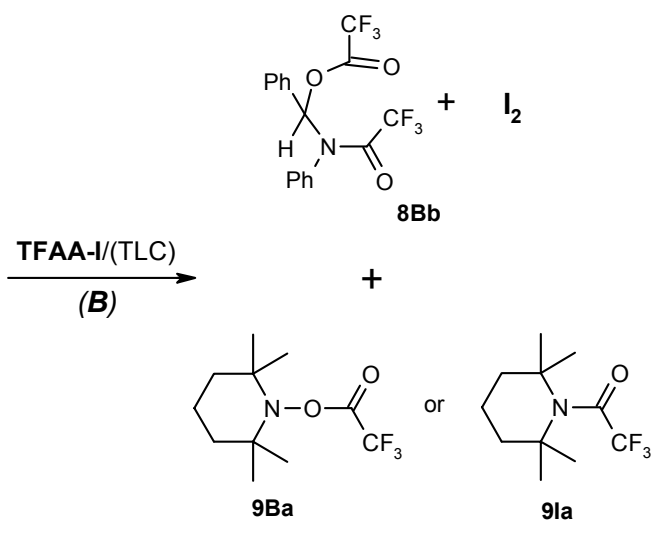

9Ba

Scheme 28 
Another possibility for the TLC differentiation of nitrones and nitroxide radicals is the use of a reverse mode of the TFAA-I procedure (Scheme 29), in which TFAA is used in the first stage $(\boldsymbol{A})$, followed by addition of $\mathrm{NaI}(\boldsymbol{B})$.

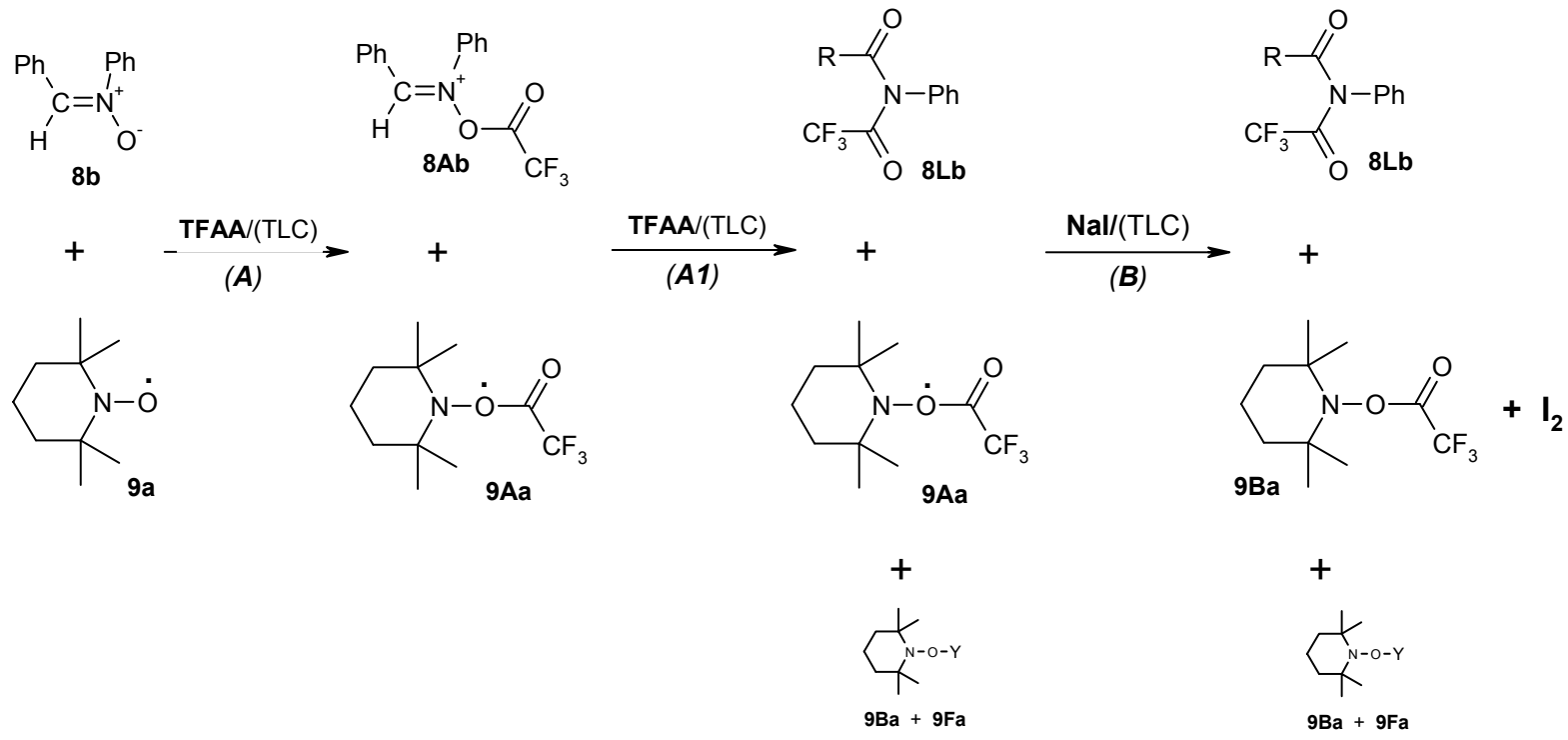

\section{Scheme 29}

Thus, the corresponding $\mathbf{8 A}$ and $\mathbf{9 A}$ derivatives, formed during the treatment of mixtures of $\mathbf{8}$ and 9 with TFAA, convert to $8 \mathrm{~L}(\mathbf{8 A} \rightarrow \mathbf{8 L})$ [also Scheme 23], and to $\mathbf{9 B}$ and $\mathbf{9 F}(\mathbf{9 A} \rightarrow \mathbf{9 B}+\mathbf{9 F})$ [also Schemes 24 and 25], respectively, which are not able to oxidize iodide anion ${ }^{21,23}$. As these reactions proceed at different rates (reactions $8 \rightarrow \mathbf{8 L}$ are much faster than reactions $\mathbf{9} \rightarrow \mathbf{9 F}$ ), the application of the reverse mode of TFAA-I procedure permits the detection and differentiation of these two types of $\mathrm{N}$-oxo compounds.

Instability of nitrosoamines $\mathbf{1 2}$ in the presence of strong acids provides an opportunity for the elimination of these compounds from their mixtures with nitrones $\mathbf{8}(\mathbf{8}+\mathbf{1 2})$ and/or nitroxide radicals $9(\mathbf{9}+\mathbf{1 2})$. The corresponding TLC procedures are illustrated in Schemes 30 and 31.

Thus, the decomposition of nitrosamines 12 in $\mathrm{HCl}$ vapour $(\boldsymbol{A})$, followed by TFAA-I detection of the residual component $(\boldsymbol{B})$, allows the selective detection of the nitrones $\mathbf{8}$ and/or nitroxide radicals 9 in the corresponding mixtures: 8 and 12 (Scheme 30) and/or 9 and 12 (Scheme 31), respectively. Such TLC plates (after TFAA-I detection) revealed only brown iodine-originated spots appearing in the places occupied by nitrones $\mathbf{8}$ and/or nitroxide radicals 9.

A subsequent treatment of the three-component mixture (Scheme 32) with $(\boldsymbol{A})$ ascorbic acid (in the starting solution) and $(\boldsymbol{B}) \mathrm{HCl}$ vapour (on the TLC plate) allows the gradual elimination of nitroxide radicals 9 (reduced to inactive hydroxylamines $9 \mathrm{G}$ in stage $\boldsymbol{A}$ ) and $N$-nitrosoamines 12 (decomposed into amines 22 in stage $\boldsymbol{B}$ ), prior to the final detection of nitrones 8 with TFAAI reagent (stage $\boldsymbol{C}$ ). 

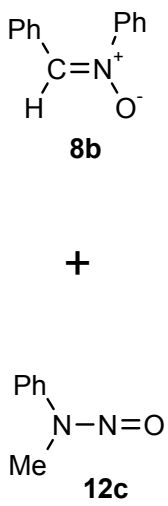
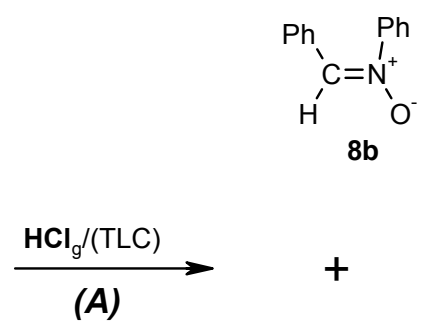

(A)

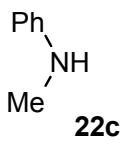

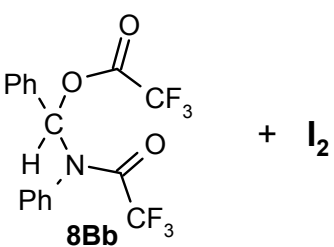

TFAA-I/(TLC)

(B)

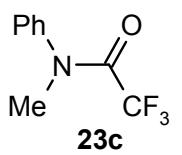

Scheme 30
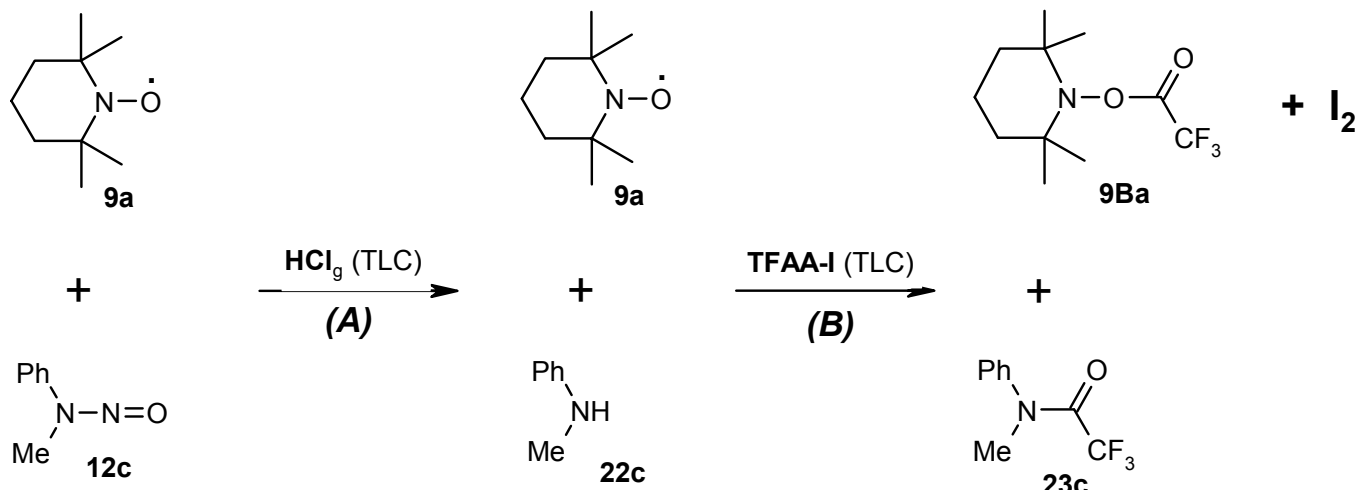

$\frac{\text { TFAA-I (TLC) }}{(B)}$
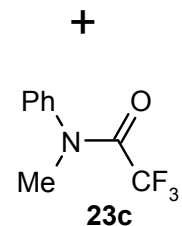

\section{Scheme 31}

Comparison of this plate with the corresponding plates obtained by instant TFAA-I detection of the starting mixture 8, 9 and 12 (Scheme 33) and by $\mathrm{HCl}$ treatment followed by TFAA-I detection (Scheme 34), permits the full TLC differentiation of all the $N$-oxo components in these mixtures. 
<smiles>[O-][N+](=Cc1ccccc1)c1ccccc1</smiles>

$8 b$

$+$<smiles>CC1(C)CCCC(C)(C)N1O</smiles>

$+$

$\mathrm{Me}^{\mathrm{Ph}}{ }^{\mathrm{N}-\mathrm{N}}=\mathrm{O}$

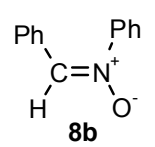

$+$
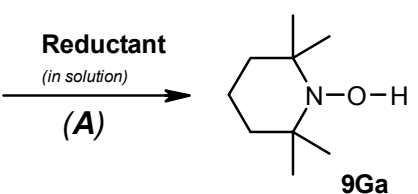

$+$

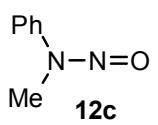

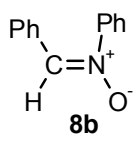

$+$

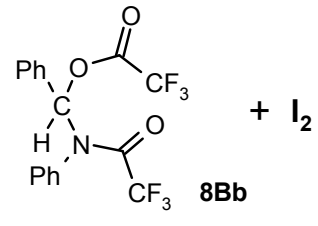

$+$

(B)<smiles>CC1(C)CCCC(C)(C)N1O</smiles><smiles>CC(C)CCC(C)(F)F</smiles><smiles>CCCCC(C)(C)N1C(C)(C)CCCC1(C)OC(=O)C(F)(F)F</smiles>

$+$
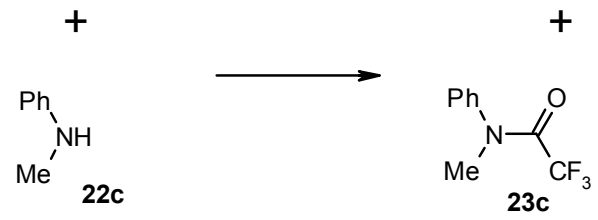

\section{Scheme 32}
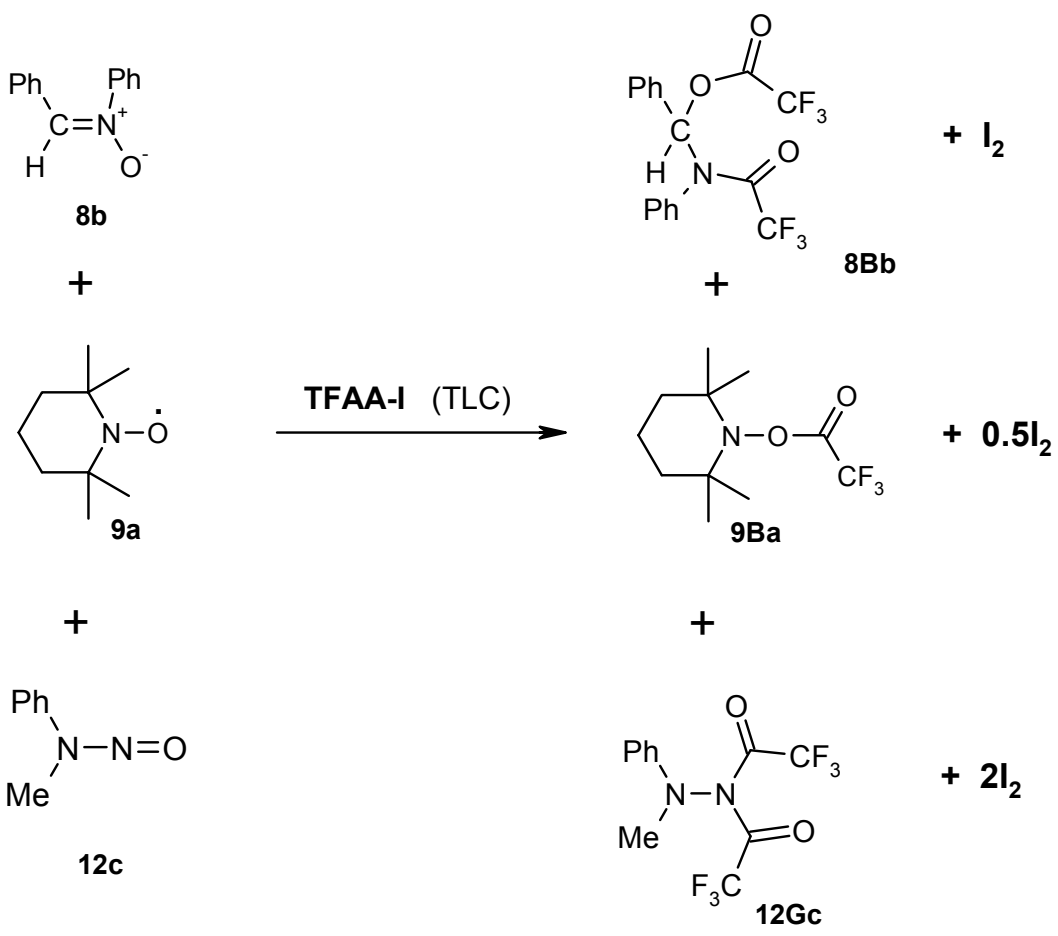

\section{Scheme 33}



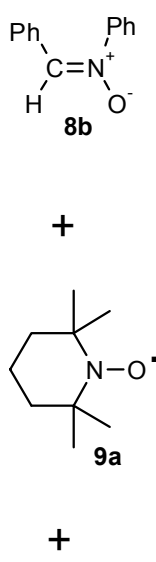

$\mathrm{Me}^{\prime} \mathrm{N}^{\mathrm{Ph}} \mathrm{N}=\mathrm{O}$
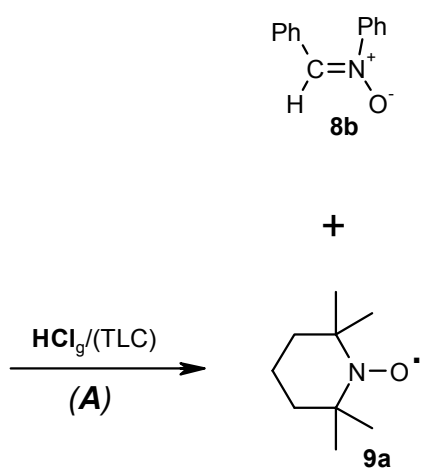

(A)

$+$

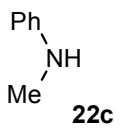

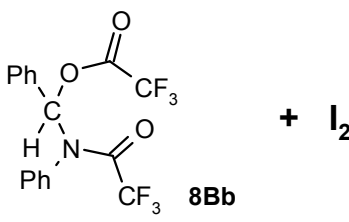

$+$
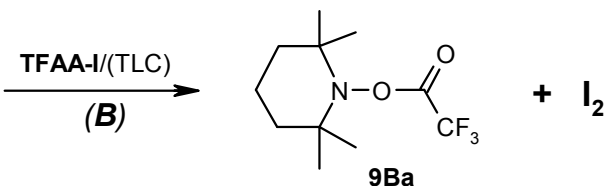

$+$

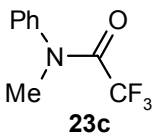

Scheme 34

The results of the differential detection of nitrones $(\mathbf{8 b})$, nitroxide radicals $(9 \mathbf{a})$ and $N$ nitrosoamines (12c), alone or in mixture, with TFAA-I as the final detection reagent are given in Tables 31 and 32, respectively.

Table 31. Comparison of procedures based on application of TFAA-I for the selective detection of nitrones $(\mathbf{8 b})$, nitroxide radicals (9a) and $N$-nitrosoamines (12c) by TLC

\begin{tabular}{|c|c|c|c|c|c|c|c|c|}
\hline \multicolumn{2}{|c|}{ N-oxo compounds ${ }^{a}$} & \multicolumn{7}{|c|}{ Procedure $^{b}$} \\
\hline & & \multirow[t]{2}{*}{$\underset{-I^{\mathrm{c}, \mathrm{d}}}{\mathrm{TF}}$} & $\mathrm{EtSH}^{\mathrm{e}}$ & $\mathrm{ASC}^{\mathrm{e}}$ & $\mathrm{H} / \mathrm{Pd} / \mathrm{C}^{\mathrm{e}}$ & $\begin{array}{l}\mathrm{SiH} / \\
\mathrm{TFA}^{\mathrm{e}}\end{array}$ & TFAA $^{\mathrm{d}}$ & $\mathrm{HCl}^{\mathrm{d}, \mathrm{f}}$ \\
\hline No & Structure & & $\begin{array}{c}\text { TFAA- } \\
-\mathrm{I}^{\mathrm{c}, \mathrm{d}}\end{array}$ & $\begin{array}{c}\text { TFAA- } \\
\text {-I }^{\mathrm{d}}\end{array}$ & $\begin{array}{c}\text { TFAA- } \\
- \text { I }^{\mathrm{d}}\end{array}$ & $\begin{array}{c}\text { TFAA- } \\
\text {-I }^{\mathrm{d}}\end{array}$ & $\begin{array}{c}\text { TFAA- } \\
- \text { I }^{\mathrm{d}}\end{array}$ & $\begin{array}{c}\text { TFAA- } \\
-I^{\mathrm{d}}\end{array}$ \\
\hline $8 b$ & & ++ & ++ & $++^{\mathrm{c}}$ & $++^{c}$ & $++^{\mathrm{c}}$ & - & - \\
\hline \multirow{2}{*}{$9 \mathbf{a}$} & & ++ & ++ & - & - & - & $++^{\mathrm{c}}$ & - \\
\hline & $\mathrm{Me}^{\prime}{ }^{\mathrm{Ph}}$ & ++ & $+/-$ & $++^{c}$ & - & $+/-^{\mathrm{c}}$ & $++^{\mathrm{c}}$ & $++^{\mathrm{g}}$ \\
\hline
\end{tabular}

${ }^{\mathrm{a}}$ The amounts of compounds spotted were ca. $5 \mathrm{~g}$ per spot $(2-3 \mathrm{~mm}$ in diameter). ${ }^{\mathrm{b}}$ Abbreviations: EtSH = ethanethiol; $\mathrm{ASC}=$ ascorbic acid; $\mathrm{H} / \mathrm{Pd} / \mathrm{C}=$ formic acid/palladium $(\mathrm{Pd} / \mathrm{C})$ reagent; $\mathrm{SiH}=$ triethylsilane. ${ }^{\mathrm{c} /}$ Brown spots. ${ }^{\mathrm{d} /}$ The reactions was carried out on the TLC plates. ${ }^{\mathrm{e} /}$ The reactions was carried out in solution. ${ }^{\mathrm{f} /} \mathrm{HCl}$ vapour. ${ }^{\mathrm{g} /}$ Brown spot turning green and subsequently blue on air exposure. 
Table 32. Comparison of procedures for the TLC analysis of mixtures of nitrones (8a), nitroxide radicals (9a) and $N$-nitrosoamines (12c)

\begin{tabular}{|c|c|c|c|c|c|c|c|}
\hline $\begin{array}{l}\text { Mixture } \\
\text { 8b }+9 a+ \\
\text { 12c }\end{array}$ & $\mathrm{R}_{\mathrm{F}}^{\mathrm{c}}$ & $\begin{array}{l}\text { Procedure }^{\mathrm{b}} \\
\text { TFAA-I }^{\mathrm{d}}\end{array}$ & $\begin{array}{l}\text { TFAA-I }^{\mathrm{e}} \\
\left(\text { TFAA-I }^{\mathrm{d}, \mathrm{f}}\right)\end{array}$ & $\mathrm{NaI}^{\mathrm{e}}$ & $\begin{array}{l}\mathrm{ASC}^{\mathrm{g}} \\
\left(\mathrm{TFAA}^{\mathrm{d}}{ }^{\mathrm{d}, \mathrm{f}}\right)\end{array}$ & $\mathrm{HCl}^{\mathrm{e}}$ & $\mathrm{NaI}^{\mathrm{e}}$ \\
\hline $\begin{array}{l}\mathbf{8 b} \\
+\end{array}$ & $\begin{array}{l}0.57 \\
(\mathbf{8 a})\end{array}$ & ++ & $\overline{-}_{(-)^{\mathrm{e}}}$ & - & $\begin{array}{l}- \\
\left(++^{e}\right)\end{array}$ & - & $+/-^{c}$ \\
\hline $\begin{array}{l}9 \mathbf{a} \\
+\end{array}$ & $\begin{array}{l}0.13 \\
(9 a)\end{array}$ & ++ & $\begin{array}{l}- \\
\left(++^{e}\right)\end{array}$ & ++ & $\begin{array}{l}- \\
(-)^{\mathrm{e}}\end{array}$ & - & - \\
\hline $12 \mathrm{c}$ & $\begin{array}{l}0.65 \\
(\mathbf{1 2 c})\end{array}$ & ++ & $\begin{array}{l}\left(++^{\mathrm{e}}\right) \\
++^{\mathrm{g}}\end{array}$ & & $\begin{array}{l}- \\
\left(++^{e}\right)\end{array}$ & $++^{\mathrm{h}}$ & - \\
\hline
\end{tabular}

a/The mixture contained ca. $5 \mu \mathrm{g}$ of each compounds. ${ }^{\mathrm{b}}$ Abbreviations and symbols as in Table 31. ${ }^{\mathrm{c}}$ Silica plates. Solvent: chloroform-acetone (4:1). ${ }^{\mathrm{d} /}$ Brown spots on a white background. ${ }^{\mathrm{e}}$ The reaction was carried out on the TLC plate. ${ }^{\mathrm{f} /}$ Detection with TFAA-I on the second plates. ${ }^{\mathrm{g} /}$ The reaction was carried out in solution. ${ }^{\mathrm{h}}$ Brown spot turning green, and subsequently blue on air exposure.

\section{Conclusions}

This account describes the reactions of trifluoroacetic anhydride - sodium iodide mixture (TFAA-NaI; TFAA-I) with several group of compounds bearing semipolar $X-O$ bond in which simultaneous liberation of iodine occurs. Presented reactions are, in majority, characterized by quantitative yields of both product (reduced substrates and elemental iodine). Moreover areneand alkyl-sulphonic acids are converted into the corresponding thiols in moderate yields. Due to stoichiometric amounts of iodine produced in the reactions of sulphoxides, sulphimides, arene$\mathrm{N}$-oxides, nitrones and nitroxide radicals, and nitroso compounds - the TFAA-I reagent can be applied to their analytical determination (titrimetric on $\mu \mathrm{mol}$ and spectrometric on nmol scale) and/or TLC detection.

\section{References}

1. Pfitzner, K. E.; Moffatt, J. G. J. Am. Chem. Soc. 1963, 85, 3027.

2. Allbright, J. D.; Goldman, S. J. Am. Chem. Soc. 1965, 87, 566.

3. Omura, K.; Sharma, A. K.; Swern, D. J. Org. Chem. 1971, 41, 957.

4. Manucuso, A. J.; Huang, S.-L.; Swern, D. J. Org. Chem. 1978, 43, 2480.

5. Tojo, G.; Fernandez, M. http://www.springer.com/0-387-23607-4.

6. Numata, T.; Oae, S. Chem. \& Ind. (London) 1973, 277. 
7. Drabowicz, J.; Oae, S. Synthesis 1977, 404.

8. Drabowicz, J.; Łyżwa, P.; Mikołajczyk, M. Synthesis 1981, 890.

9. Homaidan, F.R.; Issidores, C.H. Heterocycles 1981, 16, 411.

10. Numata, T.; Anano, H.; Oae, S. Tetrahedron Lett. 1980, 21, 1235.

11. Ciesielski, W.; Drabowicz, J.; Jędrzejewski, W.; Kudzin, Z. H. $31^{\text {st }}$ International Congress of Pure and Applied Chemistry; Sofia, Bulgaria, 1987, 6.103.

12. Ciesielski, W.; Drabowicz, J.; Jędrzejewski, W.; Kiełbasiński, P.; Kotyński, A.; Kudzin, Z. H.; Skowroński; R. XIII International Symposium on the Organic Chemistry of Sulfur; Odense, Denmark, 1988, PB-17, 144.

13. Ciesielski, W.; Jędrzejewski, W.; Kudzin, Z.H.; Skowroński, R.; Drabowicz, J. Talanta 1988, 35, 969.

14. Ciesielski, W.; Jędrzejewski, W.; Kudzin, Z. H.; Drabowicz, J. Talanta 1990, 37, 435.

15. Drabowicz, J.; Kotyński, A.; Kudzin, Z. H. J. Chromatogr. 1988, 447, 225.

16. Ciesielski, W.; Drabowicz, J.; Jędrzejewski, W.; Kudzin, Z. H.; Skowroński R. $31^{s t}$ International Congress of Pure and Applied Chemistry; Sofia, Bulgaria, 1987, 3.98.

17. Kudzin, Z. H.; Ciesielski, W.; Drabowicz, J.; Jędrzejewski, W.; Skowroński, R. PolishFrench Symposium on Heteroorganic Chemistry and Electrochemistry; Spała, Poland, 1987.

18. Ciesielski, W.; Drabowicz, J.; Jędrzejewski, W.; Kudzin, Z. H.; Skowroński, R. Polish Chemical Society Conference; Łódź, Poland, Vol. C, 1988, 28; (poster III-28).

19. Drabowicz, J.; Kotyński, A.; Kudzin, Z. H.; Skowroński, R. J. Chromatogr. 1989, 473, 289.

20. Ciesielski, W.; Kudzin, Z. H.; Tasz, M. K.; Drabowicz, J. Canad. J. Chem. 1990, 68, 679.

21. Kotyński, A.; Kudzin, Z. H.; Skowroński, R. J. Chromatogr. 1990, 516, 467.

22. Kotyński, A.; Kudzin, Z. H. J. Chromatogr. A 1994, 663, 127.

23. Ciesielski, W.; Kudzin, Z. H.; Grabowski, G. Talanta 1995, 42, 519.

24. Drabowicz, J.; Kotyński, A.; Kudzin, Z. H.; Nazarski, R. B.; Tasz, M. K. Tetrahedron 1997, $41,14169$.

25. Kotyński, A.; Kudzin, Z. H.; Ciesielski, W.; Drabowicz, J. V Polish Symposium of Heteroorganic Chemistry; Łódź, Poland, 2002, Abstract P-70.

26. Kotyński, A.: Application of the TFAA-I and Iodo-azide Reagents for Visualization of Chromatographic Detection of Biologically Active Heterorganic Compounds; Ph.D thesis, University of Łódź, Łódź, Poland, 2003.

27. Madesclaire, M. Tetrahedron 1988, 44, 6537.

28. Grossert, J. S. In: Reduction of Sulfoxides and Sulfones. Chemistry of Sulfones and Sulfoxides; Patai, S. Ed; Wiley: Chichester, 1988.

29. Drabowicz, J.; Dudziński, B.; Mikołajczyk. M. Synlett 1992, 252.

30. Mohanazadeh, F.; Momeni, A. R.; Ranjbar, Y. Tetrahedron Lett. 1994, 35, 6127.

31. Lee, G. H.; Choi, E. B.; Lee, E.; Pak, C. S. Tetrahedron Lett. 1994, 35, 2195.

32. Zhang, Y.; Yu, Y.; Bao, W. Synth. Commun. 1995, 25, 1825.

33. Wang, J. Q.; Zhang, Y. M. Synth. Commun. 1995, 25, 3545.

34. Nicolas, E.; Vilaseca, M.; Giralt, E. Tetrahedron 1995, 51, 5701. 
35. Fujiki, K.; Kurita, S.; Yoshida, E. Synth. Commun. 1996, 19, 3619.

36. Wang, Y.; Koreeda, M. Synlett 1996, 885.

37. Miller, S. J.; Collier, T. R.; Wu, W. Tetrahedron Lett. 2000, 41, 3781.

38. Firouzabadi, H.; Karimi, B. Synthesis 1999, 500.

39. Shimizu, M.; Shibuya, K.; Hayakawa, R. Synlett 2000, 1437.

40. Karimi, B.; Zareyee, D. Phosphorus, Sulfur \& Silicon 2003, 179, 77.

41. Bonini, B. F.; Bernardi, L.; Comes-Franchini, M.; Dessole, G.; Fochi, M.; Ricci, A. Phosphor, Sulfur \& Silicon Rel. Elem. 2005, 180, 1273.

42. Fernandez, A. C.; Romao, C. C. Tetrahedron 2006, 62, 9650.

43. Gilchrist, T. L.; Moody, C. J. Chem. Rev. 1977, 77, 409.

44. Cherry, F.; Cassel, S.; Wessel. H. P.; Rollin, P. Eur. J. Org. Chem. 2002, 178.

45. Bonifacio, V. D. B. Org. Chem. Highlights 2004 December 24. URL: http://www.organicchemistry.org/Highlights/2004/24December.shtm.

46. McCall, M. A.; Tarbell, D. S.; Havill, M. A. J. Am. Chem. Soc. 1951, 73, 4476.

47. Kozuka, S.; Furumai, S.; Akasaka, T.; Oae, S. Chem. \& Ind. (London) 1974, 496.

48. Ash, A. C. F.; Challenger, F.; Greenwood, D. J. Chem. Soc. 1951, 1877.

49. Oae, S.; Yagihara, T.; Okabe, T. Tetrahedron 1972, 28, 3203.

50. Borgogno, G.; Colonna, S.; Fornasier, R. Synthesis 1975, 529.

51. Still, I. W. J.; Turnbull, K. Synthesis 1977, 541.

52. Durst, T. In: Comprehensive Organic Chemistry; Jones, D. N. Ed.; Pergamon Press, Oxford, 1979, Vol. 3.

53. Special Periodical Reports, Organic Compounds of Sulphur, Selenium and Tellurium; Vols. 1-9, Chemical Society, London, 1970-1986.

54. Kajaer, A. Tetrahedron 1974, 30, 155.

55. Kalir, A.; Kalir, H. H. In: The Chemistry of Sulphur-Containing Functional Groups, Patai, S.; Rapaport, Z. Eds.; Wiley, New York, 1993.

56. Ashworth, M. R. F. In Determination of Sulphur-containing Groups; Academic Press, London, 1972, Vol. 1.

57. Karchmer, J. H. In The Analytical Chemistry of Sulfur and its Compounds; Part. II, WileyInterscience, New York, 1972.

58. Smyth, M. R.; Smyth, W. F. Analyst 1978, 103, 529.

59. Glynn, E. Analyst 1947, 72, 248.

60. Barnard, D.; Hargrave, K.R. Anal. Chim. Acta 1951, 5, 536.

61. Legault, R. R.; Groves, K. Anal. Chem. 1957, 29, 1945.

62. Karaulova, E. N.; Galpern, G. D. Zh. Obshch. Khim. 1959, 29, 3033.

63. Jancik, F.; Korbl, J. Cesk. Farm. 1962, 11, 305.

64. Allenmark, S. Acta Chem. Scand. 1955, 20, 910.

65. Gopalakrishnan, J. Patel, C. C. Inorg. Chim. Acta 1967, 1, 165.

66. Savant, V.; Patel, C. C.; Gapalakrishnan, J. Z. Anal. Chem. 1968, 238, 273.

67. Douglas, T. B. Talanta 1968, 15, 704. 
68. Rangajwamy, C.; Yathirajan, H. C.; Mahadevappa, P. S. Indian J. Chem. 1958, 30, 2060.

69. Wimer, D. C. Anal. Chem. 1958, 30, 2060.

70. Streuli, C. A. Anal. Chem. 1958, 30, 997.

71. Moravek, J.; Vlacil, F. Chem. Listy 1979, 73, 750.

72. Price, C. C.; Oae, S. In: Sulfur Bonding; Ronald, New York, 1962.

73. Dizdar, Z.; Idjakovic, Z. Talanta 1972, 19, 1217.

74. Toma, H. E.; Giesbrecht, E.; Malin, J. M. An. Acad. Bras. Cienc. 1976, 48, 41; Anal. Abstr. 1978, 34, 3B99.

75. Safronov, A. P. Zh. Anal. Khim. 1963, 18, 548.

76. Vlacil, F.; Huynh, D. K. Coll. Czech. Chem. Commun. 1979, 44, 1908.

77. Horiguchi, M.; Takashima, H.; Fujimara, K. Iso, T. Yakugaku Zasshi, 1986, 106, 1028; Chem. Abstr. 1987, 106, 131139g.

78. Thompson, J. F.; Arnold, W. N.; Morris, C. J. Nature (London) 1963, 197, 380.

79. Suchomelova, L.; Horak, V.; Zyka, J. Microchem. J. 1965, 196.

80. Fishbein, L.; Fawkes, J. J. Chromatogr. 1966, 22, 323.

81. Langler, R. F. J. Chromatogr. 1975, 104, 228.

82. Mal, D.; Biswas, G. J. Chromatogr. 1987, 387, 556.

83. Ochiai, E. In: Aromatic Amine N-oxides; Elsevier: Amsterdam, 1967.

84. Wade, P. E. In: Comprehensive Organic Synthesis, Trost, B. M.; Fleming, I.; Semmelhack, M. F. Eds.; Pergamon Press: Oxford, 1991, Vol. 4.

85. Little, R. D. In: Comprehensive Organic Synthesis; Trost, B. M.; Fleming, I.; Paquette, L. A., Eds.; Pergamon Press: Oxford, 1991, Vol. 5.

86. Katrizky, A. R.; Lagowski, R. In Chemistry of Heterocyclic N-oxides; Academic Press: New York, 1971.

87. Albini, A.; Pietra, S. In: Heterocyclic N-oxides; CRC Press: Boca Raton, 1990.

88. Bapat, J. B.; Epsztajn, J.; Katritzky, A. R.; Plav, B. J. Chem. Soc., Perkin Trans. 1 1977, 1692.

89. Breuer E.; Eurich, H. G.; Nielsen, A. In: Nitrones, Nitronates, Nitroxides; Wiley: New York, 1989.

90. Balicki, R. Synthesis 1989, 645.

91. Balicki, R. Chem. Ber. 1990, 647.

92. Balicki, R.; Kaczmarek, Ł.; Malinowski, M. Synth. Commun. 1989, 19, 897.

93. Malinowski, M. Synthesis 1987, 732.

94. Jousseaume, B.; Chanson, E. Synthesis 1987, 55.

95. Kagami, H.; Motoki, S. J. Org. Chem. 1978, 43, 1267.

96. Emerson, T. R.; Rees, C. W. J. Chem. Soc. 1962, 1917.

97. Sanz, R.; Escribano, J.; Fernandez, Y.; Aguado, R.; Pedrosa, M. R.; Armaiz, F. J. Synlett 2005, 1389.

98. Handa, Y.; Inanaga, J.; Yamaguchi, M. J. Chem. Soc., Chem. Commun. 1989, 298.

99. Yadav, J. S.; Subba, R. B. V.; Muralidhar, R. H. Tetrahedron Lett. 2000, 41, 2663. 
100.Ilankumaran, P.; Chandrasekara, S. Tetrahedron Lett. 1995, 36, 4881.

101.You, B. W.; Hwang, S. K.; Kim, D. Y.; Choi, J. W.; Kang, S. O.; Yoo, B. S.; Choi, K. I.; Kim, J. H. Bull. Korean. Chem. Soc. 2004, 25, 1633.

102.Kumar, S.; Saini, A.; Sandhu, J. S. Tetrahedron Lett. 2005, 46, 8737.

103. Somasundaram, N.; Srinivasan, C. Tetrahedron Lett. 1998, 39, 3547.

104. Radivoy, G.; Alonso, F.; Yus, M. Synthesis 2001, 427.

105.Breuer, E. In: The Chemistry of Amino, Nitroso, and Nitro Compounds and their Derivatives; Patai, S. Ed.; Wiley: New York, 1982.

106. Keana, J. F. W. Chem. Rev. 1978, 78, 37.

107.Tufarinello, J. J. In: 1,3-Dipolar Cycloaddition Chemistry; Padwa, A. Ed.; WileyInterscience: New York, 1984; Vol. 2, Ch. 9.

108. Evans; C. A. Aldrichimica Acta 1979, 12, 23.

109. Can. J. Chem. 1982, 60(2) (special collection of papers on trapping chemistry).

110.Pure Appl. Chem. 1990, 62(2) (special collection of papers on nitroxide chemistry).

111.Kliegel, W. Pharmazie 1977, 32, 643.

112.Rozantcev, E. G.; Scholle, V. D. In Chemistry of Free Radicals; PWN: Warsaw, 1985.

113.Gaffney, B. J. In: Spin Labelling - Theory and Applications; Berliner, L. H. Ed.; Academic Press: New York, 1978.

114.Symons, C. R. In: Chemical and Biochemical Aspects of Electron-Spin Resonance Spectroscopy; Van Nostrand Reinhold: New York, 1978.

115.Favier, A.; Cadet, J.; Kalyanaraman, E.; Fontecave, M.; Pierre, J.-L. In: Analysis of Free Radicals in Biological Systems; Birkhauser Verlag, Basel, 1995.

116. Boyer, J. H. In The Chemistry of Nitro and Nitroso Group; Feuer, H. Ed.; Interscience: New York, 1969.

117.Fishbein, L. In Chromatography of Environmental Hazards; Elsevier: Amsterdam, 1972; Vol. I.

118. Magee, P. N.; Barnes, J. B. Brit. Cancer. 1956, 10, 114.

119.Magee, P. N.; Barnes, J. B. Adv. Cancer Res. 1967, 10, 163.

120.Fishbein, L. Sci. Total Environ. 1979, 13, 157.

121. Mavelle, T. In: Detection of Nitroso Compounds. Analysis and Control Methods for Food and Agriculture Products; Multon, J.-L. Ed.; Wiley VCH: New York, 1997; Ch. 11.

122. Streuli, C. A.; Averell, P. R. In: The Analytical Chemistry of Nitrogen and its Compounds; Wiley-Interscience: New York, 1970.

123. Nollec, L. M. L. In: Chromatographic Analysis of the Environment. Chromatographic Science Series; CRC Taylor \& Francis: Boca Raton, 2005; Vol. 93.

124. Gouth, T. A. Analyst 1978, 103, 785.

125.Brooks, R. T. Anal. Chem. 1959, 31, 561.

126.Jones, R. A.; Katrizky, A. R. J. Chem. Soc. 1967, 297

127. Gawargidus, Y. A.; Ashworth, M. R. F. Z. Anal. Chem. 1972, 256, 117.

128. Wimer, D. C. Anal. Chem. 1962, 34, 873. 
129. Metzalfe, L. D. Anal. Chem. 1962, 34, 1849.

130.Bezinger, N. N. Zh. Anal. Khim. 1968, 23, 1538.

131.Kubota, T.; Miyazaki, H. Bull. Soc. Chem. Jap. 1962, 35, 1549.

132.Hoffmann, H. Arch. Pharm. Berlin 1971, 304, 614; Anal. Abstr. 1972, 22, 3232.

133. Ross, J. H. Anal. Chem. 1970, 42, 564.

134. Mitchel, C. H.; Zigler, D. M. Anal. Biochem. 1969, 28, 261.

135.Golubev, V. A.; Rozantsev, E. G.; Neiman, V. B. Izv. Akad. Nauk SSSR, Ser. Khim. 1965, 1927.

136. Solomatin, V. T.; Ozhegov, P. I. Zh. Anal. Khim. 1973, 28, 2129.

137.Paleos, C. M.; Dais, P. J. Chem. Soc., Chem. Commun. 1977, 345.

138.Johnson, C. G.; Caron, S.; Blough, N. V. Anal. Chem. 1996, 68, 867.

139. Yoshimura, Y.; Inomata, T.; Nakazawa, H. J. Liq. Chromatogr. Relat. Technol. 1999, 22, 419.

140.Blake, L. S.; Bate, P. Analyst 1979, 98, 103.

141.Awad, W. I.; Hassan, S. S. M.; Zaki, M. T. Anal. Chem. 1972, 44, 911.

142.Bartha, L. G. Magy Chem. Foly 1972, 78, 327; Anal. Abstr. 1973, 25, 20334.

143.Lund, T. G.; Fueggle, D. G.; Walters, C. L. Analyt. Lett. 1973, 6, 369.

144.Fan, T.-Y.; Tannenbaum, S. R. J. Agr. Food. Chem. 1971, 19, 1267; Anal. Abstr. 1972, 23, 1895.

145.Eisenbrand, G.; Preussmann, R. Arzneimittel. Forsch. 1970, 20, 1513; Anal. Abstr. 1971, 21, 1469.

146.Gawargiuos, Y. A.; Habash, G. M.; Bishara, S. W. Microchim. Acta, 1968, 1129; Anal. Abstr. 1970, 18, 1700.

147.Sen, N. P. J. Chromatogr. 1970, 51, 301.

148.Kataoka, H.; Shindoh, S.; Makita, M. J. Chromatogr. A 1996, 723, 93.

149. Chawla, K. L.; Tandon, J. P. Z. Anal. Chem. 1968, 238, 459; Anal. Abstr. 1969, 17, 2199.

150.Preussmann, R.; Daiber, D.; Hengy, H. Nature (London) 1964, 201, 502.

151.Preussmann, R.; Neurath, G.; Wulf, G.; Daiber, D.; Hengy, H. Fresenius' Z. Anal. Chem. 1964, 202, 187.

152.Kroeller, E. Dtsch. Lebensm.-Rundsch. 1967, 63, 303.

153.Sen, N. P.; Smith, D. C.; Schwinghamer, L.; Marleau, J. J. J. Assoc. Off. Anal. Chem. 1969, $52,47$.

154.Kostyukovskii, Y. L.; Malmed, D. B. Zh. Anal. Khim. 1979, 34, 1353.

155.Klimsch, H. J.; Stadler, L. J. J. Chromatogr. 1974, 90, 223.

156.Zhukova, G. F.; Pimenova, V. V.; Medvedev, F. A. Zh. Anal. Khim. 1979, 34, 1621.

157. Kostyukovski, Y. L.; Melamed, D. B.; Pokrovskii, A. A. Zh. Anal. Khim. 1978, 33, 808.

158. Gracheva, I. N.; Zhukova, G. F.; Kovelman, I. R.; Pimenova, W. W.; Totchilkin, A. I. Zh. Anal. Khim. 1986, 41, 356.

159. Serfentein, W. J.; Hurter, P. Nature (London) 1966, 209, 119.

160.Kim, K. W.; Brown, E. V. Anal. Lett. 1972, 5, 293. 
161. Sarfontein, N. J.; Smit, H. Nature (London) 1967, 214, 169.

162.Neurath, G.; Pirman, B.; Dunger, M. Chem. Ber. 1964, 97, 1631.

163. Rejo, L. J. Chromatogr. 1974, 88, 119.

164.Golubev, V. A.; Neiman, V. B.; Rozantsev, E. G. Izv. Akad. Nauk SSSR, Ser. Khim. 1965, 345.

165.Zakrzewski, J. Monatsh. Chem. 1990, 121, 803.

166.Brijk, M. E. Synth. Commun. 1990, 20, 3283. 